\title{
Ecology and Control of the Principal Flies Associated with a Compost Plant
}

\section{By}

CALVIN GALE ALVAREZ

\section{A DISSERTATION PRESENTED TO THE GRADUATE COUNCIL OF THE LNIVERSITY OF FLORIDA IN PARTIAL FULFILLMENT OF THE REQUIREMENTS FOR THE DEGREE OF DOCTOR OF PHILOSOPHY}

UNIVERSITY OF FLORIDA

1971 


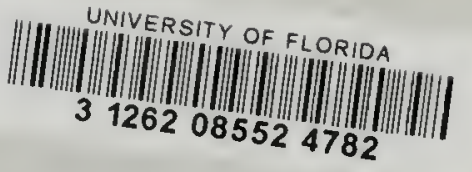




\section{ACKNOWLEDGMENTS}

The author wishes to extend his sincere thanks and gratitude to the many persons who have made this endeavor possible:

To Dr. F. S. Blanton and Dr. H. D. Putnam for serving as co-chairmen of the supervisory committee, and their assistance and friendship throughout this investigation.

To.Or. G. C. LaBrecque for serving as a committee member, for his assistance, direction, and friendship, and for providing equipment and working space at the United States Department of Agriculture's Insects Affecting Man and Animals Laboratory, Gainesville, Florida.

To Dr. J. F. Butler for his participation with the committee, for providing equipment and working space at the Medical Entomology Laboratory, and for his tolerance of the odors of rearing blow flies.

To Or. D. H. Habeck for his assistance and work with the committee.

To Dr. W. G. Eden for his guidance, encouragement, and ass istance.

To Dr. D. L. Bailey for providing equipment and advice.

To Dr. D. E. Weidhass and all the other members of the Insects Affecting Man and Animals Laboratory for providing counsel and aid on many occas ions.

To Mr. Dan Wojcik and Mr. Terry Marable for phoiographic ass istance.

To the Department of Environmental Engineering of the University of Florida for financial assistance provided by Contract number 5-701-U101029-09 from the United States Public Health Service. 
To Mr. Herb Houston, project director of the Cainesville Municipal Waste Conversion Authority, inc., and Dr. D. T. Knuth, Environmental Engineering, Inc., for furnisining equipment and facilities as provided by Department of Hea!th, Education, and Welfare Demorstration Grant number 5-D01-U1-00030-02.

Finaily, the author wishes to express his deepest gratitude to his wife, Judi, for her patience and constant encouragement during this study. 


\section{TABLE OF CONTENTS}

Page

ACKNOWLEDGMENTS................................

LIST OF TABLES................................ vi

LIST OF FIGURES................................ vii

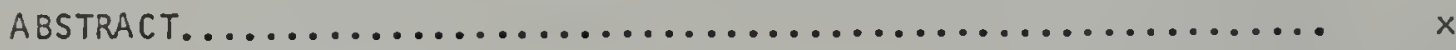

INTROOUCTION.................................. I

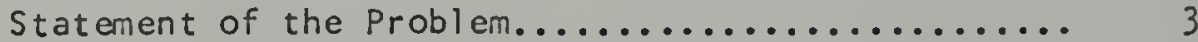

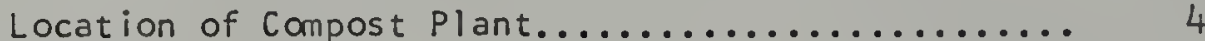

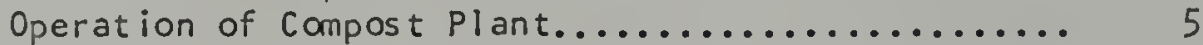

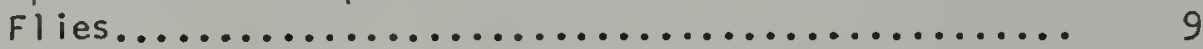

SECTION

1. FLY LARVAL MIGRATION FROM REFUSE................. 13

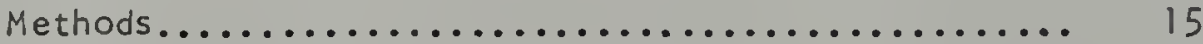

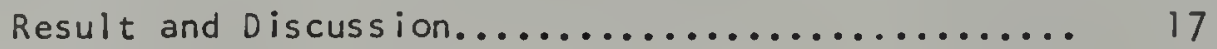

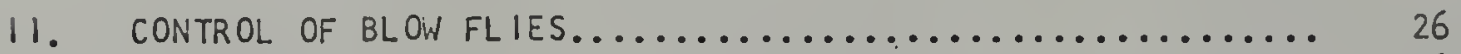

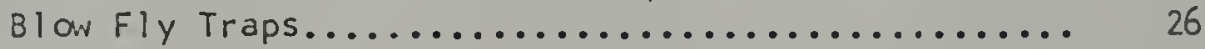

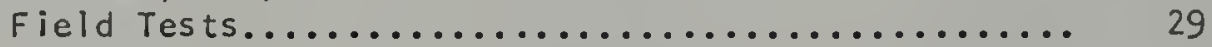

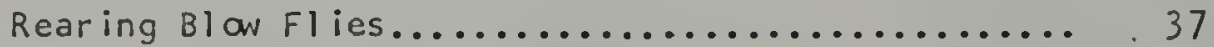

Laboratory Screening of Insecticides for

Control of $\underline{P}$ cuprina.................. 41

111. DENSITY AND SEASONAL FLUCTUATIONS OF HOUSE FLIES AT

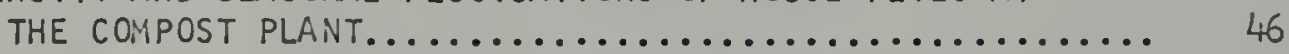

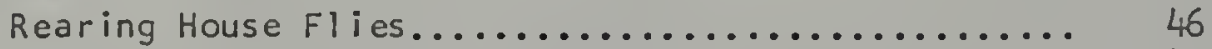

Seasonal Fluctuations of House Flies.............. 47

Evaluation of Fly Sticky Tapes................... 54

Determination of the Magnitude of the House Fly

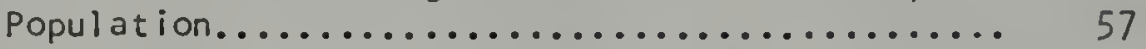

IV. HOUSE FLY BREEDING IN COMPOST.................... 60

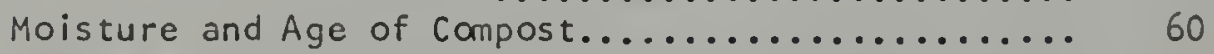

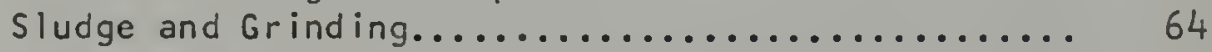

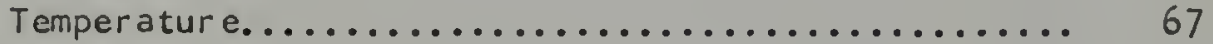


TABLE OF CONTENTS (Continued)

SECTION

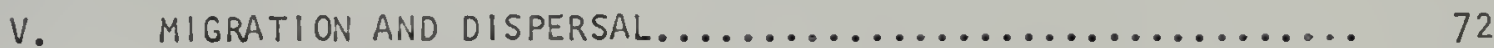

Literature Review........................ 72

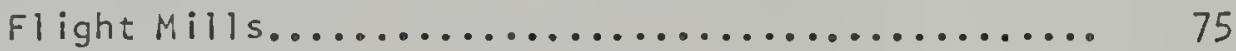

Blow Flies Released at Compost Plant............ 78

Fly Releases at the City Landfill............. $8 i$

SUMMARY, CONCLUSIONS AND RECOMMENDATIONS................ 100

APPENDIX

1. Test for the precision of the counting technique used to determine total number of larvae collected under the apron conveyor........................ 108

2. Fly larvae trapped under apron conveyor during 1969, at

the Gainesville compost plant...................

3. Percent mortality of 5-day old Phaenicia cuprina

females $24 \mathrm{hr}$ after exposure to insecticides

in a wind tunnel.......................... 111

4. Temperature in digesters............................ 114

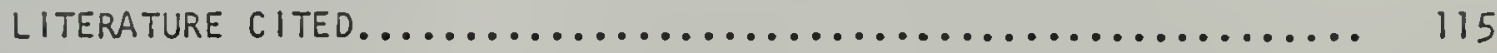




\section{LIST OF TABLES}

TABLE

Page

1. Percent abundance of species of fiy larvae trapped under apron conveyor during 1969.

2. Total number of larvae collected under apron conveyor compared to number of larvae trapped the same day..

3. Total number of larvae collected per day under apron conveyor compared to the number caught in the

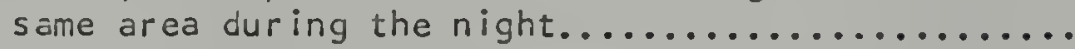

4. Sex, species, and abundance (\%) of flies caught in cone traps baited with 1 -day old fish heads

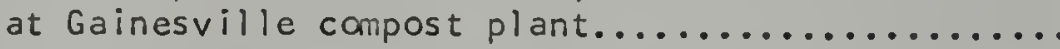

5. Number of flies caught per day in cone traps baited with fish heads as a monitor of procedures to control adult flies at the Gainesville compost

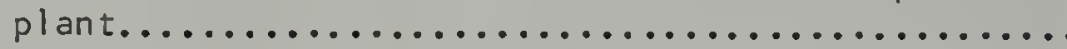

6. Sex, species, and abundance (\%) of flies caught by sweep net in grass adjacent to receiving area

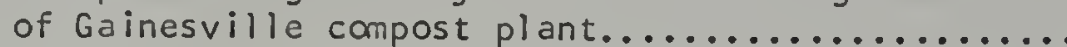

7. Analysis of several rearing media to determine the most suitable method of rearing Phaenicia cuprina....... 8. $L C_{50}$ of 5 -day old Phaenicia cuprina females to

9. Air temperatures recorded $15 \mathrm{~cm}$ above compost in digesters at Gainesville compost plant............

10. Number of adult house flies caught on sticky tapes in

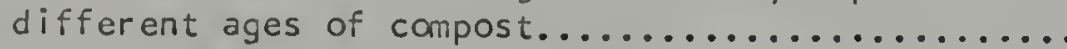

11. Recapture of 3-day old marked laboratory reared house flies by sticky tapes hung in digesters for $24 \mathrm{hr}$ follawing release of flies in the same area at the Gainesville compost plant during 1969......... 
LIST OF TABLES (Continued)

TABLE

12. Influence of moisture and age of compost on maturation

of immature house flies reared in compost.........

13. Influence of moisture on maturation of immature house

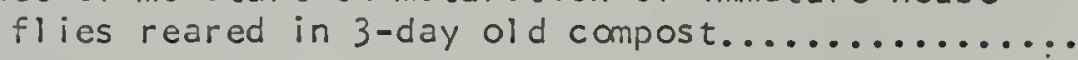

14. Influence of sludge and grinding of refuse on maturation of immature house flies reared in compost.........

15. Temperatures observed ir house fly rearing containers....

16. Temperatures observed in 4-day old compost in

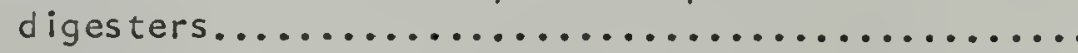

17. Mean distances flown in $24 \mathrm{hr}$ by adult Phaenicia

cuprina attached to an insect flightmill........

18. Distance flawn until death by adult Phaenicia

cuprina attached to an insect flight mill........

19. Recapture of wild marked flies by sweep net and

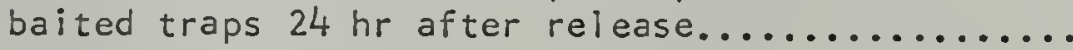

20. Recapture of marked wild flies at Gainesville sanitary

landfill by sweep net after release.............

21. Observations of marked wild $\underline{P}$. cuprina remaining at

Gainesville landfill after release..............

22. Observations of marked wild M. domestica remaining at

Gainesville landfill after release.............

23. Average percentage of flies remaining at city landfill

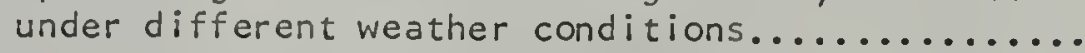

24. Rainfall recorded at Gainesville Municipal Airport during release studies at city landfill..........

25. Observations of 2-day old marked laboratory reared Phaenicia cuprina remaining at Gainesville landfill after release. 


\section{LIST OF FIGURES}

\section{FIGURE}

1. Floor plan of Gairesville municipal compost plant.......... ك

2. Refuse flow plan of Gainesvili e compost plant........... 7

3. Receiving building filled with refuse................ 8

4. Sorting conveyor carries refuse to sorting platform....... 8

5. Composting takes place in concrete digesters............ :0

6. The Finished product is discharged to outdoor storage areas. ?0

7. Fly larvae and pupae unier receiving hopper............ I4

8. Fly larvae migrating from refuse to pupation sites under wall of receiving building................... 14

9. Number of fly larvae caught under apron conveyor per week at Gainesville compost plant during 1969...... 18

10. Eastern ecige of approach ramp.................... 24

11. Fly larvae aiong base of eastern wall of approach ramp..... 24

12. Cone trap baited with l-day old fish heads to sample fly populations at compost plant.

13. Rear view of receiving building showing receiving hopper

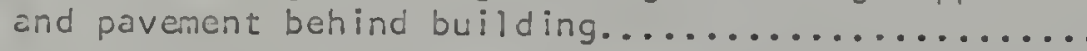

14. Mean number of adult fiies captured per sticky tape per week during 1969, in digesters at Gainesville compost plant.

15. Number of house flies captured on sticky tapes within 24 hr after release in a large outdoor cage........

16. Position of tmmerature proses in house fly redring containers. 


\section{LIST OF FIGURES (Continued)}

\section{FIGURE}

17. Diagram of insect flight mill..................... 77

18. Fly larvae in animal disposal area of city landfill...... 84

19. P. cuprina roosting on grass tassel at night at city

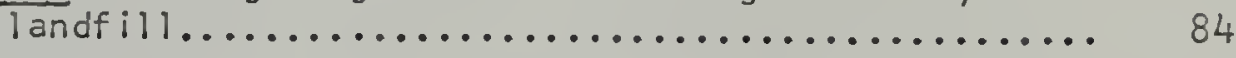

20. Predominantly $\underline{M}$. domestica roosting on weed at night at city landfill.......................... 85

21. Predominantly C. macellaria with some M. domestica roosting or dead brush in refuse at night at city landfill 


\title{
ECOLOGY AND CONTROL OF THE PRINCIPAL FLIES ASSOCIATED \\ WTH A CC:IPOST PLANT
}

\author{
By \\ Caivin Gale A? varez \\ March, 1971
}

Chairman: Dr. F. S. Elanton

Co-chairman: Dr. H. D. Putnam.

Major Department: Entamology and Nematolosy

Minor Department: Environmental Enginearing

Seasonal fluctuations of Diptera indigenous to damestic solid. Waste were examined at the Gainesville, Florida, municipal compost plant during 1968-1969. Populations of both inmature and mature forms were estimated and the efficiency of chemical and physical control procedures was tested. Adult dispersal studies were conducted during 1970 at the city landfill.

The major fly scurce at the compost plant was found to be from larvae-infested incoming refuse. The greenbottle blaw fiy, Phaenicia cuprina (Shannon), comprised more than 90 percent of the larvae which migrated into protected areas where they developed into adults. Approximately 450,000 adult flies per week were produced during the summer months. This figure could be reduced by more than 63 percent by procedural changes and gocd housekeeping.

The daily application of a dichlorvos sugar bait reduced the number of ilies by 66. - percent while a single application of dimetioate reduced

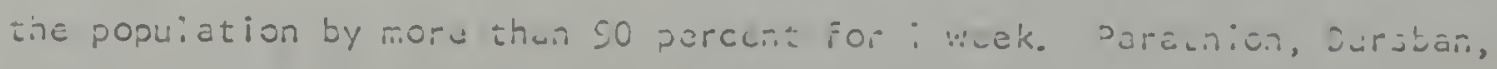
naled, ard diazinon were a!so wiflctive us stuwr by lauorato-y tes is. 
The number of house flies captured on sticky tapes was shown to be proportional to the number present in a large outdoor cage. Sticky tapes were used to show seasonal fluctuations of house $f l$ ies in the digestor building.

House flies were the predominart insect breeding in compost. They were $1 \mathrm{imited}$ to the top $2.5 \mathrm{~cm}$ in the digesters because of timperature. The optimum moisture content for house fly breeding was 75 percont. 0ra to 14 percent of the eggs placed in compost at $45-55$ percent moisture (normal operating conditions) developed into pupae. Egg survival to pupae decreased significantly when placed in refuse afier 5-10 days of composting.

- P. cuprina males $\mathrm{flew}$ an average of $19,405.4 \mathrm{~m}$ and a maximum of $30,137 \mathrm{~m}$ when attached to a flight mill until death. Females flev an average of $25,235.2 \mathrm{~m}$ and a maximum of $45,030 \mathrm{~m}$.

Wild $\underline{P}$. cuprina and $M$. comestica were marked and released 1 mi from a. landiill and later recaptured at the landfill. An average of 10.17 percent of the wild $\underline{P}$. cuprina and 1.66 percent of wild $M$. domestica released at the iandfill on days followed by 24 hr without rain were recaptured 24 hr after release. An average of 10.7 percent of the wild P. cuprina released at the compost plant were recaptured in the same area 24 hr later. An average of 11.3 percent of laboratory-reared $\underline{\text { cuprina }}$ released at the landfill were recaptured 24 hr later. Baited traps surrounding the landfill recaptured only 2 flies after a total release of 255,000 flies. 


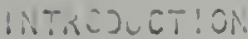

The demands of our affivent society for more goods and conve.ivin itens such as no deposit and non-returnable materials, rajlit in tha generatiun of waste products in gigantic proportions. MS the afi.unce and the population increase, the per capita and total amount oi waste increase proportiona?ly. The disposal of these trenendous cuantities of wastes has prima:-i?y been an urban problem. Since the trend in the United States is toward urbanization the problems of refuse disposal become increasingly more importart. This becomes evident when it is noted that in 1960 the estimated median waste per capita per year in urban areas was 1,430 pounds. This amounted to 80 billion pounds per year and the cost of collccting and disposing of this refuse was more than 1.5 billion doilars (1).

To combat the rising probicm of refuse disposal the "Sol id Waste Disposal Act" was enacted in 1965 to support a national program designed to implement and evaluate more efficient methods of coping with the solid waste problems. Under this act the Bureau of Solid Waste Managemert awarded a contract to the Ginesville Municipal Waste Conversion Authority for the construction and operation of a refuse composting facility. The purpose of this project was to "demonstrate the reliability,

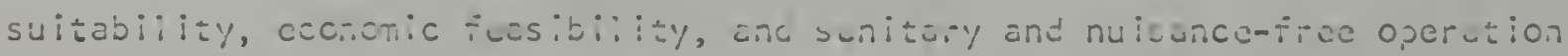

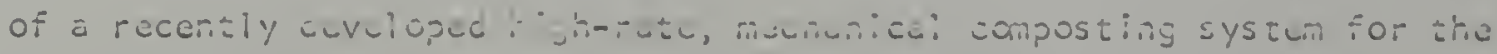

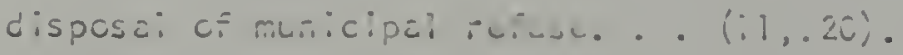


The primary objective of coriposting is to dispose of refuse by biological degradation of the organic materials. Modern scientific composting procecures which are employed in municipal disposal systems involve the rapid partial decomposition of orsanic matter by the use of aerobic microorganisms under controlled conditions (1). Municipal composting is a fairly cammon practice in many European countries. It is rarely used in the United States because lard for refuse disposal was available in close proximity to urban centers in the past. The increasing demand for land provided the stimulus for municipal it ies to seek a more acceptable form of refuse disposal. As ?ate as:950, there was little scientific information available on municipal composting in the United States. Since then several universities and the United States Public Health Service conducted studies that have as yet yielded only a limited amount of practical information. The capital and operating costs of camposting are known to be higher than most other forms of refuse disposal but the specific econonics involved in municipal compostirg in the United States are practically unknown. The feasibility of composting must be determined by the major advantage of camposting, the recycling of waste products. The sale of marketable compost and salvagable goods would reduce the net cost and may result in a profit.

There are 2 general composting processes that appear to be the most efficient and econonical under U.S. conditions. The first is mechanical digestion, a process in which refuse is sorted, ground, and mechanically manipulated in order to shorten the biological degradation process. The second method temed windroing involves the sorting, grincing, and placing of refuse in windrows allaving the materis? to compost naturally. The compost plant constructed a: Gainesvilie used the mechanical wigestion process. 


\section{Statement of the P.oblam}

As with other scientific information concernirg composting in the U.S., littie is known concerning insect problems that may arise in this type of nperation. The original purpose of the present investigation was to search out these problens, determine their magnitude, and suggest possible solutions. Initial observations revealed that large numbers of fly larvae entered the compost plant within the refuse. These larvae seeking a suitable pupation site migrated from the refuse stored in the refuse receiving building. These insects were aesthetically unpleasant to the employees as the larvae were often crushed beneath their shoes and sometimes crawled into the clothing of a resting employee. Many of the immature insects eventually became adults and further tormented the employees at the site by their constant presence while others were reputed to invade the surrounding community. Thus, the primary areas of this investigation were as follows:

To identify the larvae entering the compost plant with the refuse and to determine their magnitude and seasonal fluctuations.

To search out possible processing procedures which may reduce the number of larvae migrating into the plant.

To evaiuate mechanical and insecticidal control procedures to reduce the larval populations.

To screen several comercial insecticides for their effectiveness agoinst the emerging adult flies.

To determine the density and seasonal fluctuations of the adult house flies at the compost plant. 
To determine the extent and same or the limiting factors of house fly breeding in compost.

To determine the extent of fly dispersal fran the compost plant into the surrourding community.

Laboratory studies were conducted at the LSDA Insects Affect:ing Man and Animals Laboratory in Cainesville, Fiorida, and at the Lniversity of Fiorida Medical Entomology Laboratory. Field studies conducted at trie compost plant were begun in June, 958 . Because of a lack of funcs, this plant was closed on December 31,1969 , ard some of the studies wera not expanded as the author had intended. Most of the dispersa? studies ware performed at the C:ty of Gainesville Saniar-y Landfill during the sumer of 1970 .

\section{Location of Carpost Plant}

The compost plant was constructed on a 5-acre tract of land located in southeast Gainesville at the city's sewage treatment complex. This site was near a sewage treatment plant, an animal shelter, and an abandoned dump.

A densely populated region of middie-income apartment complexes inhabited primarily by University of Florida students and a low-income residential area were located in ane immediate vicinity. A woodland area buffered a middle- and high-income residential area located one-half mile from the plant. 


\section{Coeration of Compost Plant}

The floor plan o: the compost plank is pissented in Fig. 1 and tro

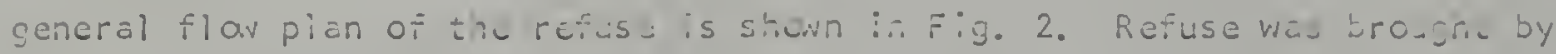
trukk and dumped on tre fioor of the raceiving building (Fig. j). Ine iefuse was then placed ints a receiving hopper by a tractor nutifiad wi:h a front-end loader. The hopper $(i 9.8 \mathrm{~m}$ iong, $3.6 \mathrm{~m}$ wide, and $3.6 \mathrm{~m}$ aecpi) constituted the rcar side of the buildirg. An apron conveyor which cons isted ot a series of overlappir.g or interiockirg apron pans was located at the bottom oi this hopper. Tne refuse was transported aionj the conveyor onto an oscillating table. This tazi e loosened the packud reiuse in order to assure a unitorm flon. A sorking conveyor cariied the refuse fran the osciliating tabie to a piatform where 6 labo-ars manualiy removed salvageable paper, cardboard, and large bulky items (Fig. 4). The paper and cardboard were dropped into chutes which fed into a baler and the bulky items were placed in chutes that emptied into a dump truck which corried these materials to a landfill. The sorted refuse thun proceeded direct?y into a crusher-disintegrator grinding mill. The ground refuse discharged from the crusher averaged $7.6 \mathrm{~cm}^{2}$ but varied in size depending upon the type and amount of material fed into the machine $(20)$.

Refuse passed fran the first grinder into a second grinding unit which reduced the particie size to approximately $5 \mathrm{~cm}^{2}$. It was then discharged fran the botton of the sccondary grinder into mixing scrass where 2 ccunterrotating ritbon-cype screws, pisced side by zide in a common trough, blendcd the meterizi with dute: or sludse. A corveyor tula carriud the moistened rutuse unaur a majnctic separato: which ramoved the ficrous 


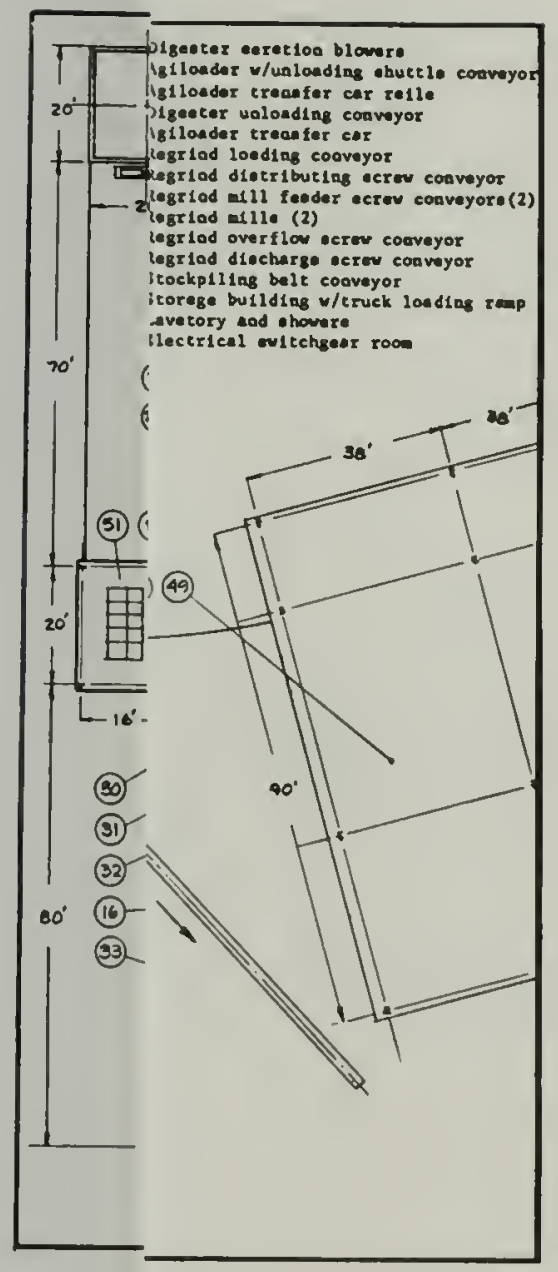

Fig 



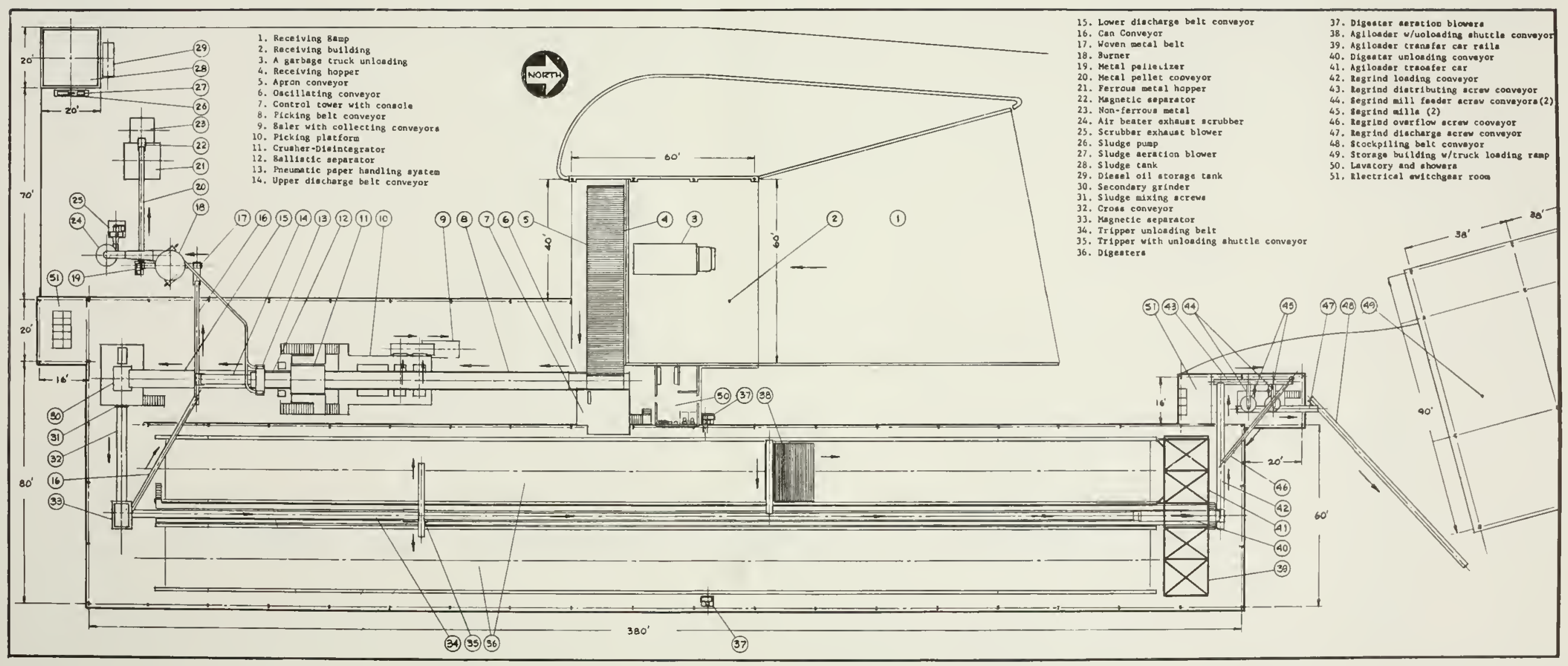

Fig. 1. Floor plan of Gainesville municipal compost plant (20), 




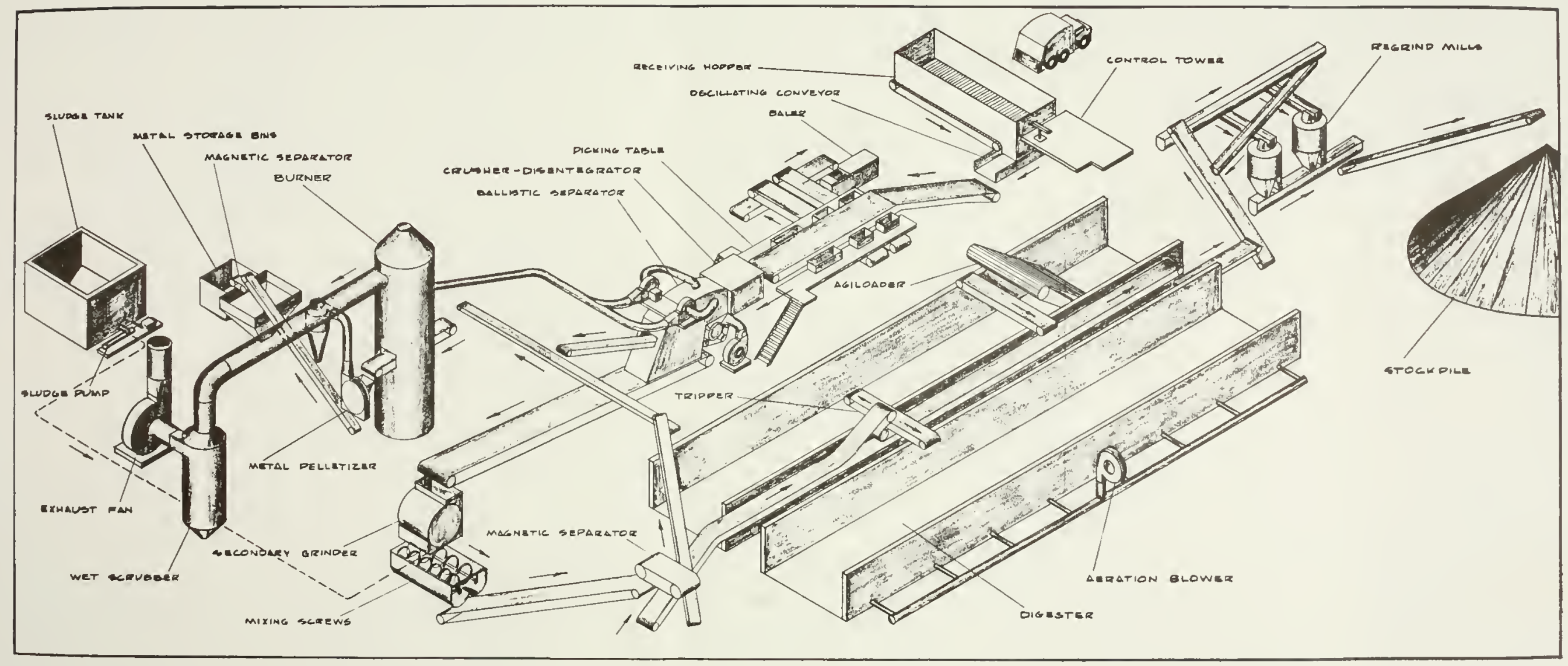

Fig. 2. Refuse flow plan of Gainesville compost plant (20). 



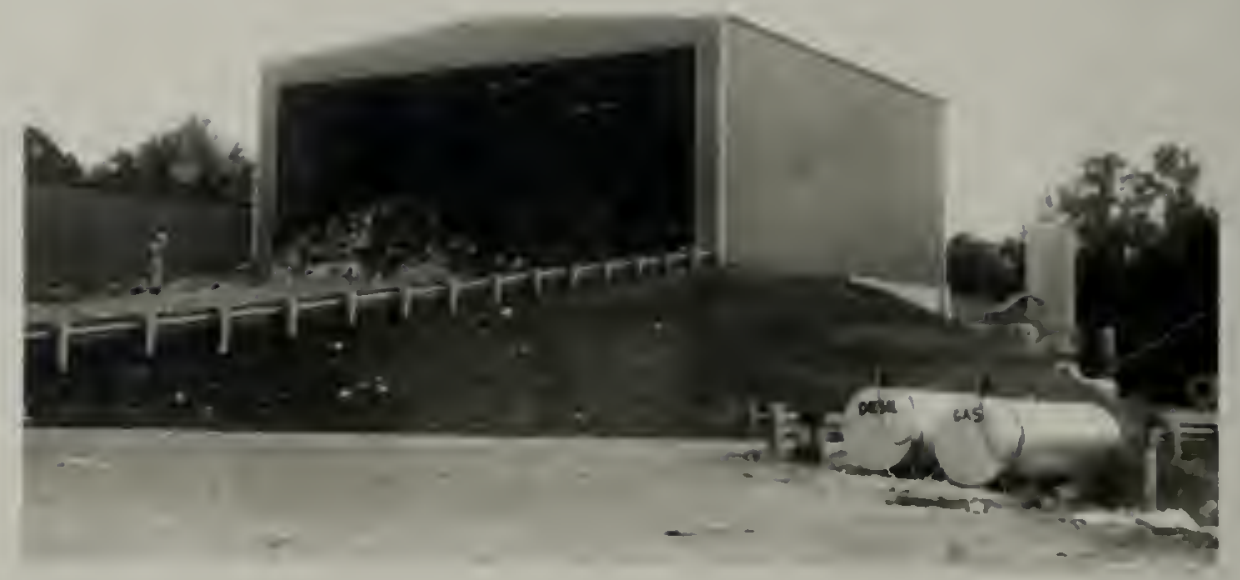

Fig. 3. Receiving building filled with refuse.

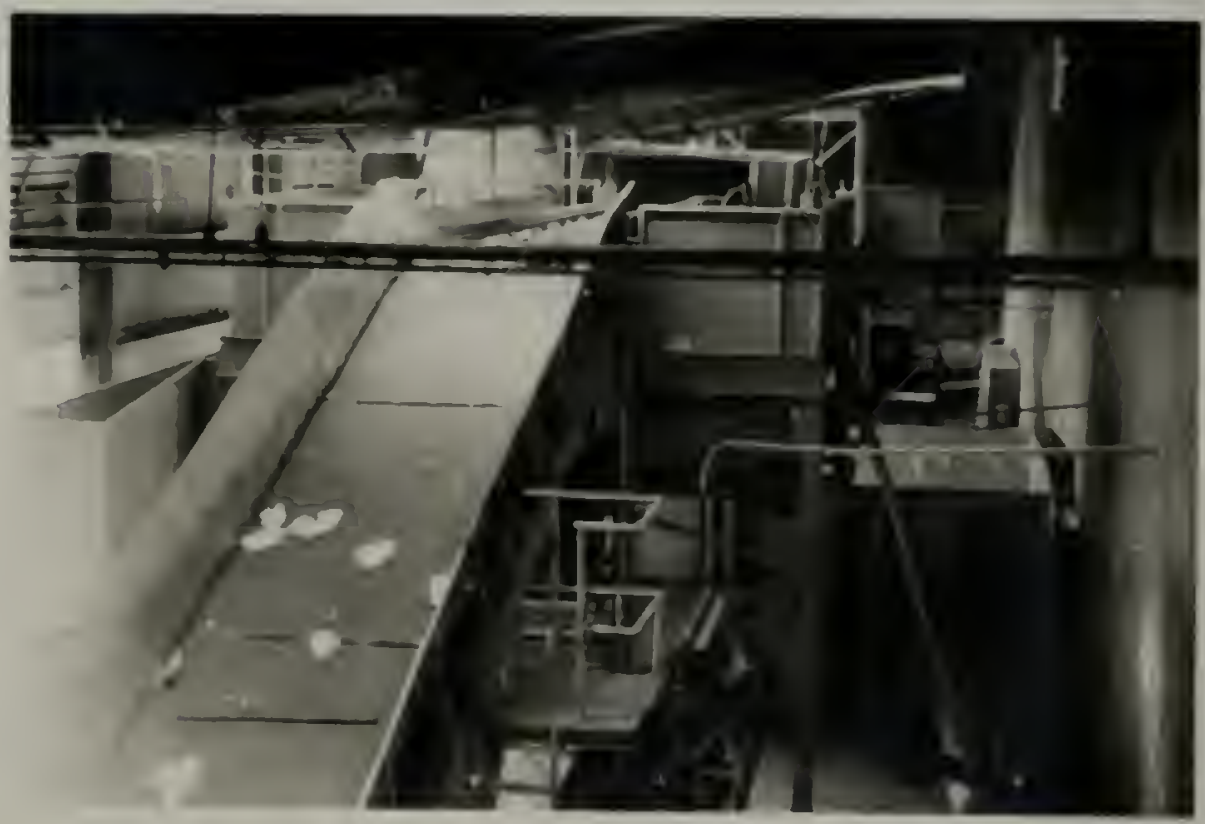

Fig. 4. Sorting conveyor carries refuse to sorting platform. 


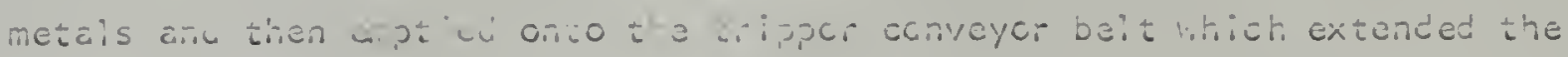
iergsh of the digesturs. A sinttie conveyor, which traveiled on a pair of steel rails bewween the digesters discharged the refuse into these ur: $t$. Fine digesters or cigesting tarirs were 2 concrete troughs 99 in long, $6 \mathrm{~m}$ wide, and $2.7 \mathrm{~m}$ deep $(F i g .5)$. The digester walls were constructed of concrete blocks and the floor was converted with perforated galvanized steel piates. These piates were above an air pierum into which air was discharged by a centrifugal ION pressure fan. River gravel approximately $0.6 \mathrm{~cm}$ in diameter covered the perforated plates to a depth of $7-10 \mathrm{~cm}$. This enabled the air to diffuse evenly through the small slots over the entire floo: o: the tank. The refuse was placed in the digesters to a depth of 1.8-2.4 $\mathrm{m}$ and all aved to compost for approximately 6 days (20). (In this investigation "compost" refers to refuse that has remained in the cigesters for a period greater than 24 hours.)

Removal of the compost was acconplished by a machine called the Ag:-Loade: (Metro-waste Patent No. 3,294,49:). This machine removed the compost and deposited it back onto the tripper conveyor. A system of conveyor beits tiansported the campost to a final grinding mill. A finely ground material approximateiy $1 \mathrm{~cm}^{2}$ was discharged fran this grinder and was tiansported by conveyor to an outdcor storage area (Fig. 6).

\section{Fi ies}

-ie nost numerous species of files piesurit at the compost p?ant were - La cammon house fly, Musca domestica Linnaeus, (ruscidae, Diptera), and

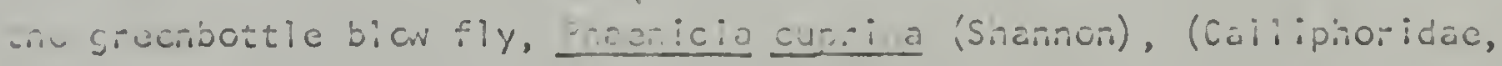
it-3ia). 


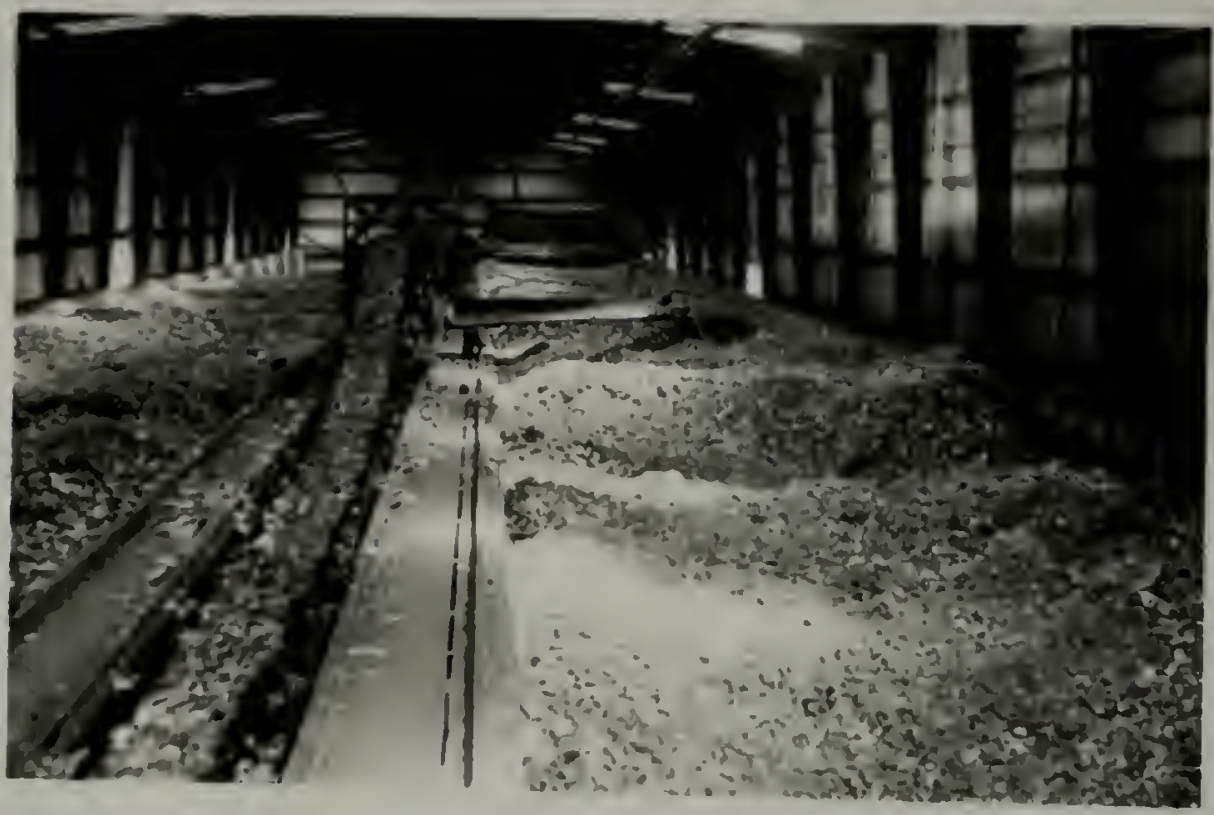

Fig. 5. Composting takes place in concrete digesters.

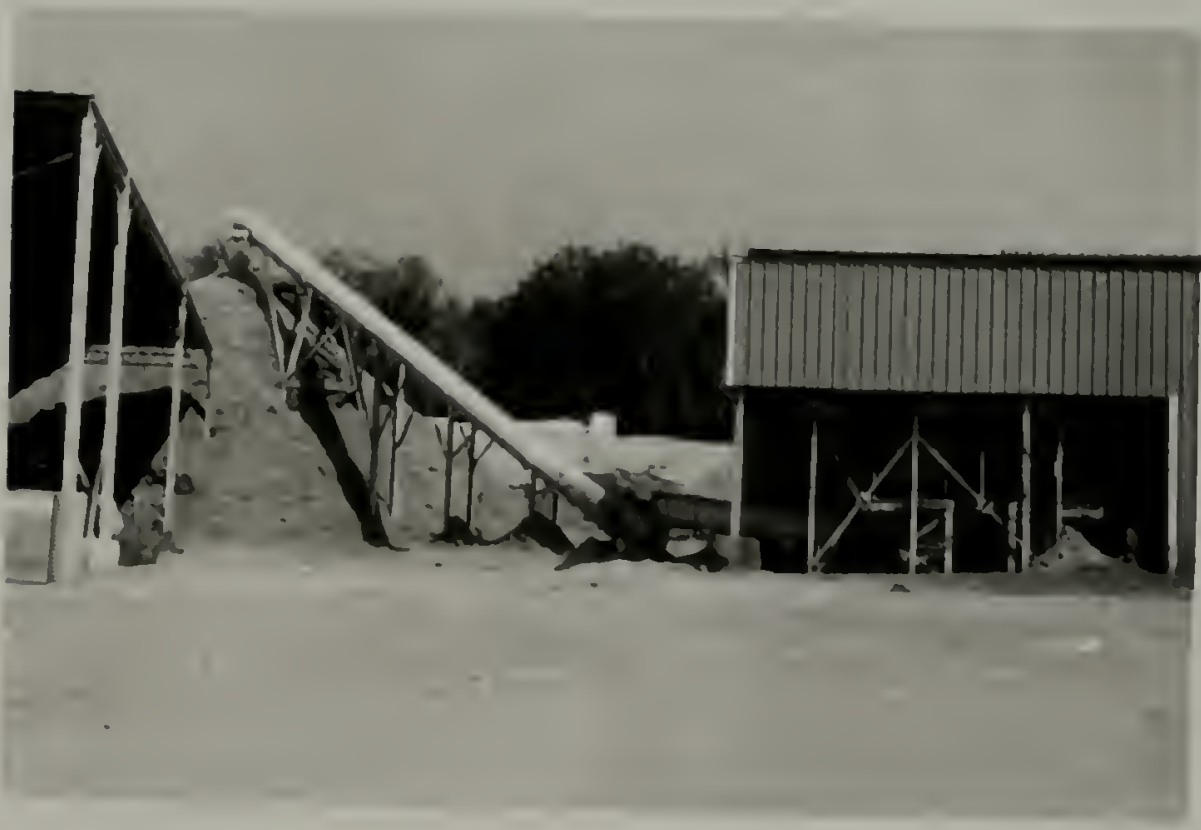

Fig. 6. The finished product is discharged to outdoor storage areas. 
The house f?y has been incriminated as a carrier of numerous diseases of man and animals including typhoid fever, cholera, and amoebic dysentary (27, 82); hovever, these claims have bean supported only by circumstantial evidence. House f?y associations with diswasas need further ciatitication as experimenta? evidcrce is sparse and contanination of house flies between caged mates has been shown to be sporadic $(2 \div)$.

Greenbottle blow fi ies may be ćmestic nuisances or carry disease organisms, but in this capactty they are far less important a...n other flies. However, the ciamage and suffering which the larvae intict upon domestic animals in same stock-raising areas is of tremendous consequcrice. In Australia, this fly is by far the most important species in fly stikc or cutancous myias is of sheep $(44,69)$. Fiy strike is a condition produced by the development of blow fly larvae on living sheep which may lead to death or a considerable loss of woo?. This is a formidable problem in Australia and amounts to an annual loss of 4,000,000 pounds to sheep raisers $(4,69)$.

The common house fly is well establ isted as Musca domestica Linnaeus but the systematics of the greeribottle blow fiy are samewhat confused. Australian authors refer to this fly as Lucilia cuorina (hiademann). Hall (20́) compared specimens From the United States and Australia and concluded they were not the same species. He described the American specius as a neil combination, $\underline{P}$. pallescenes (Shannon). Waterhouse and Paramorov (80) later examined numerous specimens from Texas, NuW York, New Orleans, Washirgton, and Australia ard concluded that there was no dirferencu in species, but a definite pair of subspuz. J. James (23) zoncurict in this view. Hall later in Stunc et al. (7E) mairtained his ccmbinazion of 
pa!?escenas (Shunnor) but recognized the works of Watorhouse and Paramonov. The autio- uscs the spccies name fran Waterhouse and Paramonov since their work appeared to be mo:e comprehensive than that of Hall. 
SECT.C.S :

FLY LARVAL MIGRATION FROM REFLSE

The major source of fiy iniestation appeared to be from i-troduction of larvae from the collected refuse and not fiom breeding at the cumpot plant. Fly larvae that were breedirg in refuse containers throigncut the city were brought so the compost piant with the refuse. This infested refuse was stored awaiting processing in the receiving arca. Many a: the larvae were mature and the added stimilus of the disruptive transfer to the p!ant caused them to actively seek a pupation site (Figs. 7 and 8 ). Sone of these larvae migrated into the working areas where thizy annoyed the employees while others reached protective areas where they metamorphosed to adu?ts. Such occurrences were not unique to the compost plant. Large numbers of larvae may escape to pupation sites during the handling, transferring, or processing of larvae-infested refuse. Green and Kane (23) found that 7200 larvae/hr/per car were escaping from railroad cars awaiting dispatch to a rural disposal area.

The infestation of refuse by larvae in the Gainesville area was anticipated because in a southern California city, with a climate similar to that of Gainesvilie, Ecke et al. (18) reported that residential refuse

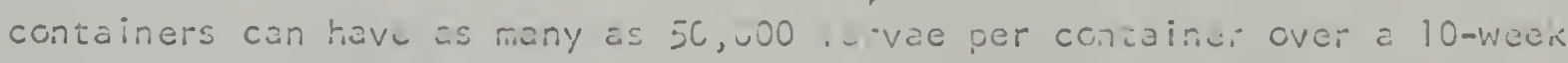

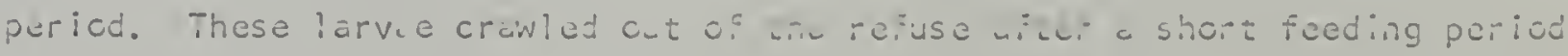




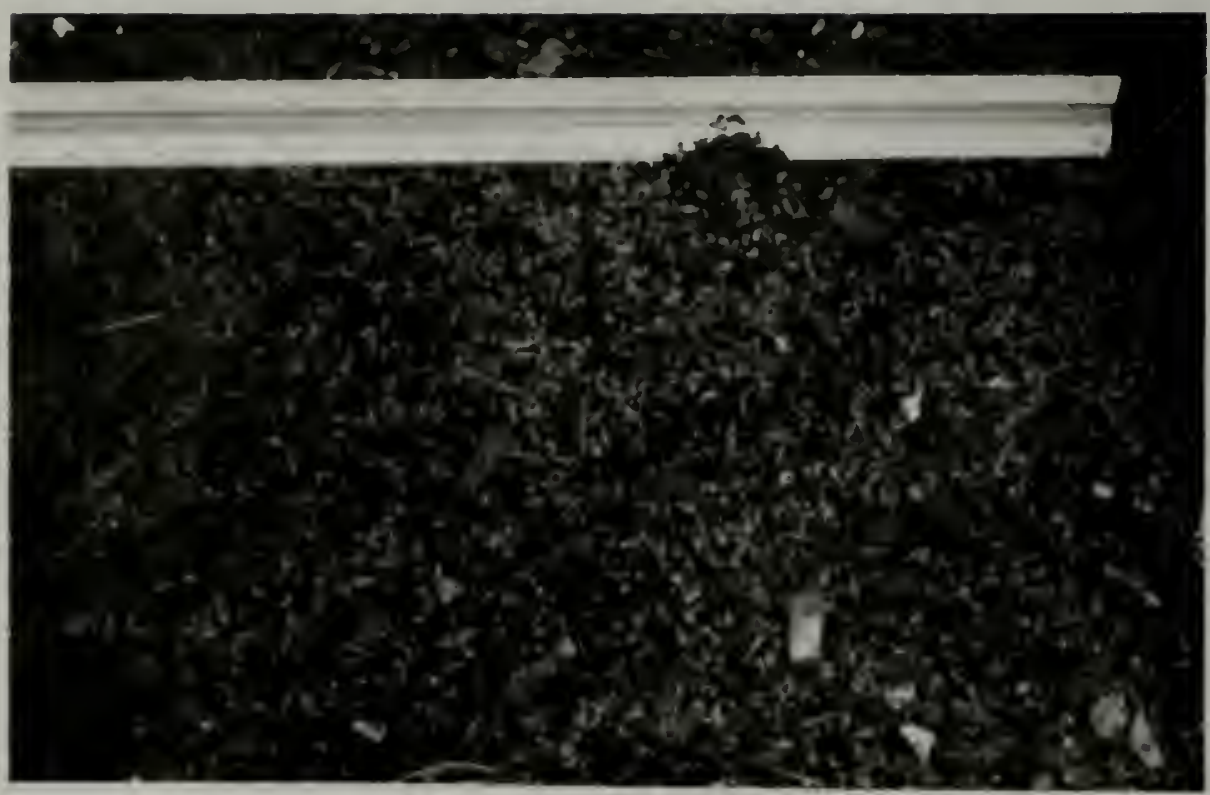

Fig. 7. Fly larvae and pupae under receiving hopper.

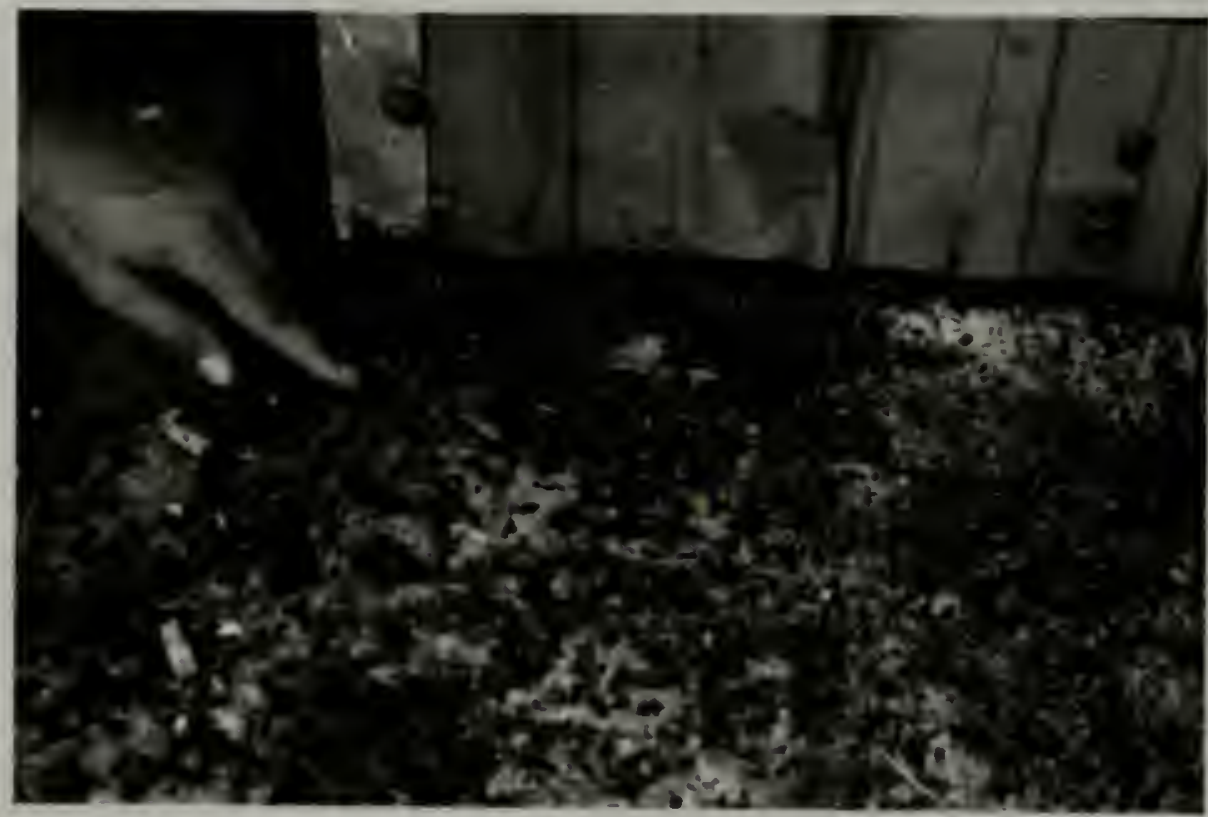

Fig. 8. Fly larvae migrating from refuse to pupation sites under wall of receiving building. 
to pupate in the soil and later emerged as adults. During the hot summer months it was reported that the feeding period was completed in 4 days (79). This observation led to the recommendation and subsequent adoption of a twice-weekly refuse collection system for several California cities

\section{$(17,79)$.}

The purpose of this investigation was to determine the species of the larvae escaping into pupation sites at the plant, to determine the magnitude and the seasonal fluctuations of this massive influx of insects, and to search out possible processing procedures which would reduce the total number of escaping insects.

\section{Methods}

\section{Seasonal Fluctuations}

Visual observations indicated that the majority of the larvae escaping from the refuse were confined to the partially enclosed area under the apron conveyor. The larvae reached this area either by crawling through the openings between the metal pans of the conveyor or by falling through the opening between the floor of the receiving building and the edge of the receiving hopper. To determine the species present and the seasonal fluctuations of the larvae entering the plant, a trap was placed in this area. This trap was similar in function to that described by Roth (58) and consisted of a $30.48 \mathrm{~cm}^{2}$ piywood box.. It was abutted to the wall under the apron conveyor so that larvae falling through the opening between the hopper and the floor would be trapped in the box. The trap was operated from January 12 to December 31, 1969. 
The trap wiss checked daily and the number of larvae recorded. A minimum of one sample catch per week was preserved in alcohol for identification.

\section{Popliation Factor}

It was desired that the larvai population trapped in the seasonai fluctuation survey bu lised to estirate the total number of larvae escapiris into the plant. To accomplish this it was necessary to dutermind w total number of larvae that entered the plant, the percentagu oi the larvae trapped, and the rai iability of the trapping piocodure.

The total rumber of larvae entering tine piant wolid be a c. i:iitu? figure to accurately cefine. Since the majority of the larvae migratad under the apron conveyor $\vdots t$ was used tc determine the total number of larvae in that area and to determine the reliability.

The larval population under the apron conveyor has determined by sweeping the area for a 10-day period beginning August 29, 1909. Thcse sweepings, which included the debris and iarvae that had fallen during the pievious $24 \mathrm{hr}$, were placed into a 55 -gallon (208 1) drum. The drum and its contents were weighed, sealud, and thoroughly mixed by rolling on the floo- for several minutes. Lmediately a volume of aporoximately 0.51 was removec and weighed on a laboratory balance (Gaus, Unicn, N.J.). The larvae in the sample were countec and the total number of larvae in the drum or hinder the apron conveyor was calculated.

To determine the precision of the above method, a sample of approximate!y 0.51 was romout, we gheu, counted, and replaced in the drum. The

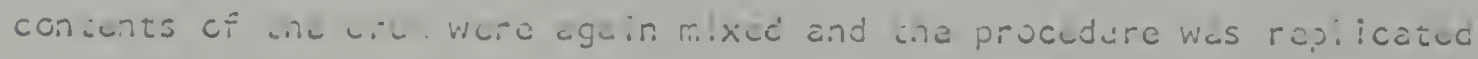

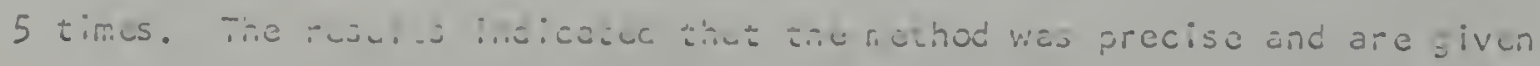
in Appondin : . 
It was standard operazirs procedure that a sufficient amount of refuse remain in the receiving bullding ovcrnight so that operations could begin the following mornisg and proseed without interruption lntil the trucks began dei ivering rufuse. To determine tha rumber of larvae escaping into the compost plant as a direct resuit of this proced re, the area under the apron conveyor was swept twica daily; once at 7:00 am,

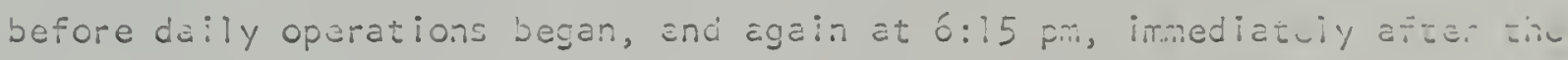
piant closed. This was repeated for $\epsilon$ consecutive days during Septemiber, 1969. The larvae collected were enmerated as described previously.

\section{Result and Discussion}

\section{Seasonal Fluctuations}

The results of a larval sampling program to determine the species present and seasonal fluctuations of the larvae escaping into the compost plant are shown in Fig. 9 and Appendix 2. These data show that relatively few larvae were captured during January, February, and March. The catch increased ir. April while a consistentiy high number of larvae were tiapped fran jure to mid-October. Tire number ceclined throughout November and larvae became relatively scarce in December.

Phaenicia cuprina was the predominant fly species collected in this survey. Table 1 shows that greater than 97 percent of the captured larvae were $\underline{P}$. cuorina. One purcent were $\underline{M}$. donestica wh: le the remainder were comprised of Cochlicmuia micull-ia (Fabricius), Hernutia illucens (Linnaus),

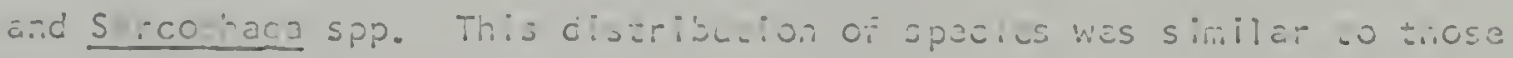

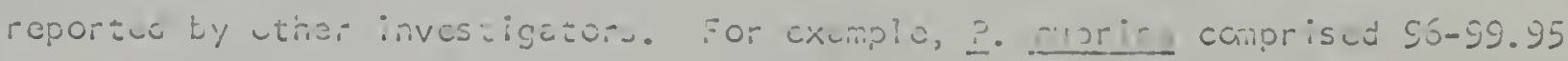




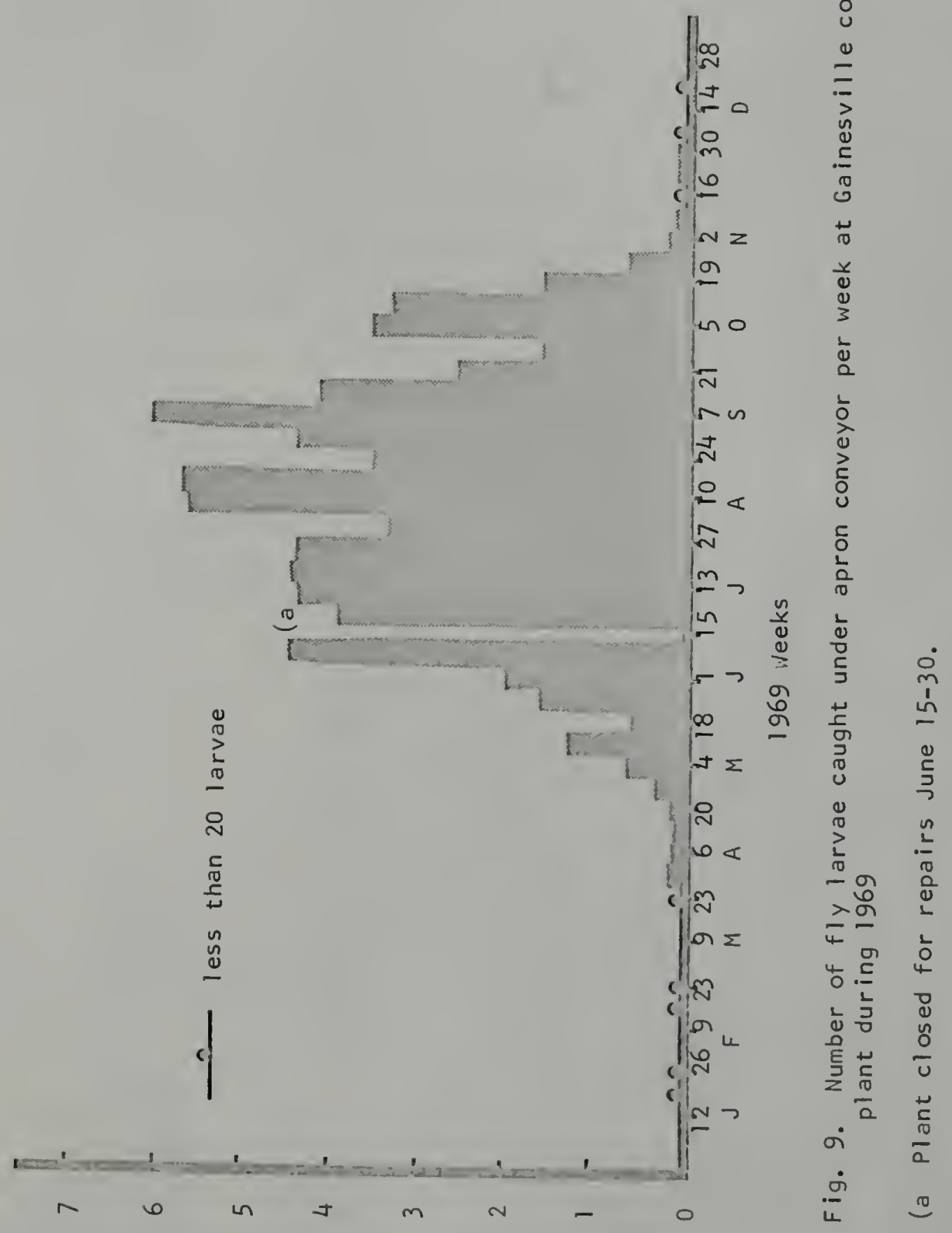

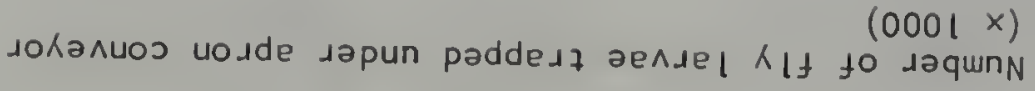


Table 1. Percent abundance of species of fly larvae trapped under apron conveyor during 1969.

\begin{tabular}{|c|c|c|c|}
\hline \multirow[b]{2}{*}{ Species } & \multicolumn{3}{|c|}{$\begin{array}{l}\text { Percent of total number of } \\
\text { larvae examined per week }\end{array}$} \\
\hline & Maximum & Minimum & Average \\
\hline Phaenicia cuprina & 100 & 90.5 & 97.2 \\
\hline Musca domestica & 6.4 & 0 & 1.0 \\
\hline Cochliomyia macellaria & 6.0 & 0 & .7 \\
\hline Sarcophaga spp. & 4.7 & 0 & .7 \\
\hline Hermetia illucens & 4.7 & 0 & .6 \\
\hline Others & $<.01$ & 0 & - \\
\hline
\end{tabular}

percent of all larvae collected from residential refuse containers in southern California $(28,18,79)$. It was also the principal blaw fly found in garbage in Orlando, Florida (31). Green and Kane (23) reported Phaenicia was the predominant genus occurring in London during the summer. Population Factor

Table 2 gives the calculated number of larvae collected per day under the apron conveyor and the percent trapped in the larval sampling program for that same day. These data indicate that an average of 0.99 or approximately 1 percent of the larvae under the conveyor were caught in the trap. The variance of 0.04 for these resuits indicates consistency.

Larval movement into the plant was not limited to the area under the apron conveyor as migration from a pile of refuse could be expected to occur randomly in all directions. Larvae migrating from the refuse in the receiving building in an easterly direction found harborage behind a wooden retaining wall. This was approximately $1 \mathrm{~m}$ from the outer wall of 


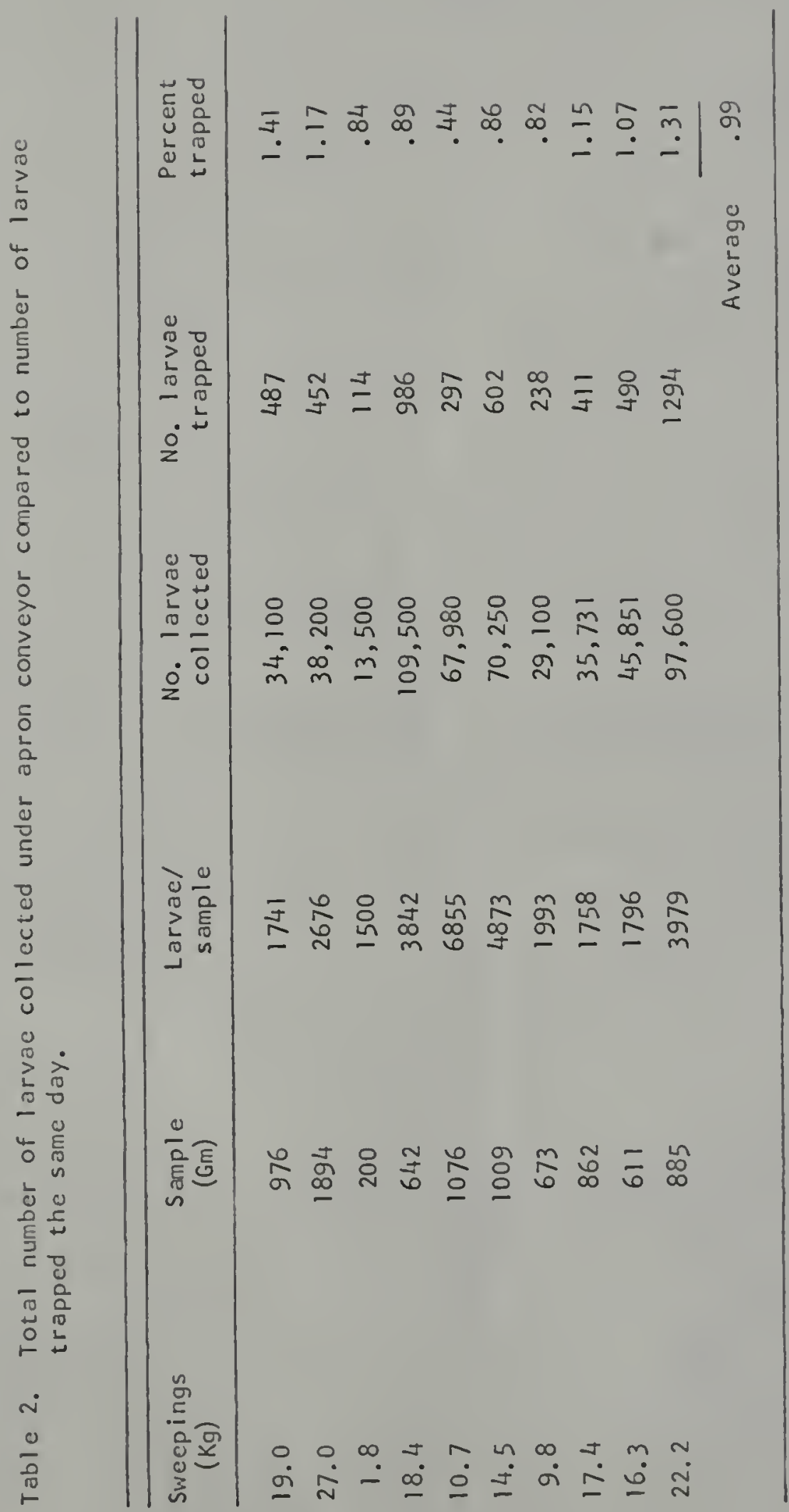


the building and extended the length of the receiving area. It was difficult to sample this area and the larval population was an approximation based on visual observation. It was estimated that the number of larvae escaping behind the east wall was approximately one-third of those escaping under the apron conveyor for any given day.

The construction of the receiving area and the practice of handling the refuse greatly reduced larval survival in other directions. Refuse was deposited toward the east wall and as it was moved into the hopper from east to west by the front-end loader, those larvae migrating in a westerly direction were scraped into the receiving hopper. Northerly migration resulted in little survival since the ramp and paved areas provided no protected areas for pupation.

Combining the estimates that two-thirds of the larvae migrating into the plant enter the area under the apron conveyor and 1 percent of these are trapped results in a population factor of 133 . This factor may be multiplied by the daily larval catch to give an approximation of the number of insects migrating from the refuse into the protected areas of the plant. For example, Appendix 2 shows that 6116 larvae were trapped the week of September 7, 1969. Multiplication by 133 gives an approximation of 813,428 larvae entering the plant during that one-week period.

\section{Effect of Clearing Receiving Building Daily}

Larvae collected under the apron conveyor during plant operation were compared to collections in the same area during off hours. The results are given in Table 3 and indicate that an average of 38.5 percent of the larvae escaping into the compost plant migrated from piles of refuse remaining in the receiving building after the plant was shut down for the 


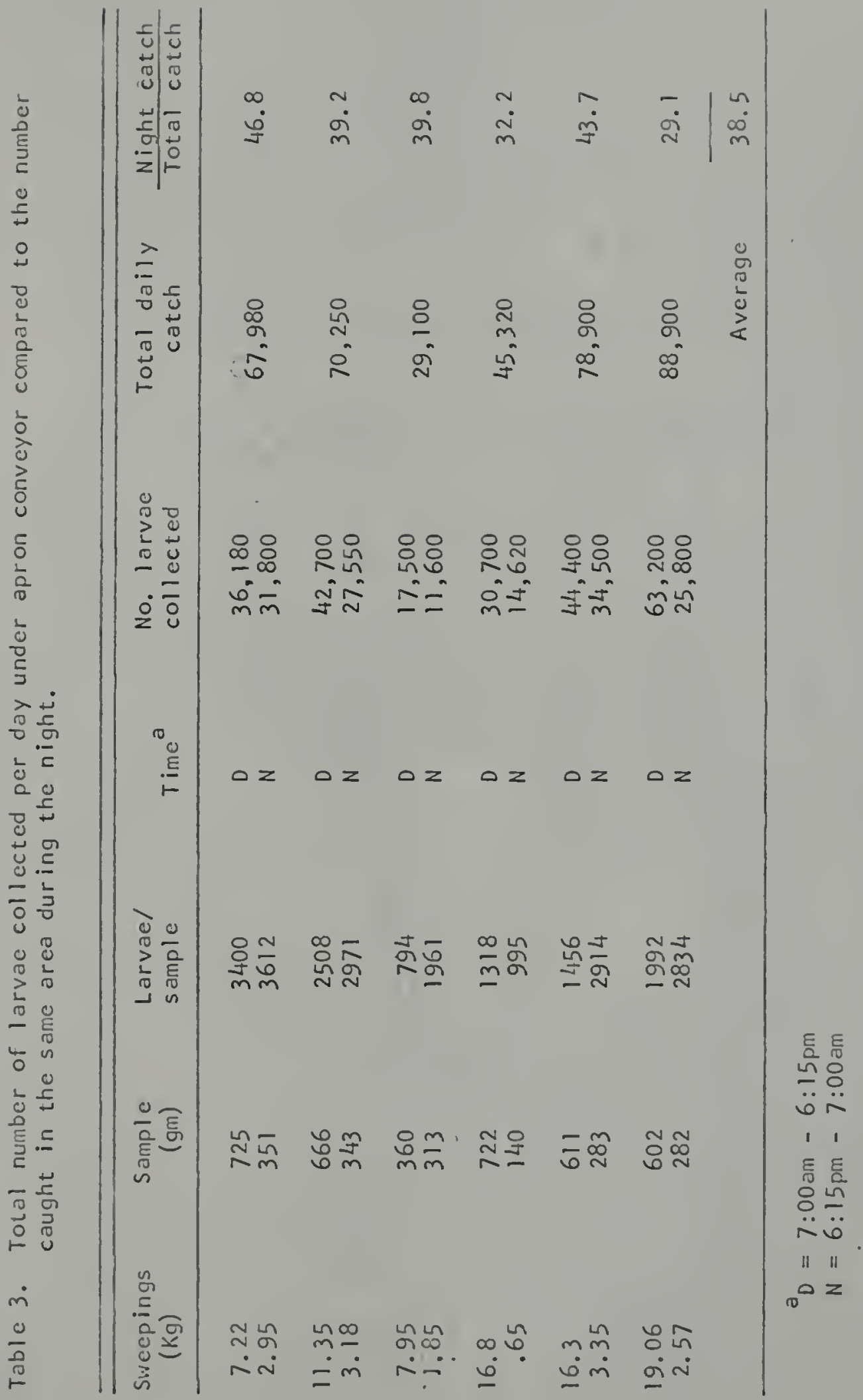


day. It is obvious from these results that not storing refuse overnight would reduce the number of larvae entering the plant by more than 35 percent and decrease the ensuing adult population.

The value of clearing the refuse fran the receiving area daily was further demonstrated by observing the large numbers of larvae along the eastern edge of the approach ramp. When refuse remained on the approach ramp for several days numerous larvae migrated fran the refuse and fell to the pavement below. On several occasions when this occurred fly larvae were so numerous that the pavement along the edge of the ramp appeared white. On one such occasion the pavement was swept clean and the larvae collected $12 \mathrm{hr}$ later. Their number was estimated to be 30,000 or 60,000 per day migrating from the ramp (Fig. 10 and 11 ). Adult Development from Larvae

The majority of the larvae that migrated from the refuse were mature and thus required only a suitable pupation site to develop into adults. This was demonstrated by placing 100 larvae collected under the apron conveyor into waxed paper cups $(0.9461)$. Twenty-five gm of refuse debris collected from the same area were added to one-half of the cups. The cups were covered with cloth, secured with a rubber band, and placed under the apron conveyor. Ten, days later the number of adult flies that had energed were counted. Nine replicates of each test gave an average of 65.3 percent adult emergence from the cups to which only larvae had been added, and an average of 88.8 percent adult emergence from the cups with debris added.

Generally there was a considerable amount of debris under the apron conveyor and behind the east retaining wall, the main areas of larval infestation. It was concluded that most of the escaping larvae reached 


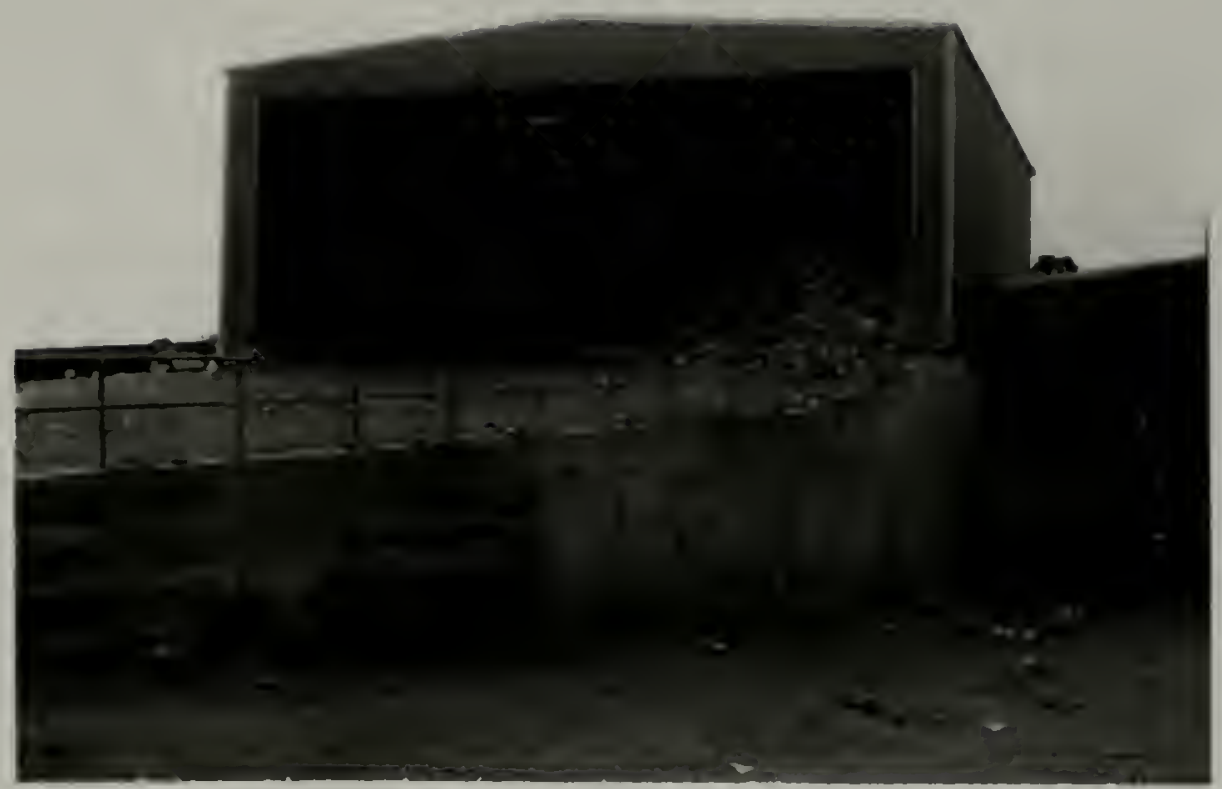

Fig. 10. Eastern edge of apporach ramp.

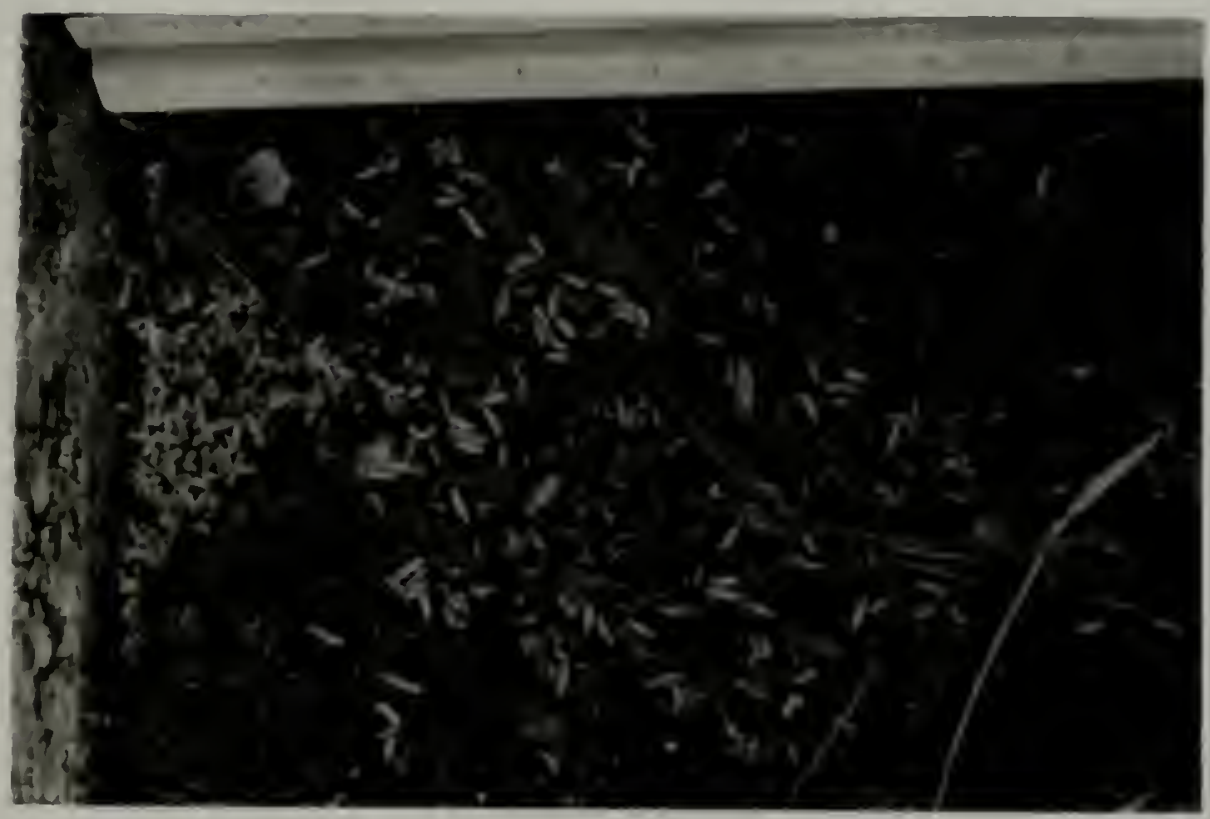

Fig. 11. Fly larvae along base of eastern wall of approach ramp. 
adequate pupation sites and close to 88.8 percent adult energence was expected. Extending the previous example given for the week of September 7, 1969, an approximation of 733,313 adult flies could be expected to emerge within 10 days as a result of larval migration from the refuse.

Survival of Larvae Through Grinding Mills

Approximately 10,000 mature house fly' larvae were passed through the secondary grinder in May, 1969. The primary grinder was not in operation at that time because of equipment failure. Nine live larvae were recovered in the discharged refuse. In July, 1969, 10,000 mature house fly larvae were passed through the recently installed primary grinder. No surviving larvae were found in the discharged refuse. 


\section{SECTION II}

\section{CONTROL OF BLO.V FLIES}

Stujies were initiated in June, 1969, to evaluate several procedures such as mechanical control and insecticide baits, fogs, and residues for the control of blaw flies emerging from the incoming refuse. The effectiveness of a control measure was determined by the reduction of flies caught in two baited traps located behind the receiving building. These investigations were terminated in October with the advent of cooler weather.

\section{Blow Fly Traps}

A suitable method to estimate changes in the number of flies was needed to evaluate the various control procedures. Sticky tapes were ineffective because the large amount of dust created in the receiving area rapidly coated the adhesive material. Grill counting was ineffective because the counts varied with hourly density fluctuations and positive species identification was nearly impossible $(42,45)$.

Norris (45) reported that bait trapping was the only generally useful method available to study blaw fly populations and that the bait employed was the most important variable. He reported that animal tissue was the best for blaw flies, being more reliable than some of the more 
recently developed synthetic attractants (14, 45). However carrion is not a uniform bait. Its attraciveness varies with age, moisture, and decomposition (42). Kawa: and Suenaga (30) found that fish 1-day-old was the most attractive to b! ow îl ies.

The traps selezted for use $3 t$ the compost finsin wore two $j 0 \times 30 x$ $54 \mathrm{~cm}$ inverted cone traps. They were baited with i-day-old fish ieads acquired loca!ly. The base of each trap was enclosed by $0.5 \mathrm{~cm}^{2}$ sciee. wire to preverit snall animals from stea? ing tha bait. Thcse trops ara shown in Fig. 12.

The traps were placed on the pavement behind the receiving area, see Figs.l and 13. The flies were collected fran the traps daily by placing the trap and $3 \mathrm{mi}$ of ethyl acetate into a plastic bag. After the flies ware anosthetized, they were removed and placed into a small plastic bag. The catches were then transported to the laboratory for couriting and identification.

Tabie 4 gives the identification of flies caught in 15 different daily catches. This shows that 89 percent of the files trapped were Phacnicia spp., 6.8 percent were Musca domestica, 3.7 percent were Cochliamyia macellaria, and 0.5 percent Sarcophaga spp. These figures are close to those percentagus recorded in Table 1 which gives the relative abundance of the varicus species of larvae entering the plant from the refuse. The differences that occur may be the result of the trapping method eiployed, different survival rates of the species involved, or immigration of adults from surrounding areas. 


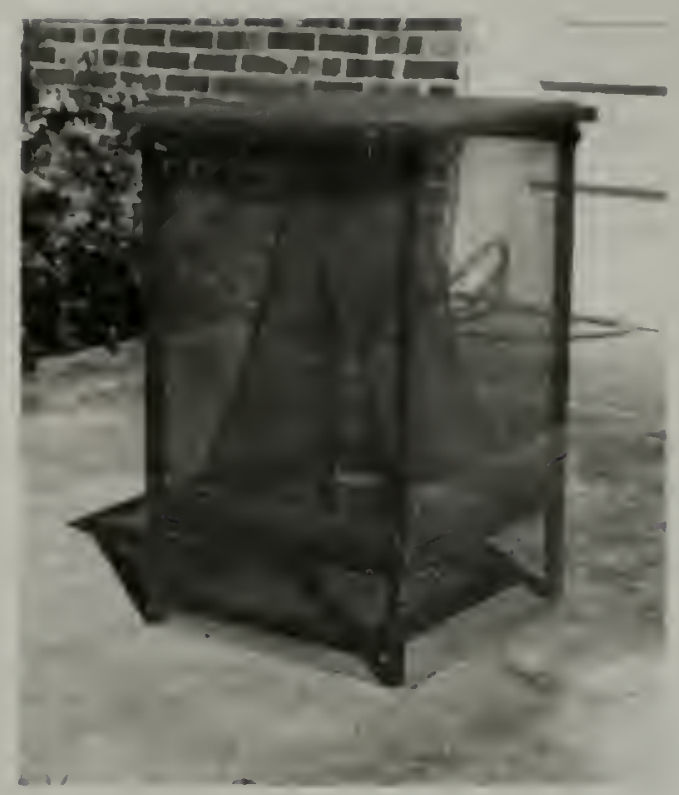

Fig. 12. Cone trap baited with I-day-old fish heads to sample fly populations at compost plant.

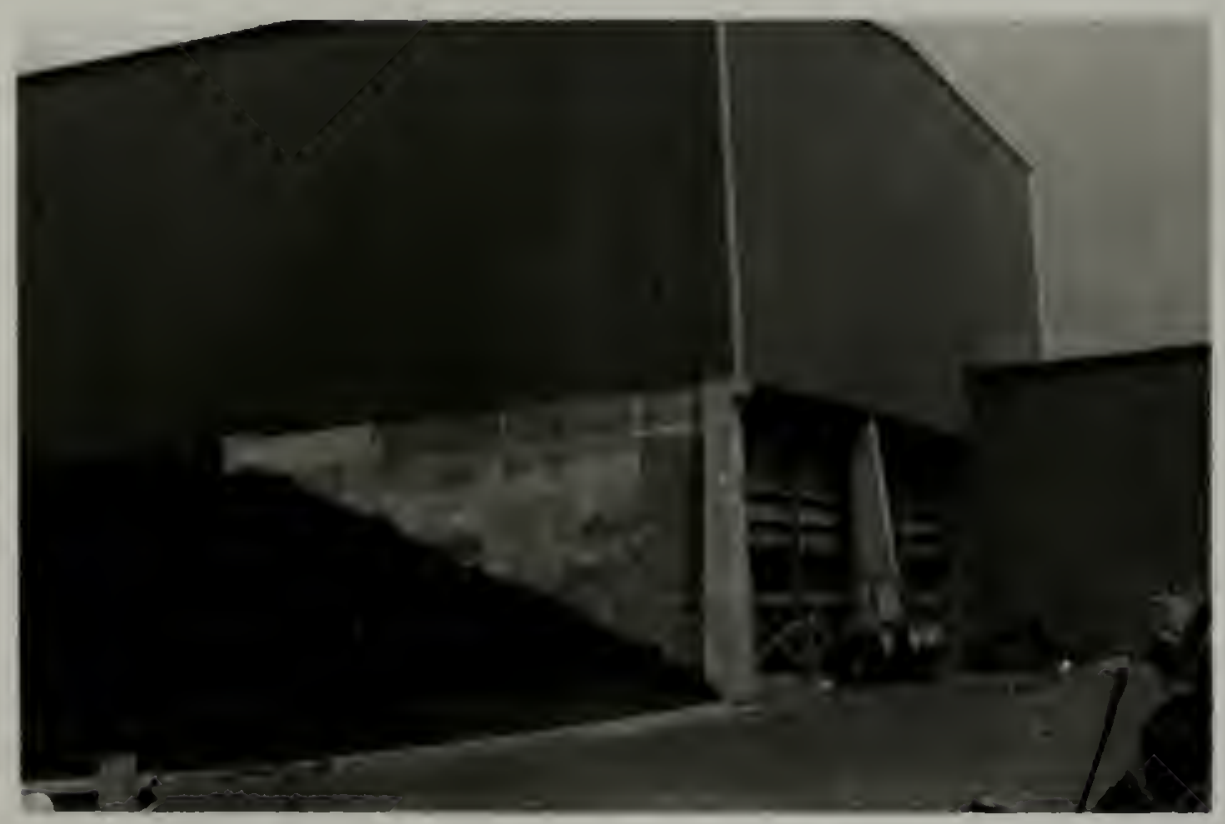

Fig. 13. Rear view of receiving building showing receiving hopper and pavement behind building. 
Table 4. Sex, species, ard abundance (\%) of flies caught in corie traps baized With l-day old ish head's at Gainesvilie compost plant.

\begin{tabular}{|c|c|c|c|}
\hline Species & 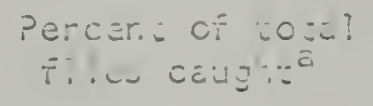 & $\% M=? e$ & $\%$ Fしna?c \\
\hline Pheericia spp. & 39.0 & 10.4 & $8 \equiv .6$ \\
\hline Musca donestica & $6 . \varepsilon$ & $? .7$ & 93.3 \\
\hline Cochliomy: macellà: a & 3.7 & 55.2 & $4 \div .8$ \\
\hline Sarcophaqa spp. & .5 & 0.0 & 100.0 \\
\hline
\end{tabular}

aean of $1:$ day catches taken at randon.

\section{Field Tests}

\section{Metrods}

Several aduit fiy control procedures were evaluated to cetermine their effectiveness and cost of application during the summer of 1909. The effectiveness of tha coniroi procedures was determined by comparing tha number of flies caught pe: day in baited traps during the treatment periad to the number of flies canght during a prior period of ro treatment. The duration of pre-treasment control sampling was 7 days and subsequent control periocs were 3 days. Treatment and control periods were alternazed and followed chronologically in the order presented in Table 5, beginning July 14, 190́9. Four to 5 clays elapsed between a treatment and the foilowing control perioc.

The control procedures are described as follaws:

Suaar bait. -- Kellor et al. (j!) in studics az dumps fourd thut trichiorfon baits gave good control of bio: files. Bailcy et al. (u) repoitce thet dichiorves in wiy sugur doits echtrolled houje flies. 


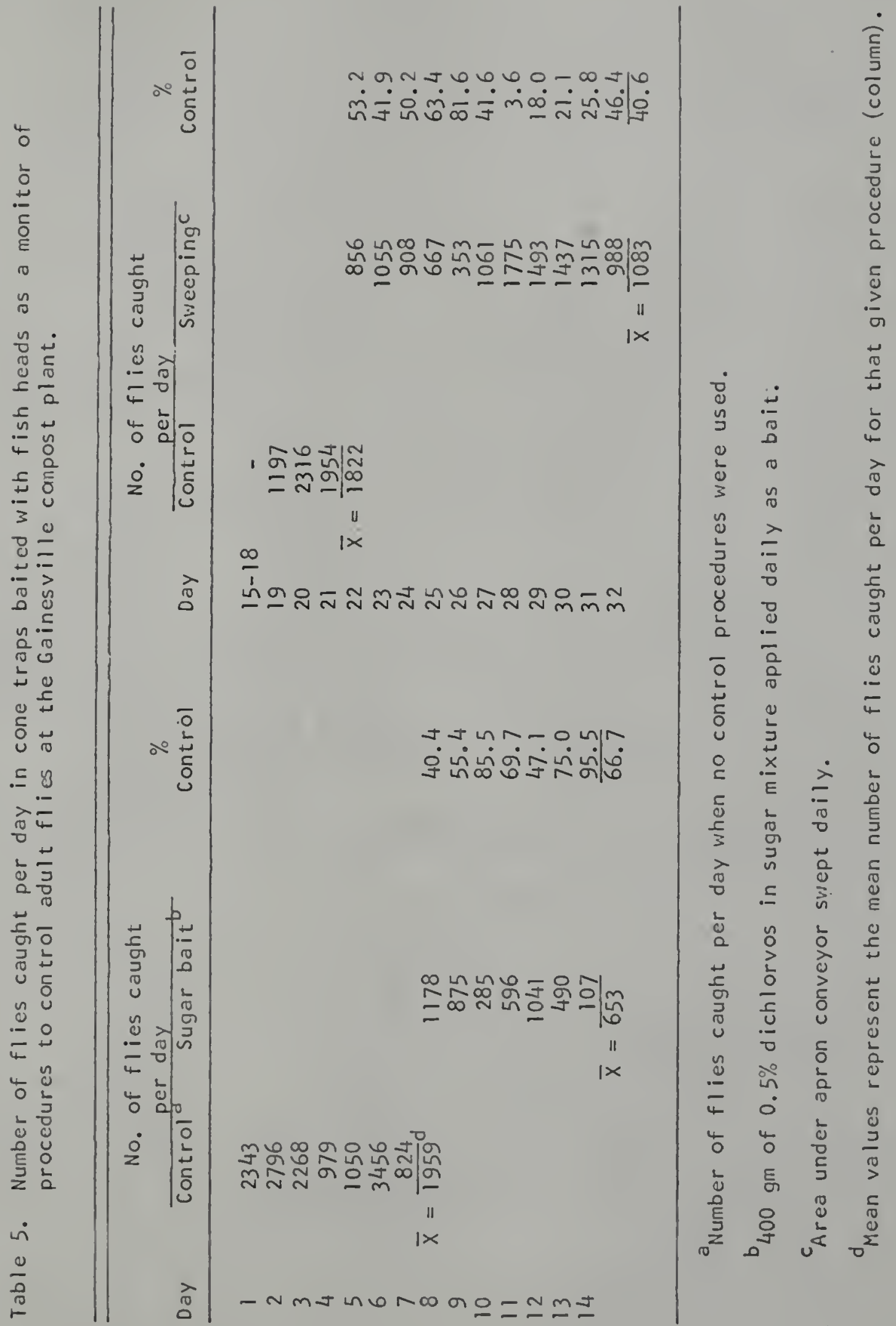




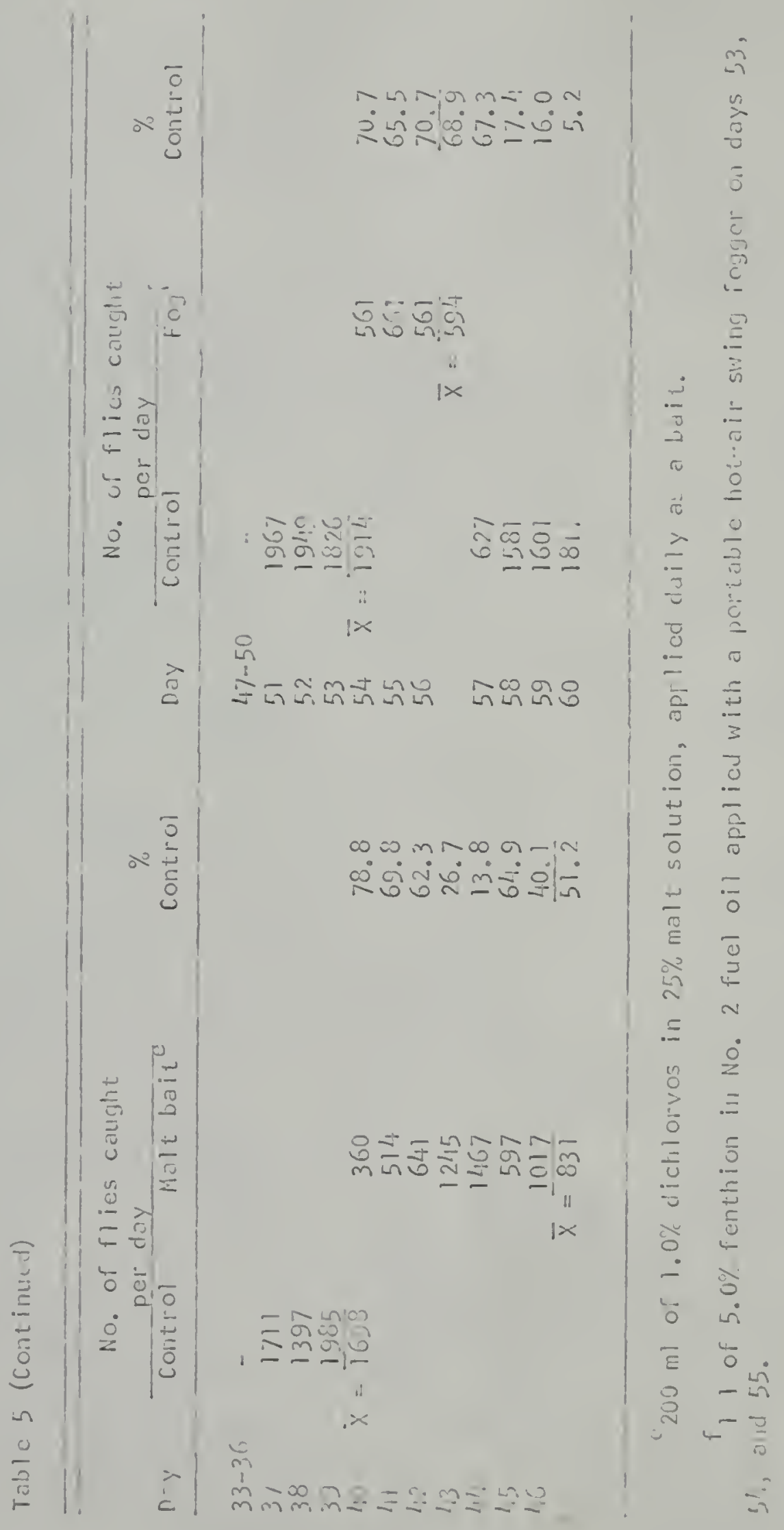




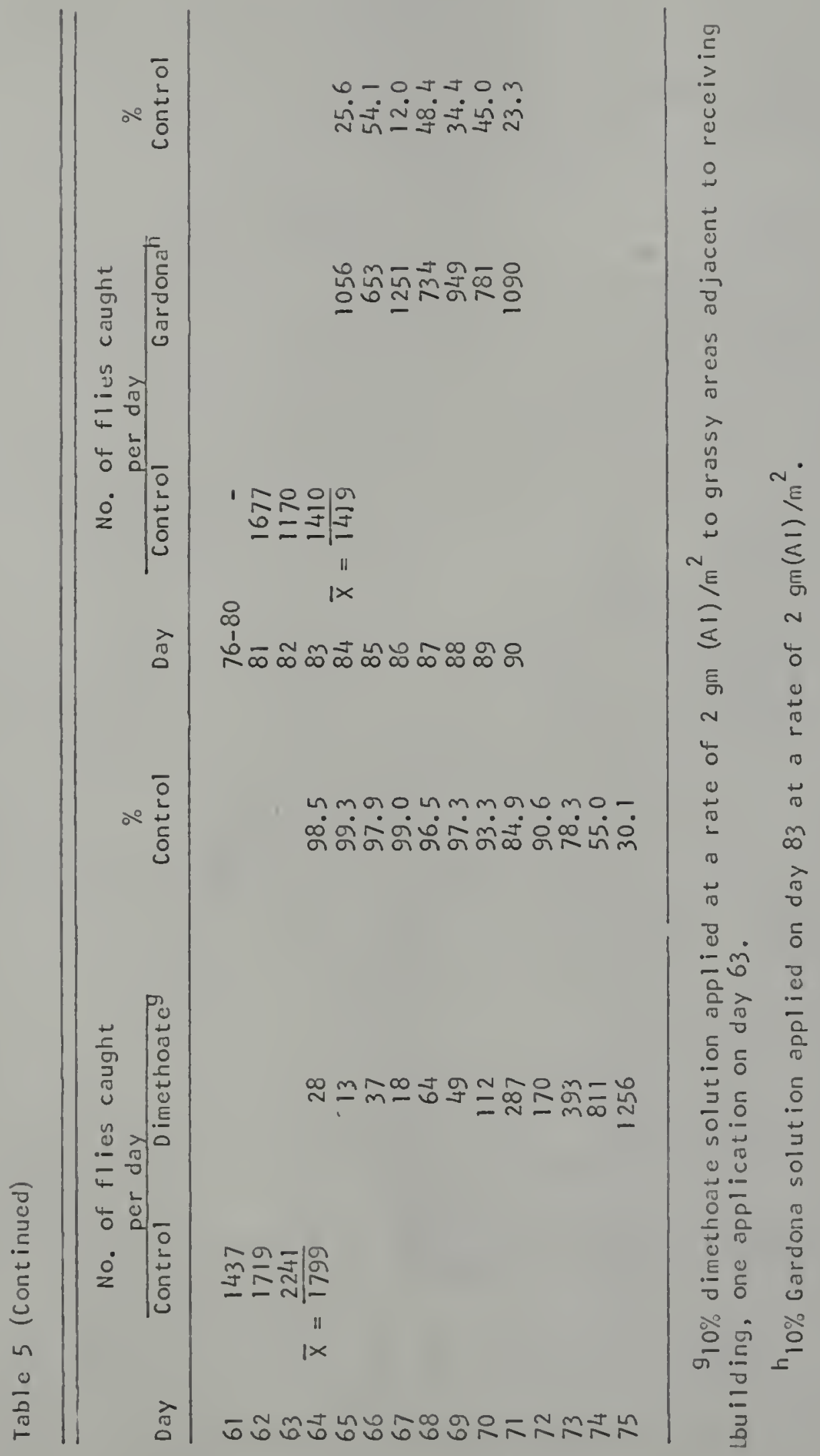


Fly Bait, a 0.5 percent dichlorvos sugar bait obtained camercially from the Fasco Chemical Co., was used prior to this investigation to control the flies at the compost plant. This bait was evaluated when applied at a rate of $400 \mathrm{gm}$ per day. The bait was distributed along the conveyor belt system for a 7-day period beginning on day 8 of Table 5.

Sweeping to remove larvae. -- The area under the apron conveyor has previously been shown to contain the majority of the larvae migrating into the compost plant. To determine the effect of collecting and removing these larvae on the total number of adult flies, this area was swept daily for 15 days.

Malt bait. -- Malathion, diazinon, chlorthion, and dichlorvos in malt or molasses were reported to be highly effective liquid baits for blow fly control around dumips $(76,31,34)$. A dichlorvos and malt solution was used to determine the value of liquid baits for the control of flies at the compost plant. Blue Ribbon malt was diluted with distilled water to form a 25 percent malt solution. Technical grade dichlorvos was added to produce a 1 percent dichlorvos solution which was stored at $4^{\circ} \mathrm{C}$ until used. Fifty $\mathrm{ml}$ of this solution were applied daily to each of 4 locations along the conveyor belt system for a 7-day period beginning on day 40.

Fogging. -- Fogging is not a highly recommended procedure for effective control of flies since fogging leaves no residue and a high concentration is necessary to kill flies. However, the effectiveness of fogging was evaluated since it was used to control flies at the Tennessee Valley Authority compost plant in Johnson City, Tennessee (61).

It was observed that the adult blow flies, predominantly Phaenicia (Table 6), left the building at dusk and roosted in the grass immediately 


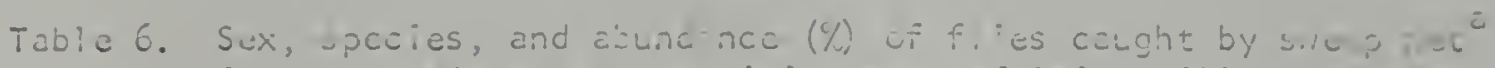
in grass acjaccin: to receivirg arca cj cuinesvilie canjo plant.

Species

Purcaric of tocu?

tilies cavyoi:

1. Mis

\% F-บi3

a. Caught during day

Pheanicia spp. 95.2

43.1

56.9

Musca domestica

$\because 3$

32.8

67.2

b. Colght at righ

inenicia - pop.

§.?

$-3.7$

$5 ? \vdots$

Nusce acrestice

.3

53.7

aiean of ten simples taken by five sweeps of net.

surrounding the piant. Thesa areas were fojged at 9:00 pin on day 53 , 54, and 55 (Tabie 5) with a 5 percent fenthion in No. 2 fuel oil sciltior. districutcd by a portabie hot-cit swing fogger. This insccticidu was selected bccuse of avaiibility and tecause a 5 percent fenthion solution kilicd 97 percent of the caged ticuse fiies $50 \mathrm{~m}$ from a roving foggar (4). Resicial spreys. -- Cortact and residual sprays are the most ofter. recommended methods of controllirg flies. These sprays are ricst uifective when applied to feuding arwas and night-tine resting placus such is shrubs and plants in tha urrouding area $(34,76)$.

Dimetnoate gave tne best control of house fl ies in Florida dairy tarns when applicd at a rate of $2 \mathrm{gm}(\mathrm{Al}) / \mathrm{m}^{2}(5,9,10)$. A 10 parcent cimuthoate

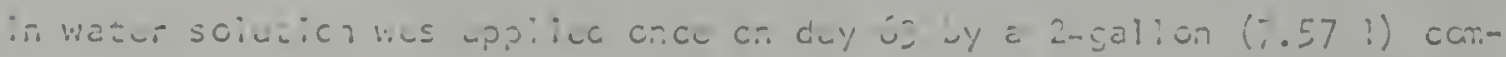

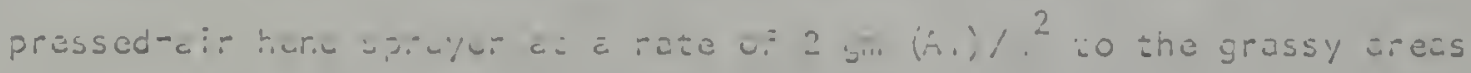
surparisinz $t n-, \ldots+\ldots$ 
Gardona, (2-ch]oro- $]-2[2,4,5-t r i c h l o r o p h e n y l]$ vinyl dimethyl phosphate), a house fly larvicide, was provided by Dr. G. C. LaBrecque, USDA Gainesville laboratory. A 10 percent Gardona in water solution was applied on day 83 in the same manner as described for dimethoate. Results

The results of the field tests are presented in Table 5.

Sugar bait. -- Daily application of a 0.5 percent dichlorvos sugar bait reduced the number of flies trapped by an average of 66.7 percent when compared to a previous 7-day period of no treatment. This control procedure cost about $\$ 3.00$ plus 0.5 man-hr per 6-day work week.

Sweeping to remove iarvae. -- The area urider the apron conveyor was swept daily to remove the larvae before they developed into adults. An average of 40.6 percent reduction in the number of flies was noted when compared to a previous 3 -day control period. This reduction is considered to be a minimal value. It was significantly lower than expected since previous estimates indicated that 67 percent of the larvae that migrated into the plant escaped under the apron conveyor. The difference between the observed and predicted reduction may have been influenced by the short test period. Since the larvae entering the plant required $8-10$ days to become adults the 15 -day study period may not have been long enough to ascertoin the true results of cleaning the area. Regular cleaning over a longer period should reduce the adult flies by a factor approaching the percentage of larvae escaping into the area.

A second factor influencing these results was the operation of the plant during the test period. Mechanical problems prevented regular operation of the plant and refuse romained in the receiving area for 
several days. This resulted in larval migration patterns differing from those encountered under normal conditions.

Since the larvae entering the plant required $8-10$ days to become adults it is reasonable to assume that cleaning the area once a week would produce the same results as daily cleaning at a reduced cost. The effects of cleaning over a long period were not investigated.

The area under the apron conveyor could be cleaned once a week at a cost of about 4 man-hr.

Malt bait. -- A 51.2 percent reduction in the number of $f l i$ es was observed over a 7-day period with the application of a dichlorvos malt solution. This bait was found to have several disadvantages; (1) it is not available commercially, (2) it must be stored under refrigeration, (3) it costs more and was less effective than dry sugar bait, and (4) its syrupy consistency made it inconvenient to use.

Fogging. -- The grassy areas of the compost were fogged for 3 consecutive nights producing an average reduction of 68.9 percent of the number of flies trapped on the follaving 3 days. The effects of fogging were minimal after, day as shown by the post treatment counts in Table 5. Thus, an effective control program would include a minimum of 3 foggings per week. This would cost $\$ 15.00$ plus 3 man-hr per week. To determine if this fogging procedure was effective on $\underline{P}$. cuprina, 100 adults were caught at night by a sweep net at the compost plant and placed in a gauze cage. The cage was placed in the center of the grass hill during the fogging operation. After the area was treated the flies were transferred to a clean cage provided with fly food and water and held for $24 \mathrm{hr}$. A control cage was set up and the fly mortaity obse:ved 
in each. This procecure was cupl "zutad For each treatment. hn average of 97.2 percent of the treared flies were daad after $24 \mathrm{hr}$ while 6.1 percent mortality was observet in the contiol cages.

Residual sprays. -- A slinsie appiication of dimethoate gave better than gu percent contro: di" ahe ":i ies tei i weo's and remained efrucuive for 10 days as shom in Tabie 5. The cost of cne application was approximately $\$ 7.00$ pius 0.5 man-hr.

Gardona was inefiective as a residual spray for the control of blan files as shown in Table 5.

Larvicides. - Green (22) demonstrated that 99.1 percent of the larvae escaping from scanding reflise zrains could be controlled by dusting the area twice weekly with DDT. However, the application of a larvicide under the apion conveyor to control biow flies was not attampted because co the large amount of dubris falling daily into this area. The effects of the larvicide woulc be short-lived since incoming larvae probably would not be exposed after $24 \mathrm{hr}$.

\section{Rearine Blow Flies}

Nethods

To screen insecticides in the laboratory foi their effectiver,ess

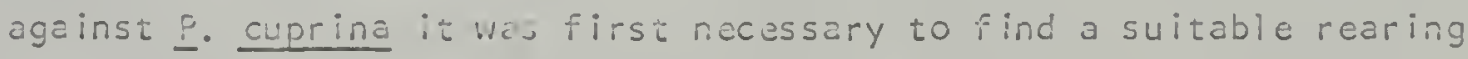
medium so icrge rumburs would be availab? in the labcratory on a clet of cecaying meat but this medium is odoriferous and also expensive when large numbers of flics are required.

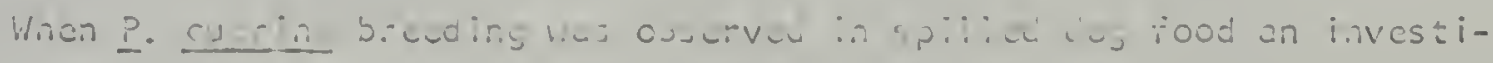

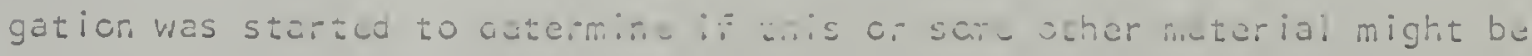


substituted for meat. Two series of tests were carried out which varied the amount and kinds of test media used. In the first series the test medium was placed in waxed paper cups $(88.8 \mathrm{ml})$ with $200 \underline{\text { P. cuprina eggs }}$ collected from wild flies captured at the Gainesville landfill. Each cup was then placed in a waxed paper cup $(0.9461)$ containing approximately $20 \mathrm{gm}$ of dry builders sand. The larger cup was then covered with a black cloth and secured with rubber bands. Eight days later the mature larvae had pupated in the sand and the pupae were removed from the medium by sifting the sand through an 18 -mesh sieve. The pupae were counted and the number recorded. One hundred of these pupae were randanly selected, washed, dried on paper towels, and weighed on a laboratory balance (Metiler, Evanston, 111 irois) to determine differences in the size of the pupae reared on the various test media. Six replicates were prepared for each medium.

The media tested included the following: lean ground beef; Alpo, an all meat dog food; Chunx, a dry dog food; Strongheart, a canned grain base dog food; and Chemical Specialist Manufactures Association house fly rearing medium (CSMA). Various amounts and combinations of these media were used as shown in Table 7. Meat was added to several test media because $\underline{P}$. Serricata was reared on CSMA fly rearing medium when provided with sufficient meat for the larvae to develop to second instars (35).

In the second series of tests $1 \mathrm{ml}$ or approximately 6,500 $\underline{\text {. }}$ cuprina eggs collected from wild flies were placed with the test medium into $4 \times 19 \times 30 \mathrm{~cm}$ enamel trays. Each tray was placed on approximately 51 of dry builders sand in a $40 \times 55 \times 25 \mathrm{~cm}$ plastic tub. A piece of one-fourth 


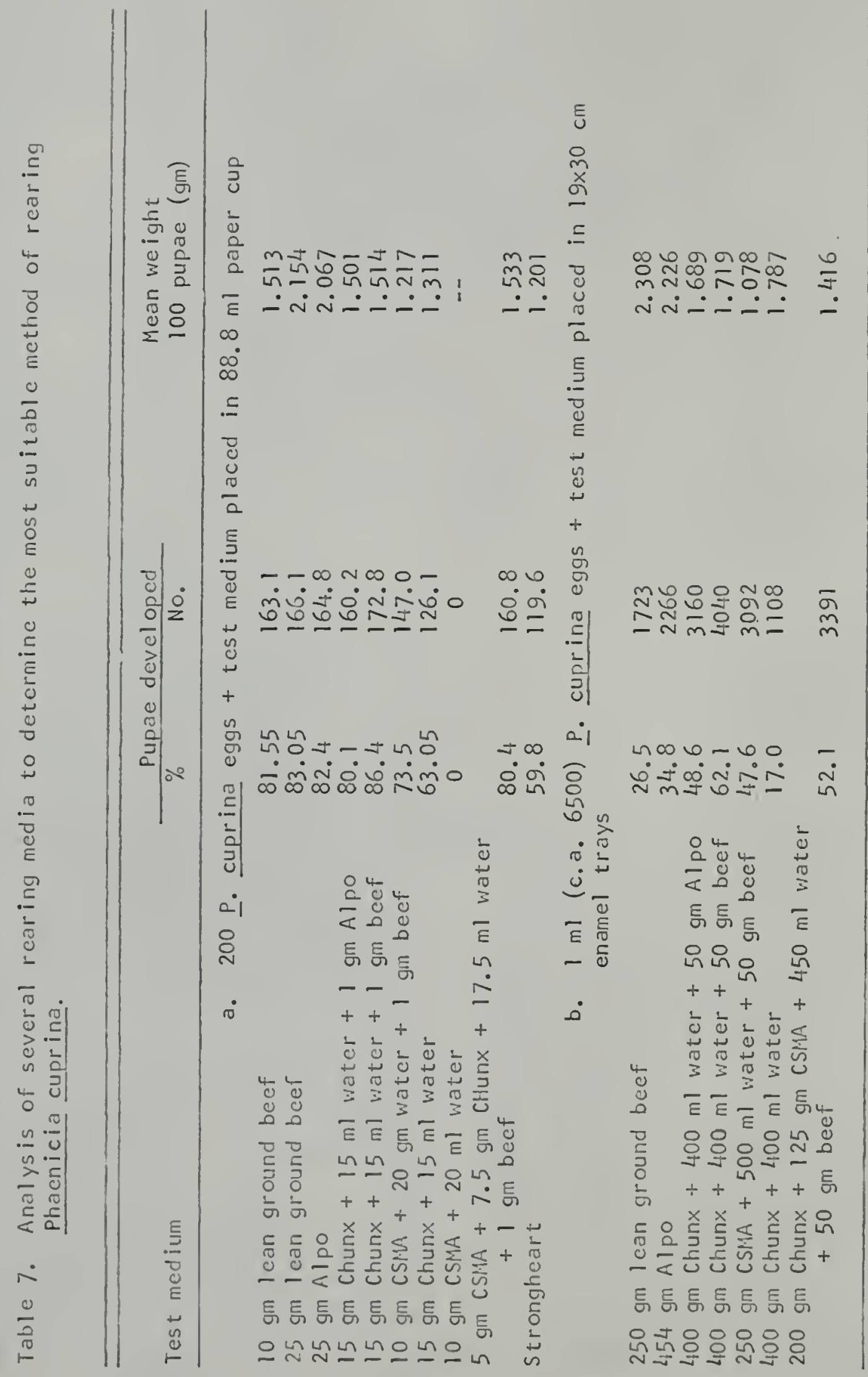


inch plywood with a $25 \mathrm{~cm}$ diameter circle cut in the center and covered with musl in cloth for ventilation was placed over the tub and secured by 4 bricks. Eight days after egging the medium the pupae were removed by sifting them from the sand and the total number recorded. One hundred pupae were then randomly selected, washed, dried, and weighed. Six replicates were prepared for each test medium.

The test media included lean ground beef, Alpo, Chunx plus Alpo, Chunx plus ground beef, CSMA plus ground beef, Chunx, and Chunx plus CSMA and ground beef.

Rearing tests were conducted on the screened porch of University of Florida building number 618 which is located northwest of the medical entomology laboratory. The porch was screened on 3 sides and covered with a roof with $1 \mathrm{~m}$ eaves. Light, temperature, and humidity were ambient. These tests were conducted during May and June of 1970. $\underline{\text { Results }}$

The results of the rearing tests are presented in Table 7 . These data show that immature $\underline{p}$. cuprina reared on a diet consisting only of meat were larger than those reared on the other diets. When large numbers of larvae were reared, as in the second test series, 4 of the diets produced more flies than did the all meat diets.

The diet of the dry dog food, Chunx, plus water and $50 \mathrm{gm}$ of ground beef was chosen to rear the flies used in the laboratory chemical screening tests. This diet was superior to all other diets tested in the numbers of pupae produced and cost less than the all meat diets without producing offensive odors. Although the pupae were not as large as those reared entirely on meat, these size differences were not 
considured greut encugh to adverseiy affect the tests or offset the advantages of the ciog icod die...

Adult biav f? ius uscd in tha chemical screening tests were reared

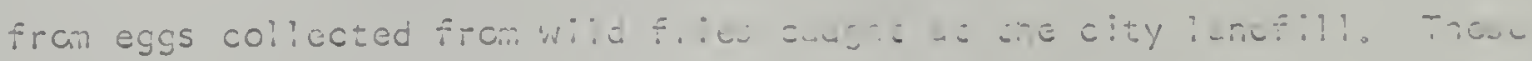

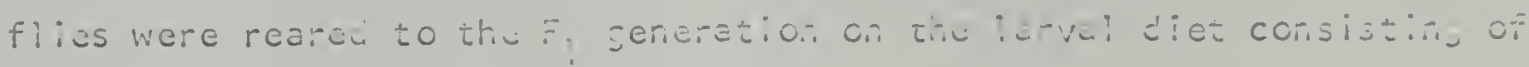
$400 \mathrm{gm}$ Churx, $400 \mathrm{ml}$ tap water, and $50 \mathrm{gm}$ lean ground bcet in the murredescribed above for the second tes series. Adult files ware hald i. $15 \times 24 \times 50 \mathrm{~cm}$ gauze-covered saces and provided with fresh water ard fly food daily. The fly food consisted of 6 parts granulated sugar, o parts noirfat diy milk, and ! part di-ied egg yolk. The cages were held in the University of Florida medical ancomoiogy laboratory ervironmenta: contro: chamber with ?6 hr of artificial day light provided by incandescent lights. Temperature and humidity were mairtained at $26^{\circ} \mathrm{C}$ and 70 percent RH.

\section{$\frac{\text { Labcratoiv Screening of Insecticides for }}{\text { control of P. cup ina }}$}

\section{Methods}

Five-day-old femaie $\underline{P}$. cuprina adults were exposed to space sprays of 12 commercially availabie insecticides in the wind tunnel described by Davis and Gahan (15). The insecticide solutions were prapared by dissolving each chemical in acetonc to attain the desired concentrations $(w / v)$. The original range of concentrutions for each chemical was based on the $L_{50}$ values obtained for an insecticide suscepible strain of

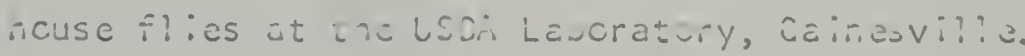


The tests follawed the procedures outlined by Bailey et al. $(7,8)$. Twenty adult females were confined in test cages made of metal sleeves closed with screen wire at each end. These cages werc placed in the wind tunnel. One-fourth ml of the insecticide solution was atomized at 1 psi into the mouth of the machine, and drawn through the cages by a $4 \mathrm{mph}$ air current. Duplicate cages of flies were treated with each concentration. imnediately after treatment the flies were transferred to clean holding cages and a cotton pad saturated with a 10 percent sugar water solution was placed on top of each cage as a source of food and water. The treated flies were held under constant 1 ight at $25^{\circ} \mathrm{C}$ and at 70 percent $\mathrm{RH}$ for $24 \mathrm{hr}$ when mortality was recorded. If the concentrations of the chemical tested produced greater than 90 or less than 10 percent mortality these data were discarded and other concentrations selected until a minimum of 4 concentrations were used that produced mortalities within the acceptable range. These data were used to calculate $L C_{50}$ 's by the probit analys is technique described by Finney (19).

Twelve compounds were evaluated in 13 tests, each of which included from 4-7 insecticides, acetone, a dimethoate standard, and an untreated check. The chemicals tested were as follaws: dimethoate, parathion, naled, diazinon, fenthion, ronnel, propoxur, carbaryl, malathion, Dursban [0, 0-diethyl 0-(3,5,6-trichloro-2-pryidyl) phosphorothioate], Gardona [2-chloro-1-(2,4,5-trichlorophenyl) vinyl dimethyl phosphate], and Bayer 41831 [Sumithion] [0, 0 -dimethyl 0-(4-nitro-m-tolyl) phosphorothioate]. Results

The insecticides tested as space sprays are listed in Table 8 in ascending order of the $L C_{50}$ values obtained by probit analysis. The fiducial limits $(P=0.05)$ are aiso $l$ isted. Dimethoate was the most effective 

Table 8. $L C_{50}$ of 5 -day old Phaenicia cuprina females to insecticides
in 5 wind tunnel.

\begin{tabular}{lccc}
\hline Insecticide & $\begin{array}{c}L C_{50} \\
(\%)\end{array}$ & $\begin{array}{c}\text { Fiducidal } \\
P=0.05\end{array}$ & $\begin{array}{c}L C_{50} \text { susceptible } \\
\text { house fly }(\%) a\end{array}$ \\
\hline dimethoate & 0.0259 & \pm 0.0064 & 0.04 \\
parathion & .0532 & .0068 & .05 \\
Dursban & .0567 & .0063 & .74 \\
naled & .0648 & .0065 & .018 \\
diazinon & .0857 & .0063 & .062 \\
Gardona & .126 & .0063 & .06 \\
fenthion & .133 & .0065 & .15 \\
Sumithion & .183 & .063 & .074 \\
ronnel & .246 & .065 & .13 \\
propoxur & .264 & .092 & .95 \\
carbaryl & 8.42 & .67 & .81 \\
malthion & $>50$. &. & \\
\hline
\end{tabular}

Data obtained fram the U.S.D.A. Gainesville laboratory.

chemical tested and along with parathion, Dursban, naled, and diazinon demonstrated potential for use as a chemical control of $\underline{P}$. cuprina. Gardona, fenthion, Sumithion, ronnel, and propoxur were less effective. Carbaryl and malathion were incffective with 50 percent malathion failing to kill 87 percent of the exposed flies. Appendix 3 shows the concentrations and percent mortalities used in the probit analysis to calculate the $L C_{50}$ 's. The Chi square tests for chance variation of a homogeneous population were acceptable at the 5 percent confidence level for all tests and are listed in Appendix 3. 


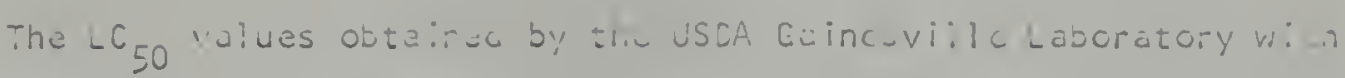
the orlando susceptibiu surin ot howse filies or the insecticides

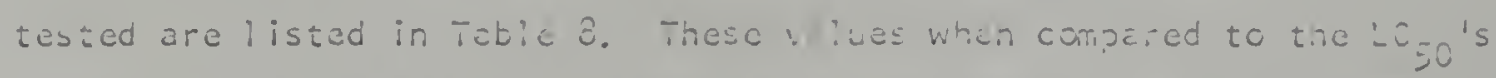

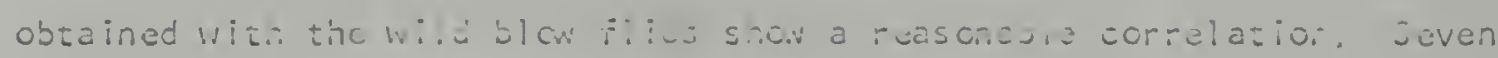

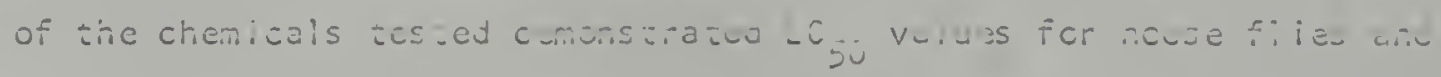

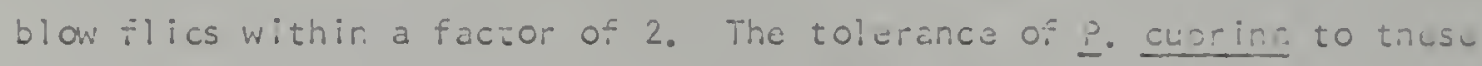
insecticides appeared to bu abcut the surea as those cf the susccitivia

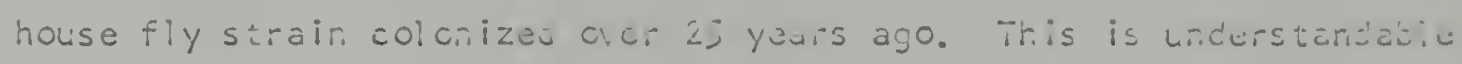
since the blaw fiy nas rot becn generably exposed to insecticidal pressures over a widespread ar es in the Un:acd States.

The iruffentivuness of ma!tinion to kill P. cuprira was unerpecteo as malatnion residuai sp-ays heve wien recommendoo to control blav $\div$ l ies at Florida dumps (34, 79). This becomes less startling, hovever, when one consiciers that maicthion cid not control P. cuprina on shup in Australia (57) and that $r$. ion has irduced a very specific res istance in the house fiy, in Culex :a:s=! is Coq., and in the blow fly, Corvsonvia outoria Wied. (il). In the case of tre blaw fly, complete resistance was induced within ó months.

P. Euprina are concroll ed in Australia and widespread dieldrin resistance has been reportad. Wild fies were ico times more res is tant to dieldrin than a susceptible strain and resistancu was also obscrved to aldrin, endrin, isodrin, chicrdaic, other syclodicnes, and Br. ( 32 , 67, 63). Since the general use of chlorinated fydrocarbons is iilecal in Florida these chemicais were not testel in $\ldots$. study.

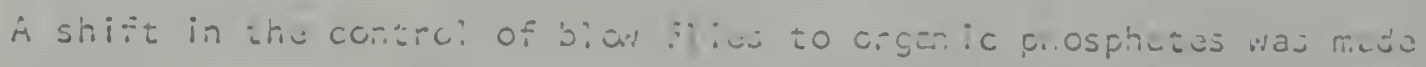

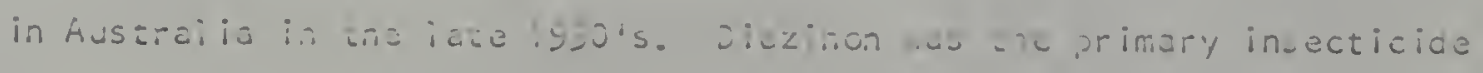


used and according to Shanahan $(70,71,72,73)$ no resistance was found after $6-8$ years of use. He terms a 3-5-fold increase in the LD 50 values of wild flies as tolerance. Schuntner and Roulston (65) found resistance to diazinon in blow flies and identified it as the breakdown of the in vivo pool of free diaoxon. A perusal of the literature revealed that resistance to any insecticide by $\underline{P}$. cuprina has not been reported in the United States. 
SECTION 111

DENSITY AND SEASONAL FLUCTUATIONS OF

HOUSE FLIES AT THE COMPOST PLANT

Observations conducted during 1968 revealed that blar flies and house flies were present in large numbers in the receiving area and around the sorting platform, while house flies predominated in the digester building. These flies annoyed the workers and posed a possible public nuisance if the plant proved to be a source of flies to the surrounding community.

A house fly sampling program was begun in January, 1969, to determine the density and seasonal fluctuations of the house fly population at the compost plant. The purpose of this survey was to determine the magnitude of the house fly population, the necessity of a fly control program, and seasonal changes that may affect such a program.

\section{Rearing House Flies}

All stages of house flies used in this and the follawing section were obtained from the insecticide susceptible or Orlando strain maintained by the USDA Gainesville Laboratory. These flies were reared in a 101 plastic tub in a mixture of 1 part CSMA fiy rearing medium and 2 parts water. A $6.5 \times 6.5 \times 10 \mathrm{~cm}$ sponge saturated with water was placed in the bottom of 
the tub to maintain proper moisture. The tub was covered with a black cloth secured with rubber bands. Pupae were collected 7 days after egging the medium and placed in $15 \times 24 \times 50 \mathrm{~cm}$ gauze cages. The adults were provided with fresh water and fly food which consisted of 6 parts granulated sugar, 6 parts non-fat dry milk, and 1 part dried egg yolk.

The flies were reared at the USDA laboratory in rooms with 16 hr of artificial light provided by fluorescent lamps. Temperature and humidity were maintained at approximately $26^{\circ} \mathrm{C}$ and 70 percent $\mathrm{RH}$.

\section{Seasonal Fluctuations of House Flies}

\section{Trapping}

The digesters were selected as the primary sampling area for adult house flies at the compost plant for 2 reasons: (1) initial observations showed that adult house flies were usually more abundant near the digesters, and (2) equipment operation in the receiving and sorting areas made sampling procedures difficult.

The grill method of sampling house flies, developed by scudder (66), was initially selected for use in the seasonal fluctuation study. This sampling procedure results in an index of the population and not an actual measure of population density (43). The reliability of grill sampling is debatable. Murvosh and Thaggard (43) reported a high correlation between grill counts and the total number of house flies in kitchens on the Island of Mayaguana, while Schoof (62) found that grill counts did not increase linearly with the population sampled. Welch and Schoof (81) reported that grill couning was subject to individual error and was no more accurate than visual estimates. 
Grill counting was incffective at the compost plant becausc of tne large volume of attractive materials present.

One-foot square $\left(32.4 \mathrm{~cm}^{2}\right)$ masonite boarc's covered by a thin layer of Stichem (Michal and Pelton Co., Emryv.ile, California) wcre evuluz=cd for trapping ilius i.z the cigestor. Truse bourse ware attached te stailas $1 \mathrm{~m}$ in length which wure then divus into the compost in the digesta-s. This procedure was discardes because such ?arge numbers of fli i w we

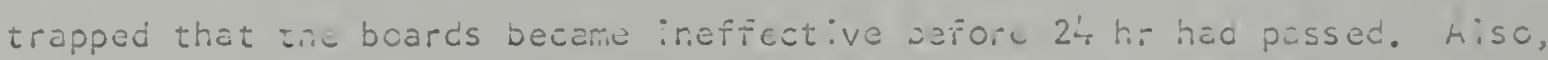
more than 1000 flies per board wore trapped and a population recuction this great niay have significant?y raduat the ectal poplation.

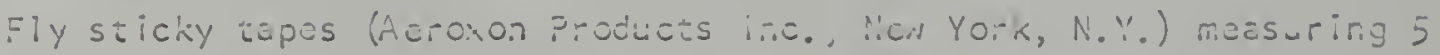

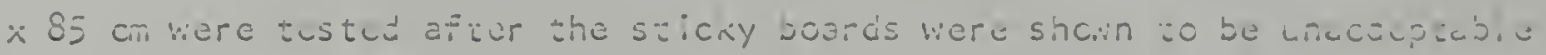
Fo: trapping ti.e Fli ies. haybou: 1 (5), 55, 56) reported that st.cky tapes were more accuraze than 5.:!? ccunts in samp?ing house fly papul dtidu in ffrica because they were lass dependunt on human judgment, took into account temporary iluctuetions in dersitios, and allowed for the identification of the flies. Stichy tapes nave also been shown to be more accurate than vacuum collections und visual counts at poultry farms (2), and baits at dairy bar.ss (51). Tasts during Decmber, 1963, reveaied that sticky tapes were acceptabl for trupping nouse fils at the compost plant. House flics were sampled in the dijesters from January 12 to Deckmaer 31,1969 , usirg sticky iäpes slspunied from 1.2 m wooden stakus driven in:o the ccipon. Five sakes were mployad daily and each stuke was placed in a diffurut age of compest virying fromi-s days of aga.

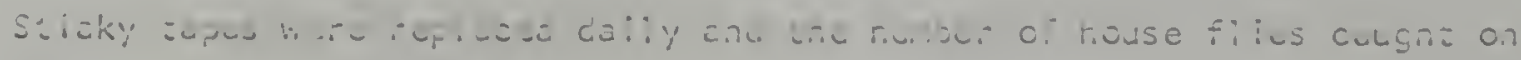

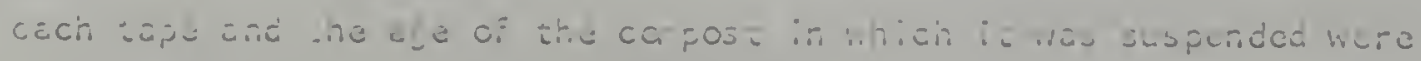
recercis. 
The mean number of flies caugat per sticky tape per week wis calcuiated by divicing the numbe: ot "jias caught per weak by the rutuc: of sticky tapes. These data are shewn in Fig. 14. Effects of Temo:rature

The maximum and mininum ambient a i rempuratures were rucorded da:?y at the suvage treatment facility which vins lecatud immediately adjacent to the compost plart. These cita were made availabie througn tric ccurtesy of Mr. C. R. Eenret, manager of the treatmert faci, iay. ir.e weekly means of the maximum daily a:- temperatures were calcuiated and are shown in :ig. i4.

A comparison ci the mean week?y catch of t? tes in the digwters and

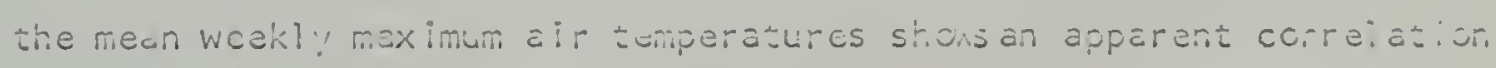
between these data from Jaxhary to Jure. The compost plant was closed to replace the primary grincing mill on June 15, 1969. When operations resumed cn July 6, a cifinite ciop in numbers of trapped flies was observed. A check with the plant foreran iavealed that the operating procedures were the same as those before the plant closed for repairs. The only otservab?e difference was that the refuse discharged into the digesters was slightly smaller in size. There was no reason to bel ieve that this would greatly affect the number of ilies in tha area.

It was ooserved that temperatures in the digester building wure higher than the ambient air temperaturesbecause of the heat generated in the composting process and the construction of the musul digesting building. A hycrotiermograph was piaced on a platform $15 \mathrm{~cm}$ above the

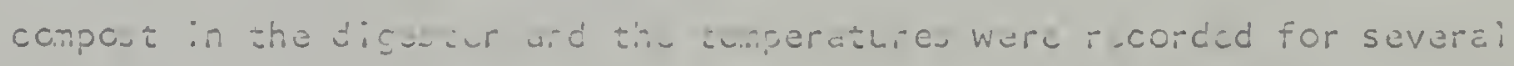

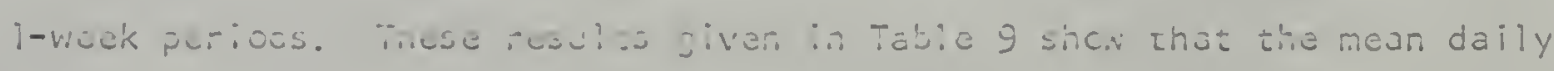


Weekly mean of maximum daily air temperature ${ }^{\circ} \mathrm{C}$
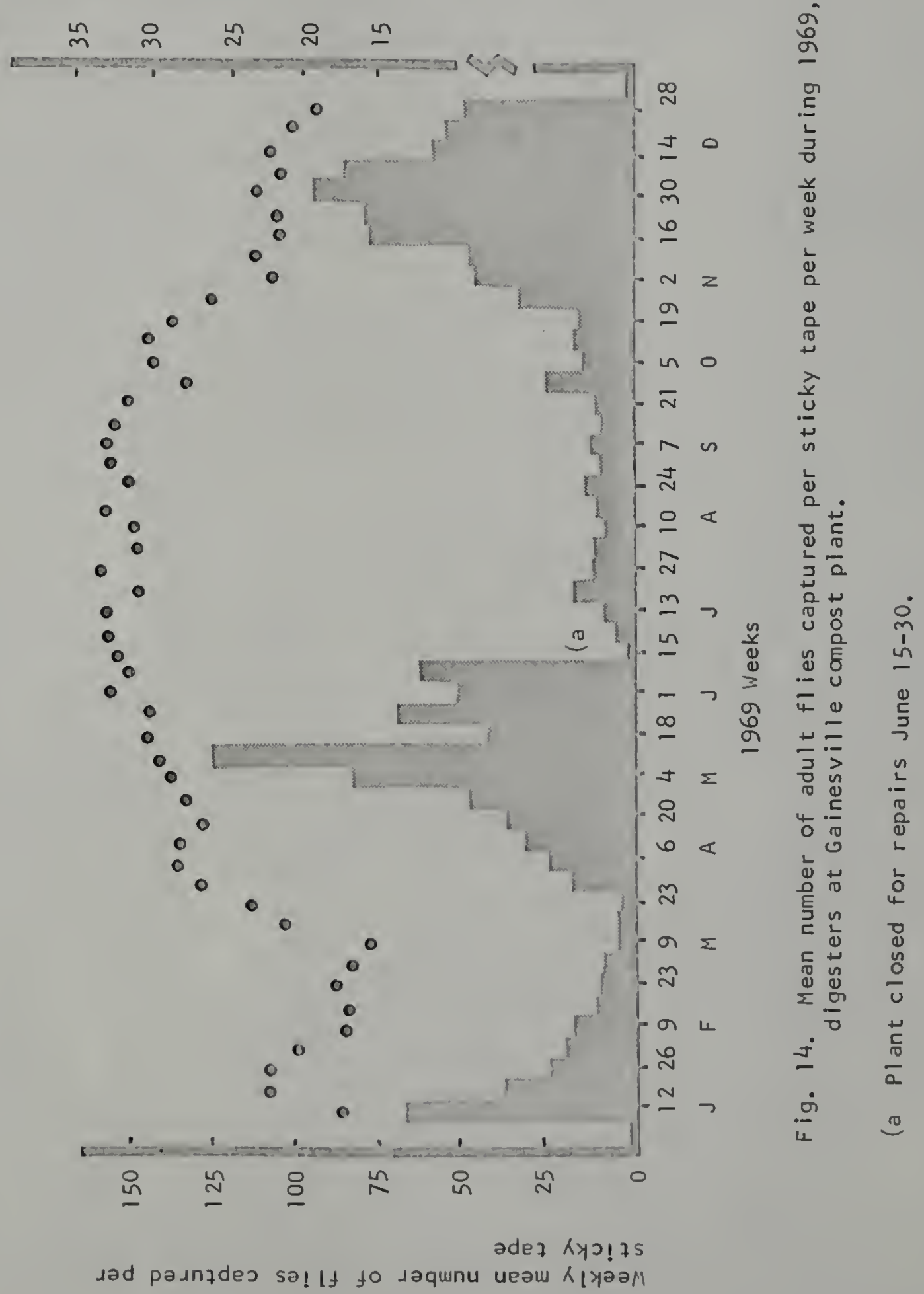


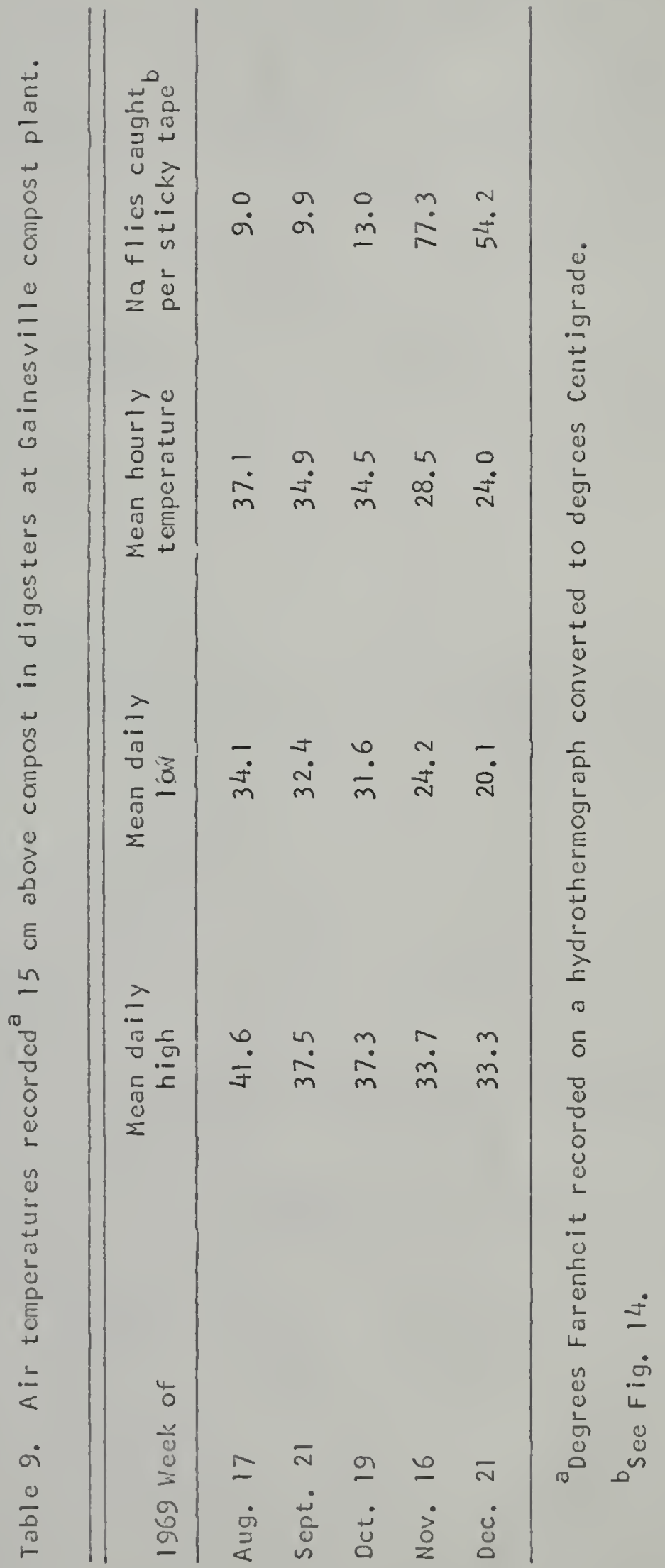


maximum wir temperature in the disester bullding could be expected to exceed $37^{\circ} \mathrm{C}$ during the sumer monins. Apperentiy these tumperatures discouraged the flics from entering the building, resulting in a laler number of tilies trappud cin the sticky tipas.

The numbar of fildes trapsed increased in late ocusus while

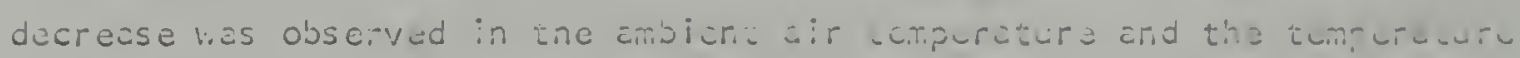

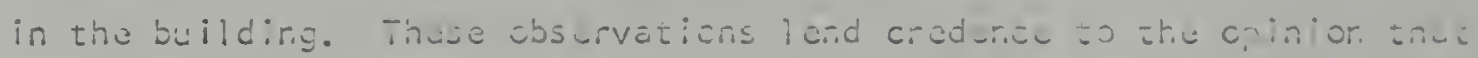

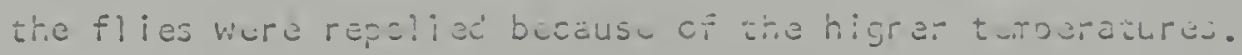
in cucrease in the rumber of filies and the enblent air temucraturc Was obsurved in December.

This investigaticn vics origina!ly designud to determire tü suasonal Fiuctuetions of howe flies at the compost picnt. The temperiaures in the digsster bulicing where the traps were located affected the number of flies caught during the sunince mor.ths and this saudy failed in its original goal. rowever, thase cata do show a general trond during the cooier months end dumonstrated thet the tuliding design reducud the number of flies present in the digustar building during the puried when fly nubers were potentially the grearest.

The rumber of flies caujuc on sticky tapes placed in the diffurert ages of compost are shawn in Table 10. These deta demonstrate thet flies prefer the fieshly ground refuse. Greater than 50 percunt of the Fi.cs in the oigusters normaliy congregated in the area of the l- ard 2-day old campost. 


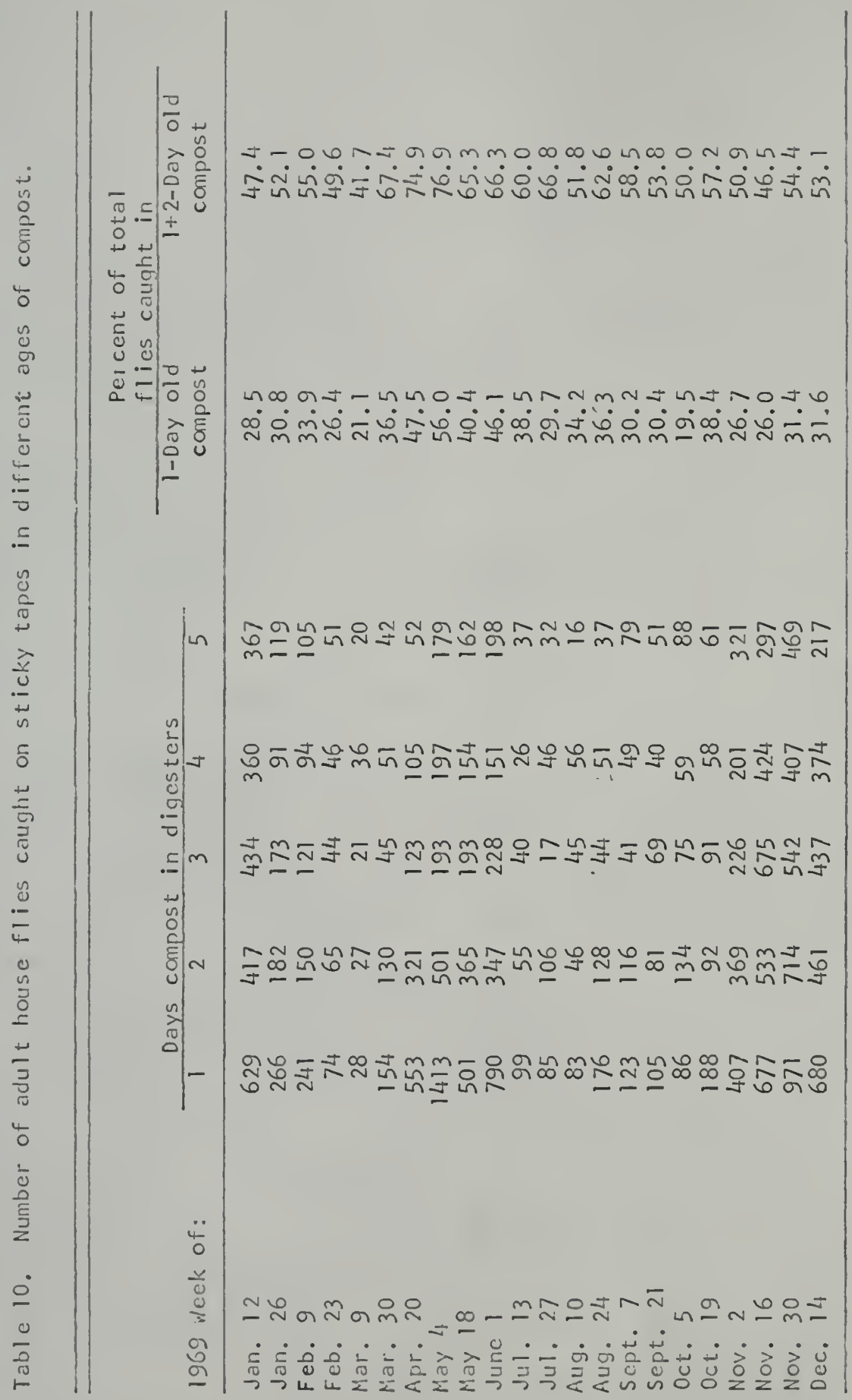




\section{Evaluation of Fly St cky Tases}

Methods

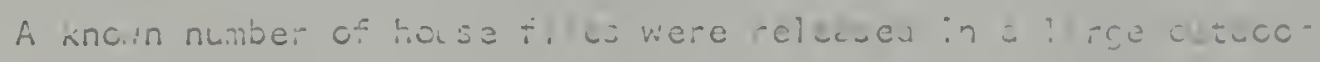

screun cage with sticky tapus to cen-mine if we runiver ci filez eught

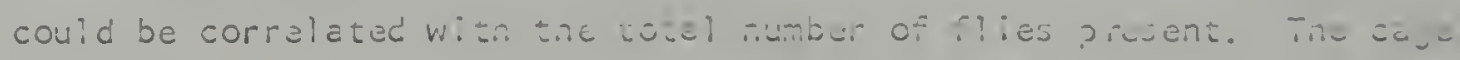

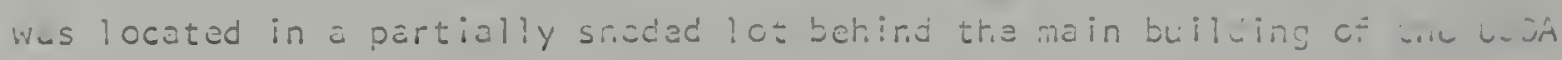
Gainesvilie lworazory. The cuse had a $\$ \times 5 \mathrm{~m}$ basa with a coshic aratr roof $3.5 \mathrm{~m}$ high. The flooi cuns isted oï soil and was kept cleaned o: weeds and grasses during the tests. Wo $1.2 \mathrm{~m}$ stakis wore driven intc the ground on the center line oi the cage l mo fran each end. A sa.tuy tupe was hung on ach stake ard tepiacud da:ly. A jo $5120 \times 120 \mathrm{~cm} 3$-ahcif metal stand was pianed in the center of the cage to hoid the food and water suppiled cially and to provide sholtar for the flies. Tests were conducted during June, Ju!y, and nugust of 1969.

Test irseats were obtained as pupe from the LSDA's insecticin suscoptibie house ily colony and were held in cages until aduit ilies were beginning to emerge. At the onset of eclosion approximately 200 pupae werc placed in a $15 \times 24 \times 27 \mathrm{~cm}$ sauze cayu. Atter 24 hr the remaining pupae wore renoved. The cagu were provided daily with iresh fiy rood and water and wore held in a room providud with 16 hr of artificial daylight by tilorescent lanips. Tempereture and humidity werc maintained at $26^{\circ} \mathrm{C}$ and 70 percent Rir.

Flies used in the test wore removed fran the cayes, anosthutizud with carbon dioxide and conted. A $1: 1$ ratio of males to famales was scicctu -á

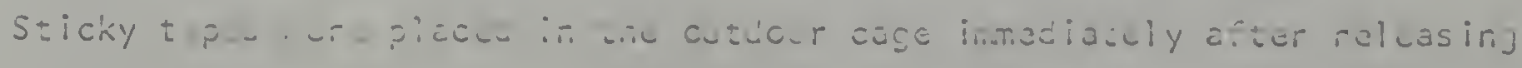


the flies. Twenty-four hr later the tapes were collected and the numbers of flies counted. All flies remaining in the cage following a test run were killed using a fly swatter. Pupae, 1-, 3-, and 5-day old house flies were released in the cage in numbers of $100,250,500,1000$, and 2000. Duplicate tests were conducted for all ages and numbers of flies tested. One-day old flies were released in the outdoor cage $24 \mathrm{hr}$ after placing the energing adults in the small cages. This procedure provided flies which were $1 / 2-24 \mathrm{hr}$ old at the start of each test. Three-day old fli es had emerged 48-72 hr prior to release and 5-day old flies had emerged 96-120 hr prior to release.

In one series of tests, mature pupae were counted and placed in the large outdoor cage. Sticky tapes were hung on the stakes and $24 \mathrm{hr}$ later the number of adult flies which had emerged during the test was determined by counting the number of remaining pupae.

\section{Results}

The number of flies caught on sticky tapes was 1 inearly correlated to the total number of flies present in an outdoor cage as shown in Fig. 15. A high degree of correlation was noted for flies of the same age while there was a smaller though acceptable linear relationship in the combined values of all ages between number caught and number present. The slope of the correlation was calculated following the procedures outl ined in Dixon and Massey (16).

The percentage of flies released as pupae, 1-, 3-, and 5-day old flies caught on the sticky tapes were 11.9, 24.8, 17.1, and 19.2, respectively (Fig. 15): 


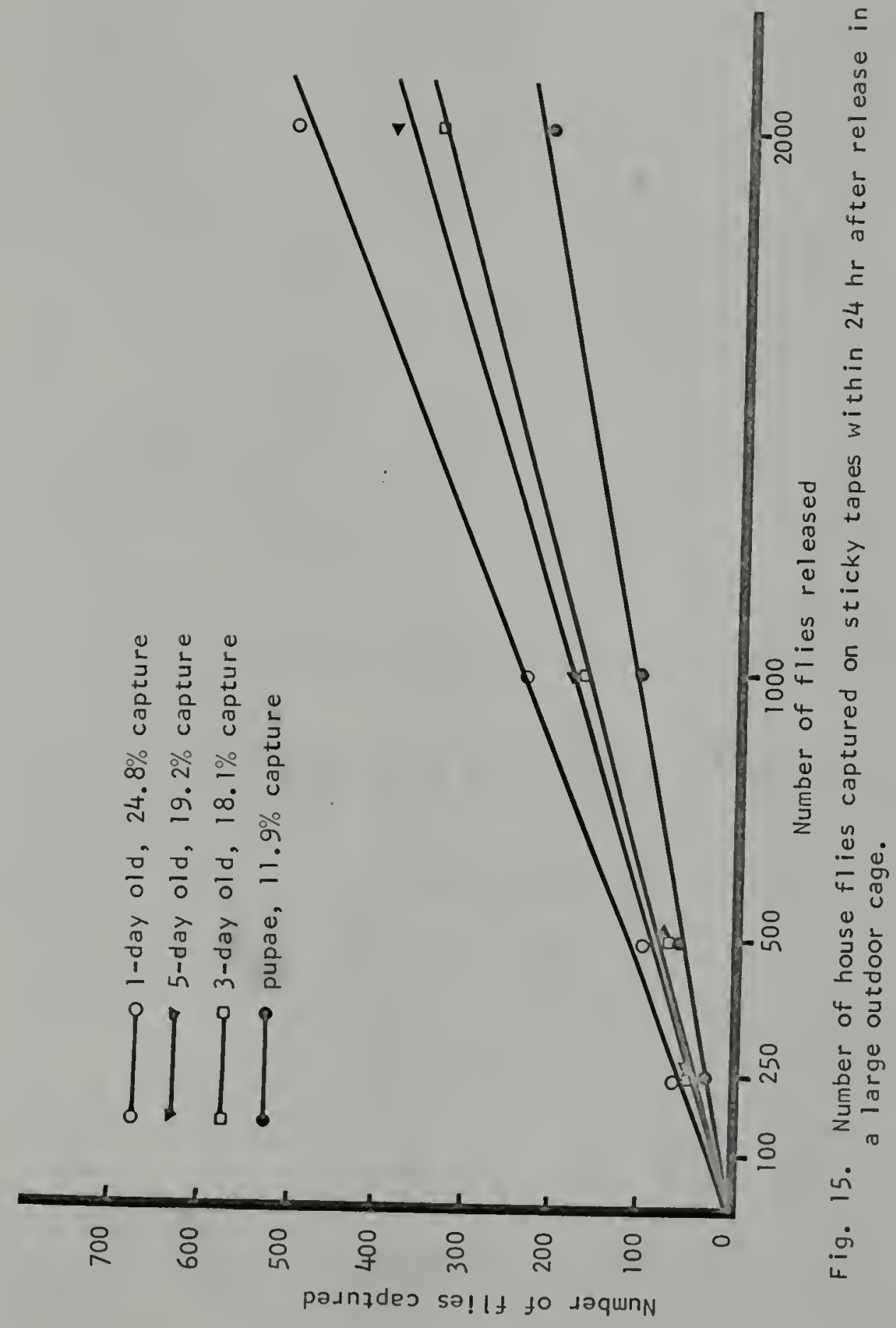


The smalier number of 7 lies trapped when fupas was alloned to emerge in the outdoor cage were not surprising sirce a higher mortality rate was expected.

\section{Determination of ine Macritude of the Hcuse Fly zosulation}

\section{M.thods}

The total number of house fli es in the digester building was estimated by determiring the percentage ö marked il ius captired on sticky tapes that were released in that area. Tiree-day oid nuse ti ius from the USDA sLsceptibia colony were anesthetized by carbon dioxide ard placed into small screer. holding cages. These tiles were marked by adding ore-hal: teaspoon of Daycio (Switzer Brothcrs Inc., Clevuland, Oh:o) fiuorescent dust to app-opirately doo flius and sently rotating tie cages. The tivs were t..en transierred to i5 $524 \times 27$ gauze cages. Following a l-hr period to allow the flies to recover, the flies were transported to the ccinpost piant and released in the digester building. A:i re?eases ware maie betwear :0:00 - 11:00 am on a Saturday or a Sunday when tine plant was not in operation. Although ail the doors in the building were closed, flies were not confined to the digester buildirg because the siding did rot fit fiush to the base of the building i eaving a $25 \mathrm{~cm}$ opening.

The flies ware capturad by 5 sticky tapes suspendicd from stokes in the cigesters and were the same as descrived previous!y for the seusonal fluctiation survey. The sticky tipcs were collected 24 hr after cech

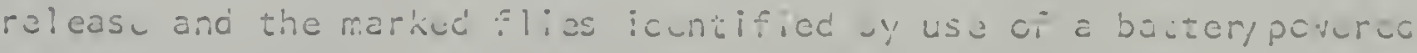

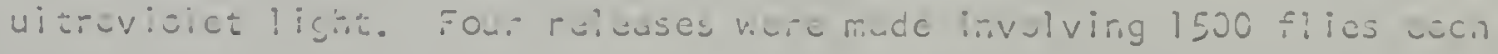
and 3 wer made wi ih 5000 flius wath. 
Results

An average $0: 1.3$ percent of the latoracory-rearud houde flies released in the digusters ware capturud on sticky tapes (Table 11). The eapture of house fijes on sticky tapes in a large cutdoor cas- was

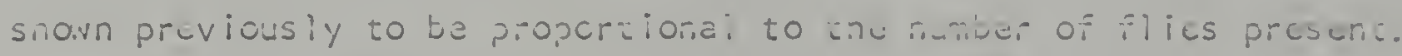
Whetner the percutage capoured is if percunt as shoun jor j-ciay old flies reieased in ch outwoor cage as shown in Fig. 5 or 1. E perit.t as sho.n in Táble 11, would depend on the circuinszances. Adnitteoly, any va?ue assigned would be questionable due to death, dispersal, and enviionmental factors. Hovever, in the presun case tho va?ue 1.8 percent is given creduce since Murvosh and Thaggard (4.3) counted 1.25 pereent of the house ilies presert in a similar portiaily open situation. This figure (1.S parcent) can be usid to estimate the total numier of house flies preser.t in the digesters based on the numbers caught on the sticky tapus. For example, Fig. 15 sho.vs that 48.9 flies per stake per day ware caught the waek of April 27, 1969. An estimate of the total numper of flies present can be calculated by 100 percent $\div 1.8$ percent $\times 5$ stahes per day $\times 48.9$ flies per stake and is equal to 13,569 house flies per duy prejent in the disester building during the week of April 27, 1906. 


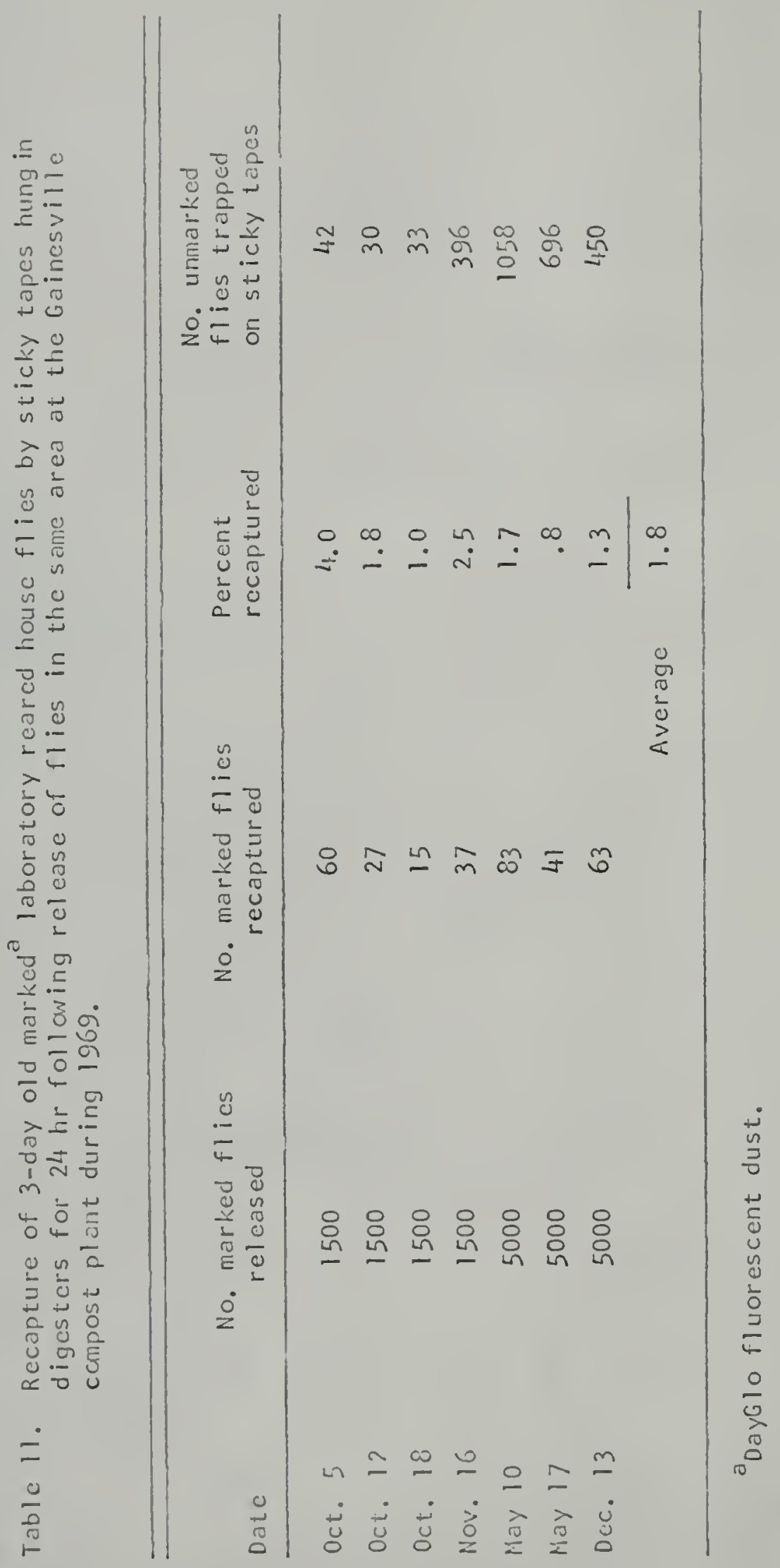


SECTION IV

HOUSE FLY BREEDING IN COMPOST

Observations conducted during 1968 and early 1969 revealed that house fly larvae were present in the compost in the digesters and along the conveyor belts where spillage had occurred. The ability of house flies to breed in compost presented the possibility of great numbers of flies reproducing in the enormous amounts of compost available.

An investigation began in April, 1969, to determine the extent and some of the limiting factors of house fly breeding in compost in order to devise procedures that may be used to prevent or hamper house fly breeding.

\section{Moisture and Age of Compost}

\section{Methods}

Composts of various ages and moisture (\%) were evaluated to determine their effects on house fly breeding. Compost $0,1,3,5$, and 10 days of age was tested at $30,45,60,75$, and 90 percent moisture. The age of the compost was determined by the length of time the compost had been in the digester. The 0 days of age compost was freshly ground refuse taken off the conveyor belt just prior to discharge into the digester. Compost 10 
days of age was tested prior to and after it had passed through the final grinders.

The samples taken from the digesters were removed from a depth of 30-60 cm and placed into a plastic bag. A minimum of 5 areas were sampled for each bag. The bag was then sealed and the contents thoroughly mixed. A $10 \mathrm{gm}$ sample was removed from the bag and the moisture content determined with a moisture determination balance. The moisture content of the compost in the digesters usually varied from 35 to 55 percent moisture. Since this was greater than the lowest moisture content tested, a portion was removed from the bag and placed into a plastic screen mesh bag. The mesh bag was then placed in an oven maintained at $80^{\circ} \mathrm{C}$. After a short drying period, the compost was transferred to a separate plastic bag. A $10 \mathrm{gm}$ sample was taken to determine the remaining percent moisture.

The desired moisture content was obtained by adding tap water. The amount of water added was calculated by the following equation:

$$
\begin{gathered}
\quad x=\frac{(y)(100-z)}{(100-y)}-z \\
x=m l \text { of water added per } 100 \mathrm{gm} \text { of compost } \\
y=\text { moisture content desired }(\%) \\
z=\text { moisture content of sample }(\%) \text {. }
\end{gathered}
$$

After the amount of water needed for each desired moisture content was calculated, the compost was divided into $100 \mathrm{gm}$ portions and each portion placed into a separate plastic bag. Tap water was added in the amounts calculated and the bags were sealed and the contents mixed. Fifty gm dry weight samples were removed from the bags and placed into waxed paper cups $(0.946$ 1) which were marked for identification. Either 100 eggs or 100 48-hr old larvae of $\underline{M}$. domestica were added to each cup. The cups were then covered with black cloth and secured with rubber bands. Temperature 
and hunicisy were maintainud $a=2 \varepsilon^{\circ} \mathrm{C}$ and 70 purcert Rh. Sever cuys after egging or 5 cisys after placing the larvac in the compost, the cups Were emptied into a pun of water and the fluting pupau werc ccilnctal

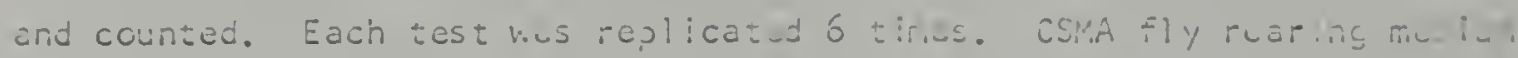

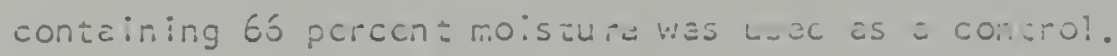
Rasul is

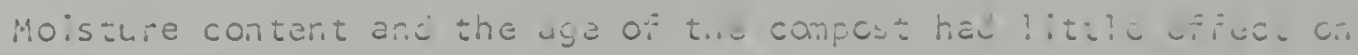

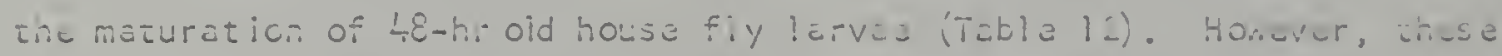

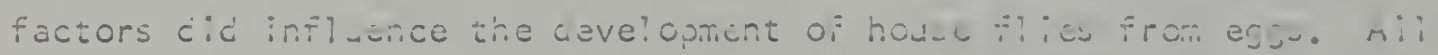
ages of compost testud containing 60 anc 75 percent moisture suppo.ted house fiy development to scme extent. Ninety purcent moisturc inhinitad house fly deve:opmant white 45 percont moisture wo insufficiant ro ruar house flies. Forty-five percent moisture in freshly ground ruflise resulted in lass thon I percent survival to pupat. It should be notec that tnese tests weru sujjacted to ambient RA ( $70 \%$ and moisture fluctuations during the tut period were not neasurec.

The age of the cumpost affected house fly devulopment but this was secondary to moisture as shc.n in Tablu 12. There was a significart reduction in the number of cggs that diveloped to pupae in 3-cay o:d compost at 63 percont moisture but no significant reduction occurred in the ages of compost testld et 75 percent moisture.

The effects of mo.sture cn house f?/ dülopment from eggs was exiendud to cefire more closely thu ontimum roisture of compost for fly oreecing. In this test series $100 \mathrm{M}$. dchestica eags were placed in 3-day old coninost

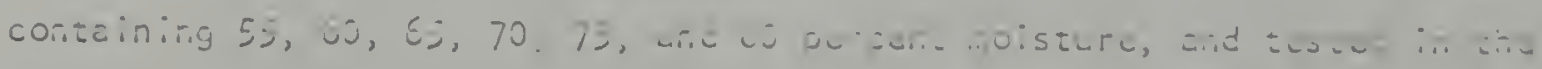

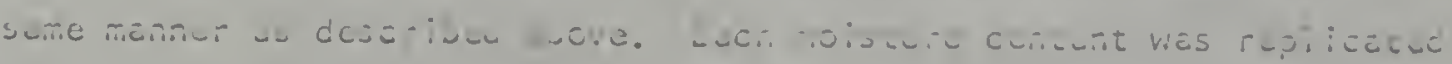




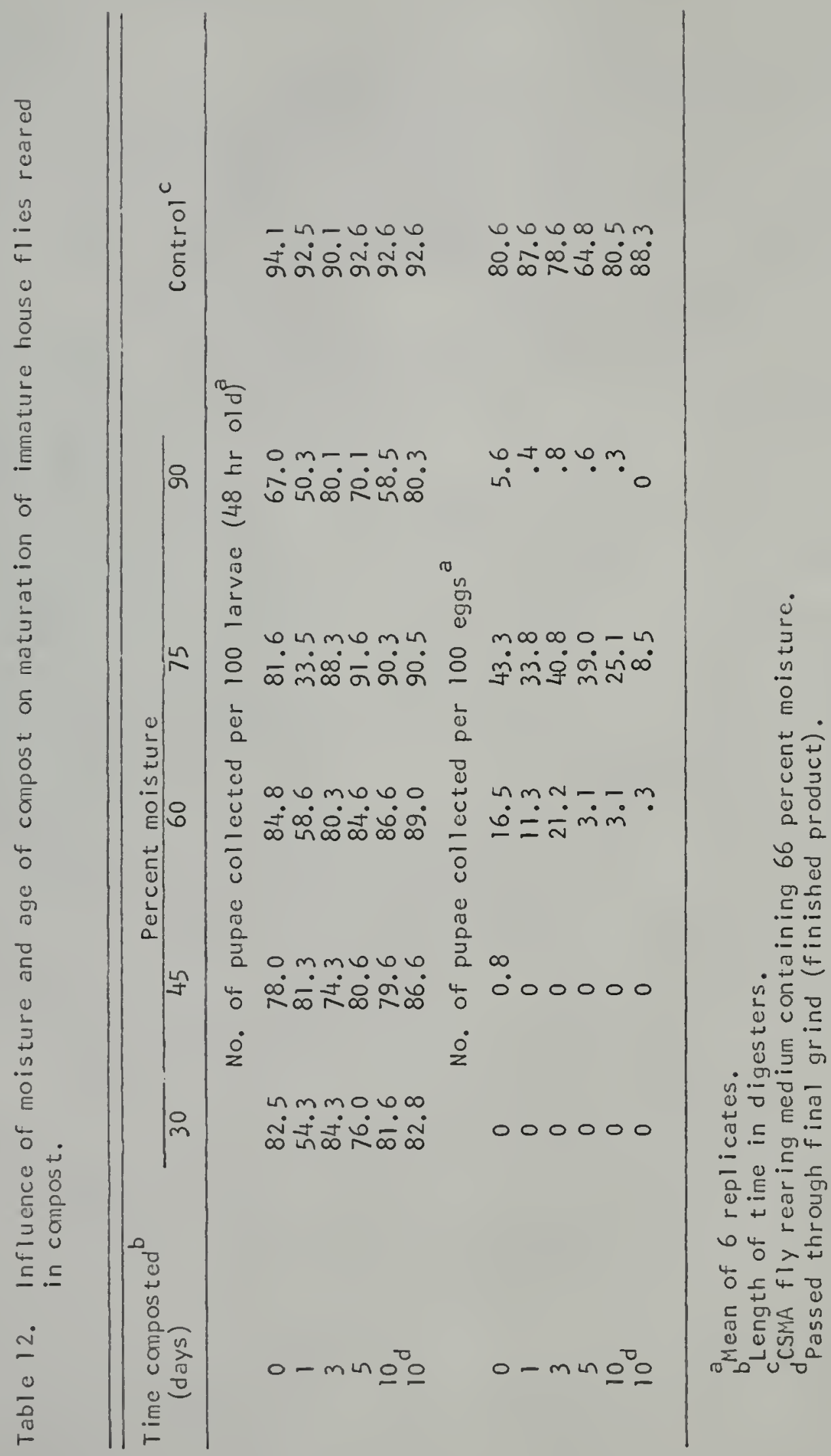


10 times. CSMA fly rearing medium containing 66 percent moisture was used as a control. The optimum moisture content for house fly development was 75 percent (Table 13).

\section{Sludge and Grinding}

\section{Methods}

A test similar to the preceding experiments was conducted to determine what effects the addition of raw sewage sludge and the grinding of refuse had on house fly development. In these tests either tap water or sludge (approximately 98 percent moisture) was added to various grinds of refuse to obtain the desired moisture content. The sludge was obtained from the storage tank at the compost plant which was maintained by the city sewage treatment facility. Sixty and 75 percent moisture contents were chosen to be tested with the various grinds. The amounts of water and sludge added to achieve these moistures were calculated as in the previous study.

Four sizes of refuse particles were evaluated in this study. These were obtained from refuse taken immediately after primary grinding, refuse taken after secondary grinding, a $1: 1$ mixture of refuse from the primary and secondary grinders, and refuse that had passed through a small laboratory mill with a $0.63 \mathrm{~cm}$ grid. These samples were placed in plastic bags and mixed with water or sludge in the same manner as described for the previous experiment.

One hundred $\underline{M}$. domestica eggs were added to $50 \mathrm{gm}$ dry weight of the test materials and placed in waxed paper cups $(0.9461)$. The cups were covered and the pupae collected by flotation 7 days later. CSMA fly 
Table 13. Influence of moisture on maturation of immature house flies reared in 3-day old compost.

$\begin{array}{cc}\text { Percent } & \text { No. of pupae collected per } \\ \text { moisture } & 100 \text { eggs }\end{array}$

$\begin{array}{cc}55 & 14.0 \\ 60 & 21.7 \\ 65 & 23.7 \\ 70 & 30.2 \\ 75 & 39.4 \\ 80 & 21.6 \\ \text { Control b }^{\text {b }} & 80.3\end{array}$

Mean of 10 replicates.

${ }^{b}$ CSMA fly rearing medium containing 66 percent moisture.

rearing medium brought to 66 percent moisture by adding either water or sludge was used as a control. Six replicates were prepared for each test.

\section{Results}

The addition of raw sewage to compost of all size ranges produced a higher yield of house fly pupae than the addition of an equal amount of water as shown in Table 14. Such an increase is not surprising since the total organic content was increased and since 01 son and Dahms (49) found sewage sludge an ideal breeding medium for house flies.

The effects of grinding compost were not clearly demonstrated. The results shown in Tables 12 and 14 indicate that the larger particles were more conducive to house fly survival. However, the size of the refuse 


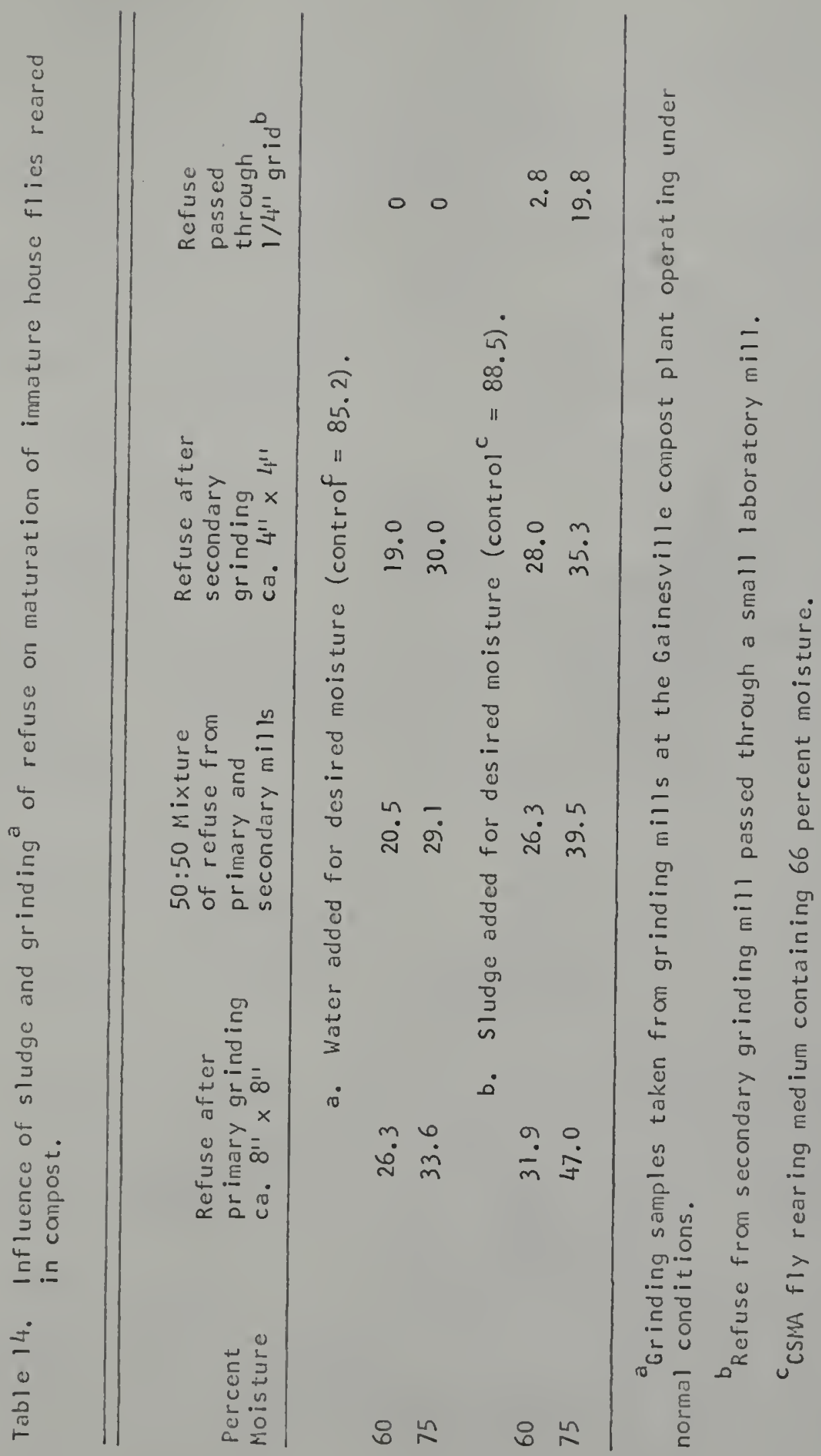


particles varied with the daily vivar of the grinding mills and the exact size range was difficult to ascerti in.

\section{Tancara-ne}

The temperatures occur-ing in tous z : ly rearing coniaincrs ルre investigated to aeterminc the scmperuture range profured by immatur

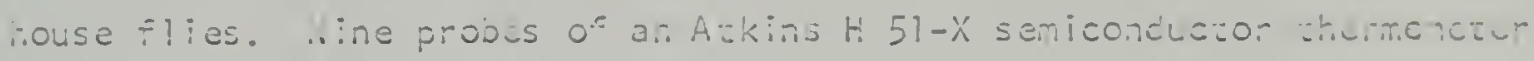

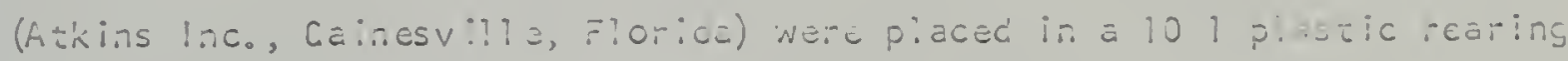

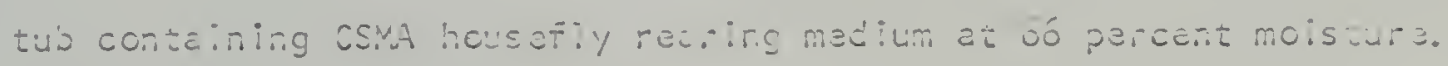
The probes were piaced ir ...e positicns anc ueptrs shown in Fis. ís. The temperaures ware reccrded erery z' hi for ó days. mis proeccur was replicazed 3 tines.

The mean tumperazure recorced in the rearing tubs at each position are presented in Tab?e 15. The blocked data in Tat:e 15 reprcsent those probes in areas occupied by iarvae. The maximum tomperature observed in the larval region was $1.6 .1^{\circ} \mathrm{C}$. - -hese data indicate that larvae develcp in a temperature range of $28-45.1^{\circ} \mathrm{C}$.

The maximum tomperaclre in which immazure house flies can develop is not knüvn. There are many referunces dealing with temperature studies on house flies bul ?itle definite information was found concerning this particuiar area. West (82) steted that house fly eggs cannot suivive a temperature above $46.1^{\circ} \mathrm{C}$ whil e Roubaud (59) reported that larvae died in 3 minutes when exposed to $50^{\circ} \mathrm{C}$.

To determine if tho temperatures attained in the digustis muy prevent fiouse ily davelopmont in the compost er. Alkins H 5l-k sunlconducter

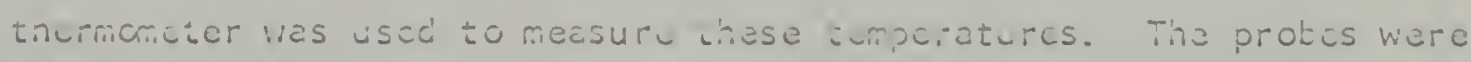




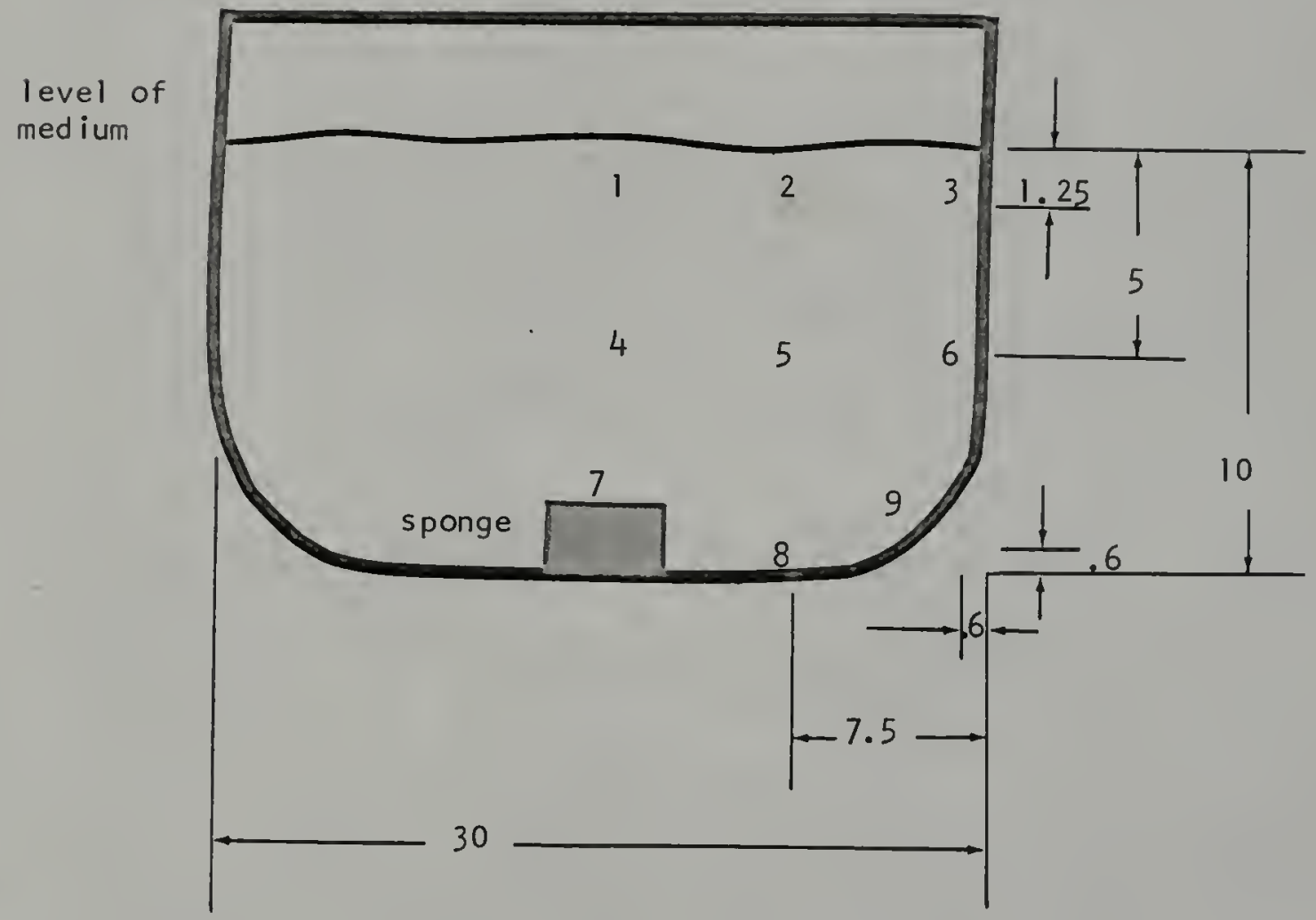

Fig. 16. Position of temperature probes in house fly rearing containers (distances in $\mathrm{cm}$ ). 


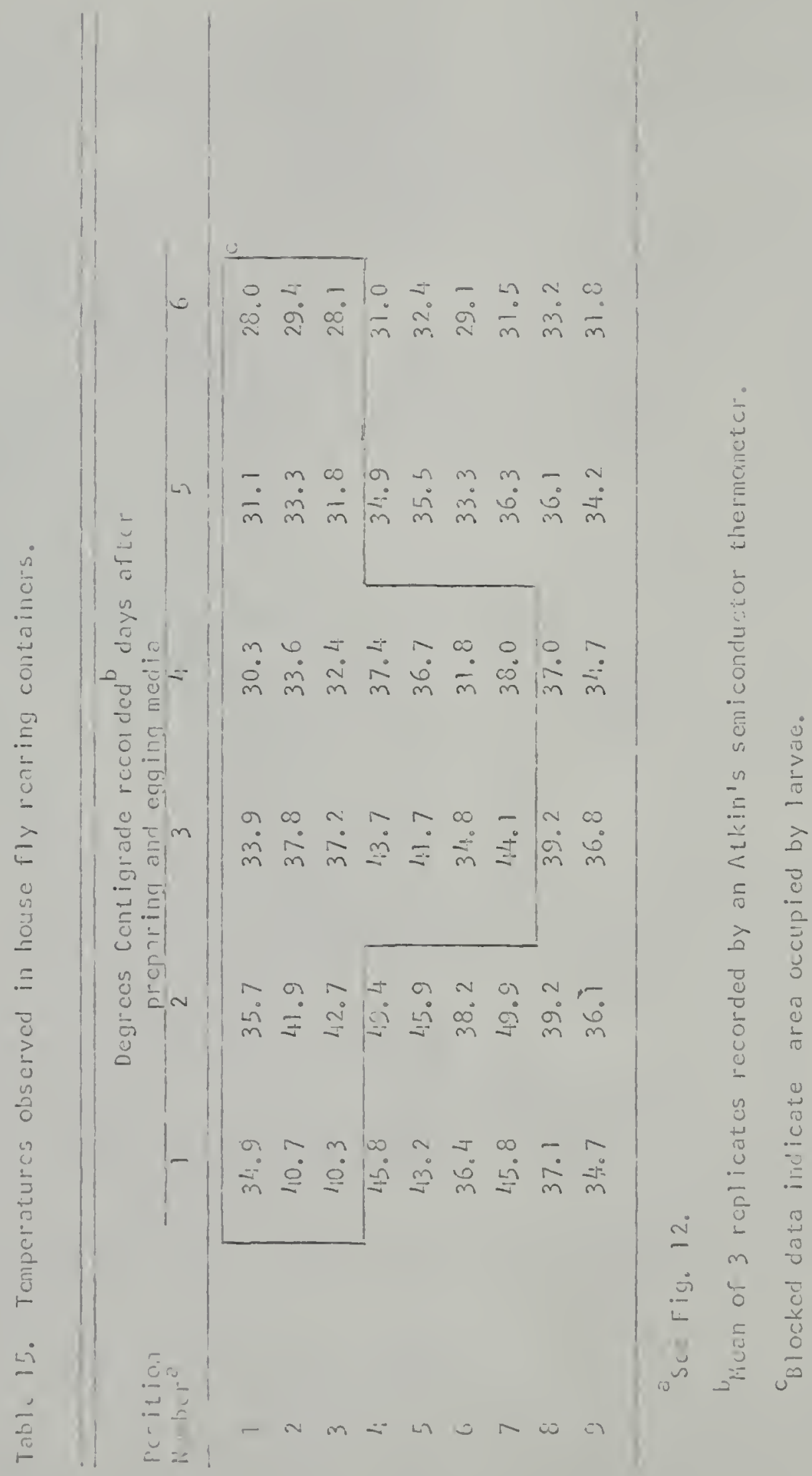


placed in 4-day old compost at depths ranging from $1.27-15.24 \mathrm{~cm}$ and allaved 10 minutes to equilibrate. The temperatures were then read and recorded. Twenty-five readings were made at each depth over a period of several weeks. The temperatures ranged from a mean of $38.2^{\circ} \mathrm{C}$ at a depth of $1.27 \mathrm{~cm}$ to a mean of $59.4^{\circ} \mathrm{C}$ at $15.24 \mathrm{~cm}$ (Tabie 16). Information on the temperature in the digesters at greater depths was supplied to the author by Dr. D. T. Knuth, Environmental Engineering, Inc., Gainesville, Florida, and is presented in Appendix 4. From these data it can be concluded that temperature would prevent house fly breeding in the digester except in the top $2.5 \mathrm{~cm}$ of the compost. 


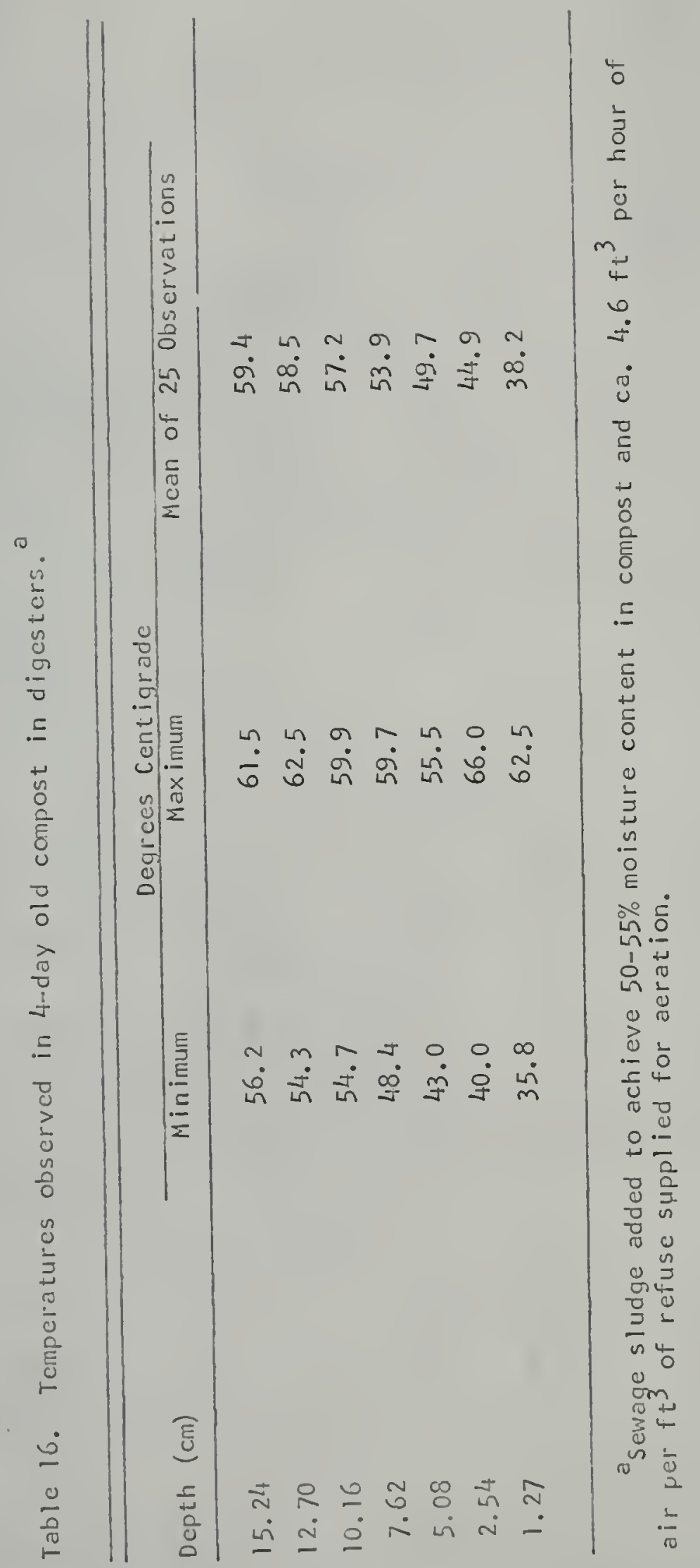




\section{SECTION $V$}

MIGRATION ANO OISPERSAL

Compost plants and other similar types of refuse handling systems are centrally located to lower the transportation costs. These facilities are optimally designed to operate in these central locations without causing a nuisance to the surrounding community. The Gainesville compost plant has previously been shoun to produce approximately one-half million adult flies per week during the summer months. These flies may disperse into the surrounding community, thus discounting the value of central location. An investigation to determine the extent of fly dispersal from the compost plant was begun in 1969. When the plant closed in December, 1969, these dispersal studies were completed at the city landfill.

\section{Literature Reviav}

\section{House Flies}

There is an undue prominence often attached to the maximum distance of dispersal of flies (63). Flies released from a central location and recaptured later at some distance in very limited numbers imply that the area covered is subject to infestation from the release point. Although this may be true, it should be noted that those one or two flies 
recovered at some great distance were among the exceptionai fer. thet, by same element of charce, managed to achieve this cistance. The dispersel of the mass of the fiy popuiction rathe. than that of a fe: indivicuail

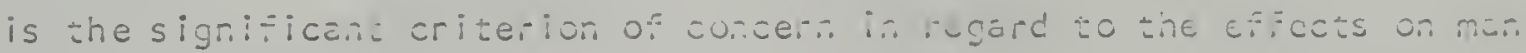
(63). The dispeiscl cepecity ot tite ness pop-iation is cxpected to be expended witrin i/2 - 2 mil as becuuse o: the meandaring characzer o: house fly movament (i3, 48, 50, 53, 63, 64, 75). Tre Fiy moves tran cin field of a stimulus causirg a sopic raccion to that cf arotiner (30). A fly may travel $15 \mathrm{miles}$ to reach a distance 1 mile from its origin ( $6 j)$. The attrectiveness of the ralease site may greatly influuce cispersa?. Pickens et $\underline{a}^{i}$. (5!) recaptured 73 percent of the liberated house flies at the relesse sita when the site was an attractive barn. When thoy re? wased flies in an open area located at the center of a $1 / 2 \mathrm{mile}$ circle of 4 barns only 4.l percun of triese fiies were recaptured. Schoot (ój) found that in mary instances flies dispersed from a location despite the presence of an apparent excess of feeding and breeding areas.

There are conflicting reports of the eifects of wind on fiy dispersal $(25,40,52)$. Hovever, the more comprehersive studies of Schoof and Silverly $(64)$ found that ncusa fly movement was not equal in magnitude in al? directions anc $P$ : ekenset cl. (5!) revealed that fly dispersal was randon when the winc was variable and upwind bhen the wind blev predaminantly from 1 quarter.

Ogata et El. (L.8) demonstrated that house fly dispersal was not influencu sy hignways, rice fields, or mountains. Dispersal is intluenced

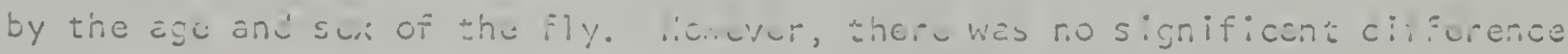

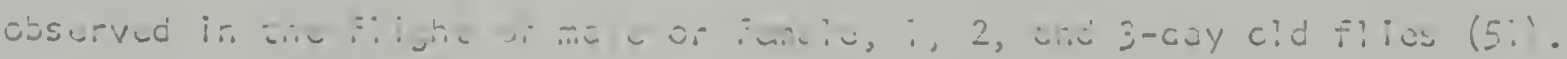


Schoof and Silverly $(64)$ concludud that the ccmon characteristic of fly disparsal was a basic randanness of movement influcneed by 5 conditions:
(1) population pressure,
(2j) differentialiy attractive sites,
(3) guographica!

barriers, (4) preferenzial novenert, and (5) irherunt tencency of flies to disparse.

The maximu fight range of fi ius recorced in most jthdies wes usuelly the maxirum distance of trapping. The maximum recorded ilignt of nouse flies is 20 milas (83).

Elai filies

Gimore et al. (2i) found that $\underline{P}$. Itprin released at a central point were distributid randon!y after 2 days in open sheep country. Mac'cat

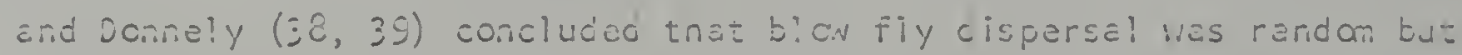
that agsregations licie formed producing a clumped distribution. These aggregations were due to ditferent dagreus of attraction offercu to t.rose individuals in tneir random movement across the activity artas. These authers later diceided on two types of tlon fly rlight: a sustained cispersai flight, irdupendent of the environment, and an interspersal fligtit whist. may irvaive no nat displacemer.t $(10)$.

Gurncy anc doosh:?: (2j) Fcund that $\underline{P}$. cupp. na tended to fly davn or across a picvailing wird, while Macheod ard Donnelly $(40)$ found no evidence of wind afiecting bloil fly fight. Jaenicia spp. has demonscratud a seusonal migration in ajtumn from the forest to the citics in finland

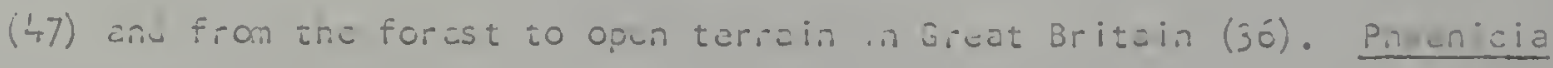
spp. Wus unaffuctud by stacp slopes of a val iey in uplind sheco cunntry

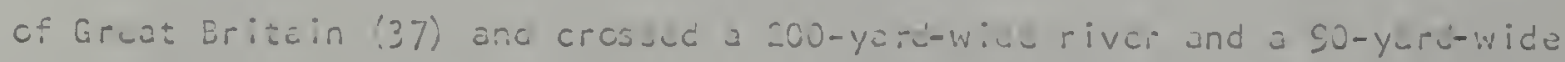

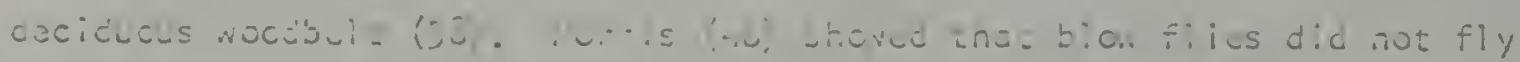

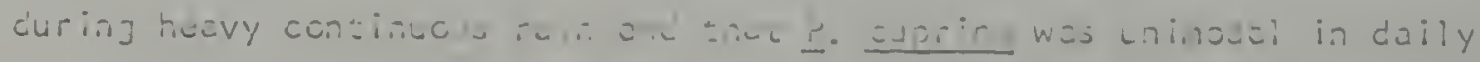




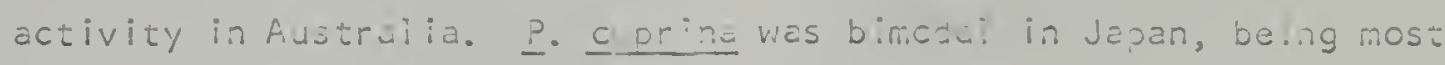
numerous in the atterrocn peak (7!). ‥ cuprina was recorded $4.7 \mathrm{mi}$ is fran their ? iberasiz.n s: w w thin 30 h. (2!).

Comprehens ive reviews of referer-as on 2ia: Fly aispersal and

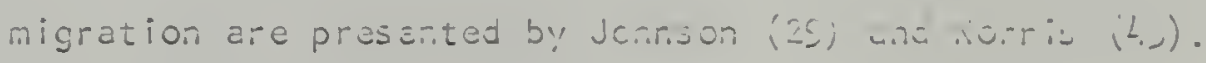

\section{$=1: 240.115$}

Flighe mills provide a convenicna mearis of cuse.ving cruiacze- sties of insece ilight lider controliud envircmundal condicions. Sirce

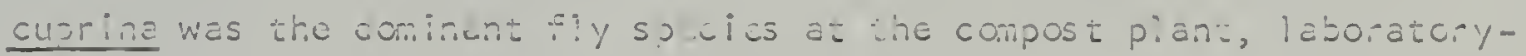
reared specimen- whre actuched to a flight mili to derermine the maximum distance they may travel in dispersal flighes.

A simply constructac fi i nt mi? i was used by Atkins (3) with the scoiytid, Denmoczcnus pseudois ae Hopk. This devi:a was improved ay Snith and Furniss (77) and Rovley tt al. (60) by automatically reconding the reviutions of the mills by means of phoioelectric cells and eiectric counters. Chambers and o'connel (1-2) further improvec this tes ricue by reducing the fiction of tha wills by supporting the pivot batween? mugnets.

Mathous

The filghi milis used in niz study were generously provided by Ur. O. L. Bailey, USuA, Geinesviiic. The rovoi arms of these milis wuie

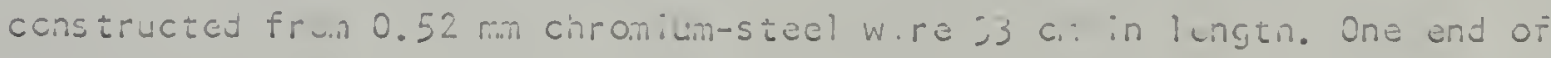
this wire was bant into 2 right angles as shcwn in Fig. i7, so than the

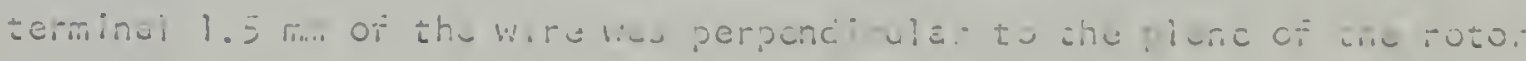

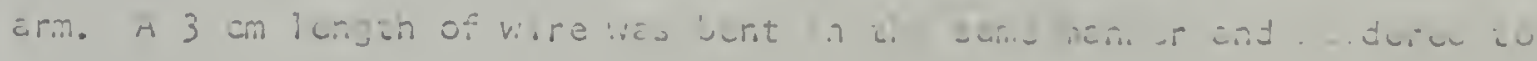


the end of the rotor arm to produce the double end shown in Fig. 17. A pivot was fastened $16 \mathrm{~cm}$ from the end of the arm so that the circle it described had a circumfrence of $1 \mathrm{~m}$. The pivot was a No. 0 insect pin with its head removed which was glued, point upward, to the rotor arm between two $6 \mathrm{~cm}$ circles of paper. The pivot was suspended between two $6 \times 25 \mathrm{~mm}$ magnets (stirring bars) so that the pin was in contact with the upper of the 2 magnets and was stabilized by the lower magnet. The magnets were supported by 2 wooden dowels connected to a steel rod frame.

The revolutions of the arm were counted and recorded by a method similar to that described by Smith and Furniss (77). A 6 volt lamp was attached to the wooden davel holding the lower magnet as shown in Fig. 17. A photoelectric cell was positioned above the lamp so that a $2.54 \mathrm{~cm}$ black paper disc glued on the rotor arm would interupt the beam of light with each revolution of the arm. This paper disc was $7 \mathrm{~cm}$ from the pivot on the short end of the rotor arm and also functioned as a counterbalance. The photoelectric cell was connected to a pover unit which operated an electric counter.

Flies used in this study were reared on a diet of 1 ean ground beef in the method described previously. The flies were anesthetized in a cold room maintained at $2-4^{\circ} \mathrm{C}$. These $\mathrm{flies}$ were then attached to the radius of the mill with a drop of rubber cement on their pronotum. The rotors were then immediately mounted on the mills. In one series of tests, P. cuprina of various ages were placed in constant light provided by fluorescent lamps for $24 \mathrm{hr}$ and the distances flown recorded. Ten male and 10 female flies were used for each test.

A second test involved 10 male and 10 female $\underline{P}$. cuprina which were attached to the rotor arm approximately $4 \mathrm{hr}$ after they emerged as adults. 


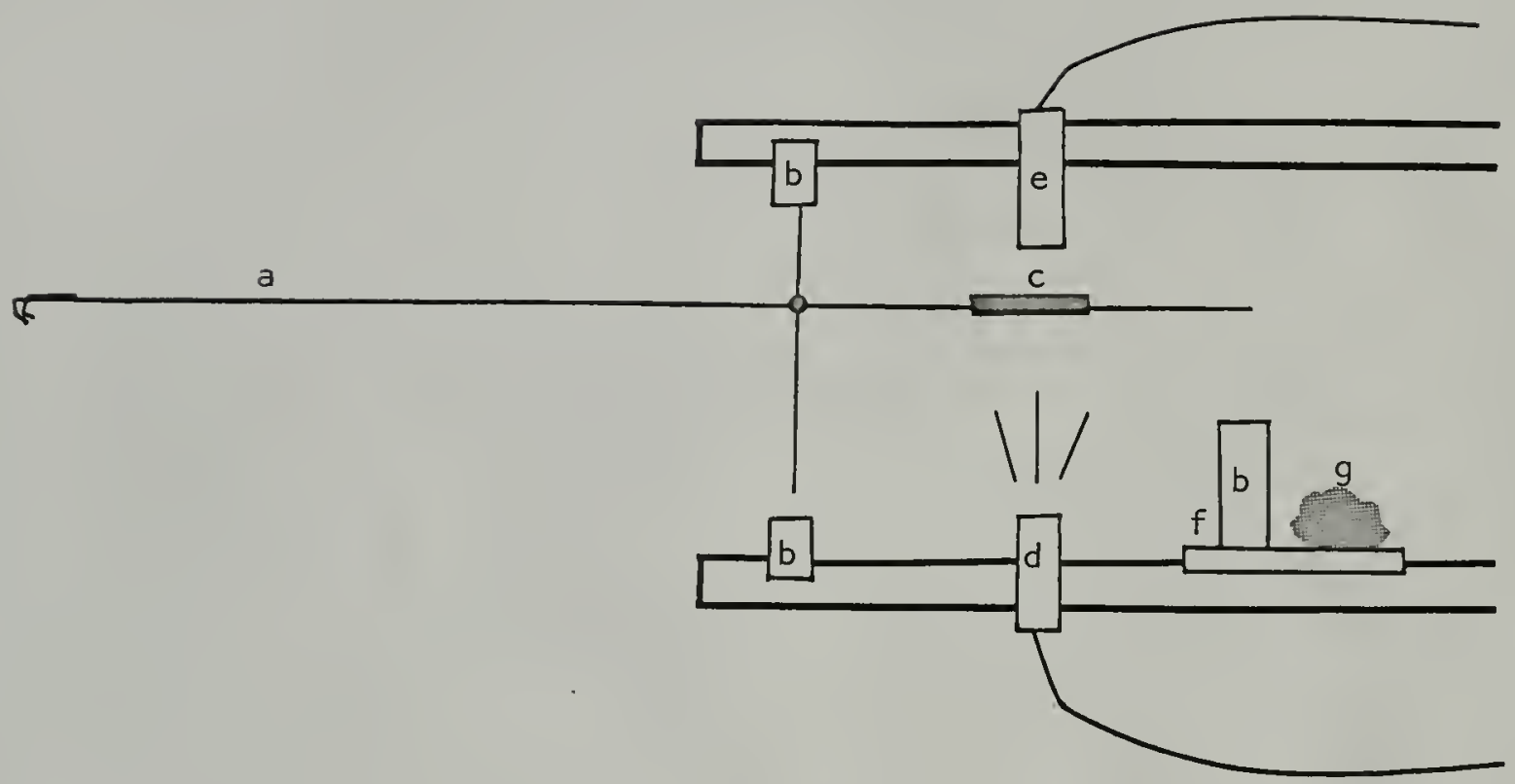

Fig. 17. Diagram of insect flight mill. a-rotor arm; b-magnet;

c-counter-balance; d-light source; 3-photoelectric cell; f-metal plate; g-cotton ball. 
These insects were allared to fly until death. The flies were allowed to fly from 8:00 am to 6:00 pm each day under constant light. In the evening, the rotor arm was fastened to a magnet placed on the metal plate as shown in Fig. 17, and the flies were allowed to feed on a cotton ball saturated with a 10 percent sugar solution. The 1 ights were turned off and the flies remained in this position overnight. All tests were conducted at the USDA laboratory in a room where temperature and humidity were maintained at $26^{\circ} \mathrm{C}$ and 70 percent RH.

\section{Results}

The mean distances flown by various ages of $\underline{P}$. cuprina attached to a flight mill for $24 \mathrm{hr}$ are presented in Table 17 . The greatest distance travelled by an individual male was accomplished by a 5-day old fly that flew $24,129 \mathrm{~m}$. The greatest distance travelled by an individual female was $19,603 \mathrm{~m}$ by a 3 -day old fly.

Male and female $\underline{P}$. cuprina flew an average of $19,405.4 \mathrm{~m}$ and $25,235.2 \mathrm{~m}$ and a maximum of $30,127 \mathrm{~m}$ and $45,030 \mathrm{~m}$ respectively, when attached to a flight mill until death, as shown in Table 18. Assuming these were less than ideal conditions, flies in the field could be expected to travel these distances and further, especially when taking advantage of the winds.

\section{Blow Flies Released at Compost Plant}

\section{Methods}

Four releases of wild flies were conducted at the compost plant during September, 1969, to determine theit dispersal patterns in this 
Table 17. Mean distancesaflown in 24 hr by adult Phaenicia cuprina attached to an insect flight mill.

\begin{tabular}{lrrrr}
\hline $\begin{array}{c}\text { Age of fly } \\
\text { (Days) }\end{array}$ & \multicolumn{2}{c}{ Males } & \multicolumn{2}{c}{ Females } \\
\cline { 2 - 3 } \cline { 4 - 5 } $1 / 2$ & 3,671 & $(2.28)$ & 2,914 & $(1.81)$ \\
1 & 8,356 & $(5.19)$ & 7,725 & $(4.82)$ \\
2 & 11,335 & $(7.04)$ & 10,168 & $(6.32)$ \\
3 & 6,341 & $(3.94)$ & 8,289 & $(5.15)$ \\
4 & 5,559 & $(3.45)$ & 10,776 & $(6.70)$ \\
5 & 10,273 & $(6.38)$ & 11,438 & $(7.11)$ \\
6 & 5,556 & $(3.45)$ & 7,785 & $(4.84)$ \\
7 & 5,476 & $(3.40)$ & 7,849 & $(4.88)$ \\
\hline
\end{tabular}

aean of 10 replicates.

area. The wild flies were captured by sweep net from the grassy areas surrounding the compost plant and placed into a large plastic bag. They were immediately anesthetized by carbon dioxide supplied from a portable lecture bottle. One teaspoon of DayGlo fluorescent dust was placed in the bag and the flies were marked by gently rotating the bag. The flies were volumetrically counted by pouring them into a $50 \mathrm{ml}$ beaker. This volume represented approximately $500 \mathrm{flies}$. The flies were then placed into gauze cages, allowed I hr to recover, and then transported to the release site. Two releases of $1000 \mathrm{flies}$ each were made at the compost plant, and 2 releases involving $1500 \mathrm{flies}$ each were liberated at the citiy animal shelter. The flies were captured around 9:30 pm and releases were made about 11:00 pm that same night. 
Table 18. Distance flown until death by adult Phaenicia cuprina attached to an insect flight mill.

\begin{tabular}{|c|c|c|c|c|c|c|}
\hline \multicolumn{4}{|c|}{ Females } & \multicolumn{3}{|c|}{ Males } \\
\hline Meters & (Miles) & $\begin{array}{l}\text { Age of Insect } \\
\text { At Death (Days }\end{array}$ & & Meters & (Miles) & $\begin{array}{l}\text { Age of Insect } \\
\text { At Death (Days }\end{array}$ \\
\hline 26,651 & $(16.6)$ & 5 & & 29,546 & $(18.4)$ & 3 \\
\hline 16,931 & $(10.5)$ & 3 & & 19,892 & $(12.4)$ & 5 \\
\hline 13,283 & $(8.3)$ & 3 & & 16,601 & $(10.3)$ & 4 \\
\hline 15,445 & $(9.6)$ & 4 & & 6,477 & $(4.0)$ & 3 \\
\hline 45,030 & $(28.0)$ & 6 & & 23,658 & $(14.7)$ & 5 \\
\hline 23,386 & $(14.8)$ & 8 & & 30,127 & $(18.7)$ & 3 \\
\hline 26,195 & $(16.3)$ & 9 & & 21,698 & $(13.5)$ & 5 \\
\hline 18,994 & $(11.8)$ & 9 & & 14,361 & $(8.9)$ & 5 \\
\hline 25,599 & $(15.9)$ & 7 & & 9,126 & $(5.6)$ & 3 \\
\hline 40,838 & $(25.4)$ & 7 & & 22,568 & $(14.0)$ & 4 \\
\hline $25,235.2$ & $(15.7)$ & $\bar{x}=6.1$ & $\bar{x}$ & $=19,405.4$ & $(12.1)$ & $\bar{x}=4.0$ \\
\hline
\end{tabular}

A sample of approximately 200 marked $f 1$ ies was taken from each release and identified. Greater than 99 percent of these flies were P. cuprina.

The marked flies were recaptured by sweep net after they were identified by examining the blaw fly roosting areas surrounding the compost plant with a portable battery pavered ultraviolet light. Baited cone traps, described previously, were placed behind the receiving building, at the city animal shelter, and in the backyard of an apartment $200 \mathrm{~m}$ east of the plant. These traps were checked every $24 \mathrm{hr}$ for 4 days after 
each release. The trap at the animal shelter was removed for those releases at that location.

\section{Results}

An average of 10.7 percent of the blaw flies released at the compost plant were recaptured in the same area $24 \mathrm{hr}$ after liberation as shown in Table 19. Traps baited with l-day old fish heads at the city animal shelter and behind the apartment failed to capture any marked flies for these 2 releases. Flies released at the city animal shelter were recaptured at the compost plant at an average of 5.65 percent. The trap behind the apartment failed to trap any marked flies in these releases.

\section{Fly Releases at the City Landfill}

The compost plant closed December, 1969, forcing the completion of the dispersal studies to be conducted at the city landfill. The landfill presented a situation different from the compost plant but similar in the large amounts of attractive materials present and the generation of a large number of flies. It was concluded that dispersal patterns observed in this area may be interpolated as to general trends which may be applied to the compost plant.

\section{Location of City Landfill}

The landfill was located on a 30-acre tract of land north of the Gainesville Municipal Airport. This area was surrounded by pine flatwoods and the closest residence was located $1.2 \mathrm{mi}$ south of the landfill. The Gainesville Industrial Park was located I mi west of the landfill and the airport runways began $1 / 2 \mathrm{mile}$ southwest of the landfill. Three residences were located $1.5 \mathrm{mi}$ north of the landfill while woodlands extended for several miles to the east. 


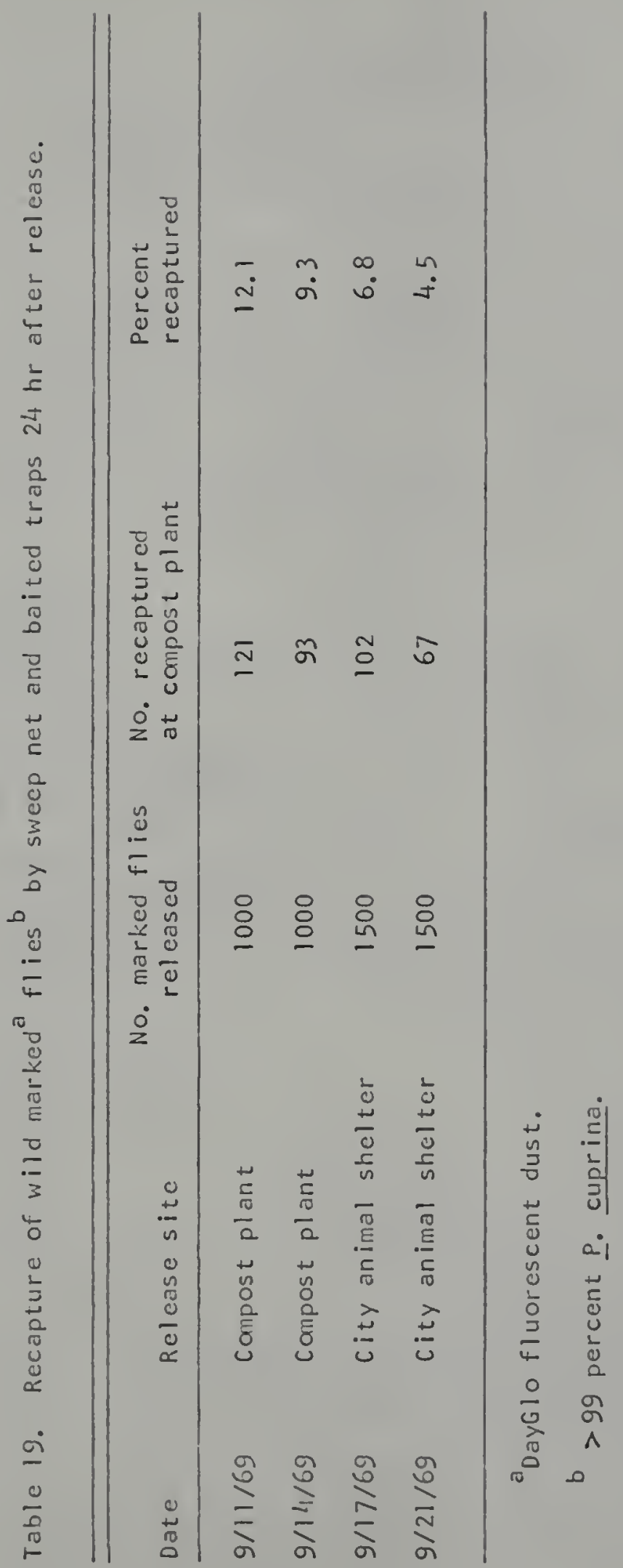


Operation of the Landfill

The refuse was brought to the landfill by truck and dumped into trenches $15 \mathrm{~m}$ wide and $5 \mathrm{~m}$ deep. A bulldozer was supposed to crush and pack the refuse into the trenches and then cover it with soil at the end of the day. Such an operation would be in compliance with the standards of the American Public Works Association for the operation of a sanitary landfill (1). Unfortunately these procedures were seldam complied with because of equipment failures. Refuse was observed to remain uncovered for several days on many occasions.

A separate area of the landfill was used to dispose of dead animals and the maintenance of this area was poor. Too frequently animals were not completely covered with soil or else not covered at all for several days. This resulted in large numbers of flies developing in this area (Fig. 18).

\section{Fly Behavior Patterns Observed at the Landfill}

Before a general discussion of the releases can be undertaken some observations concerning fly behavior at the landfill should be reported.

Blaw $f l$ ies and house $f l$ ies were inactive at night, roosting on the refuse or on vegetation surrounding the refuse until sunrise (Fig. 19 and 20). As the roosting sites were exposed to the sun the flies crawled about the plant or refuse to position themselves in direct light where they groaned themselves for 15-90 minutes. The flies then left the roosting sites, flying as it seemed, an orientation flight. These flights occurred in all directions, with the majority of the flies finally appearing at a sunny, sandy area, absent of vegetation. The sunny sides of the mounds of sand used to cover the refuse were preferred sites. The flies 


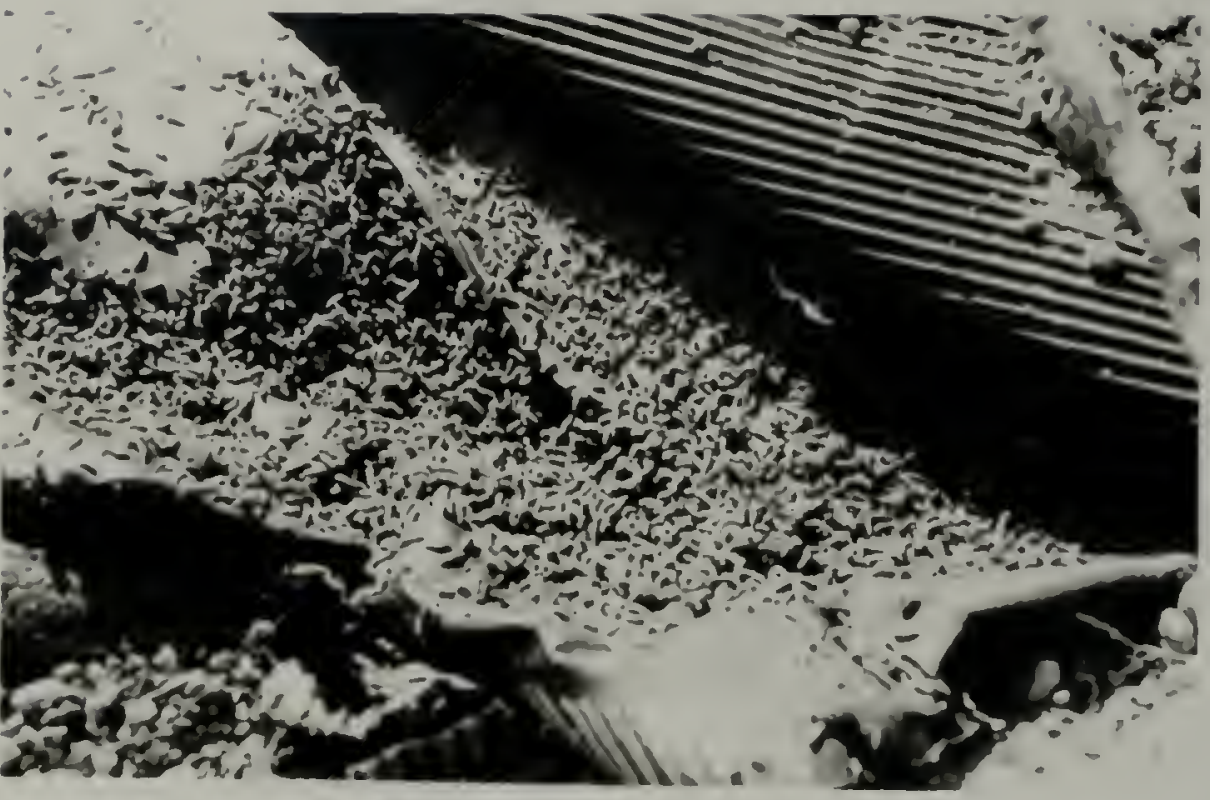

Fig. 18. Fly larvae in animal disposal area of city landfill.

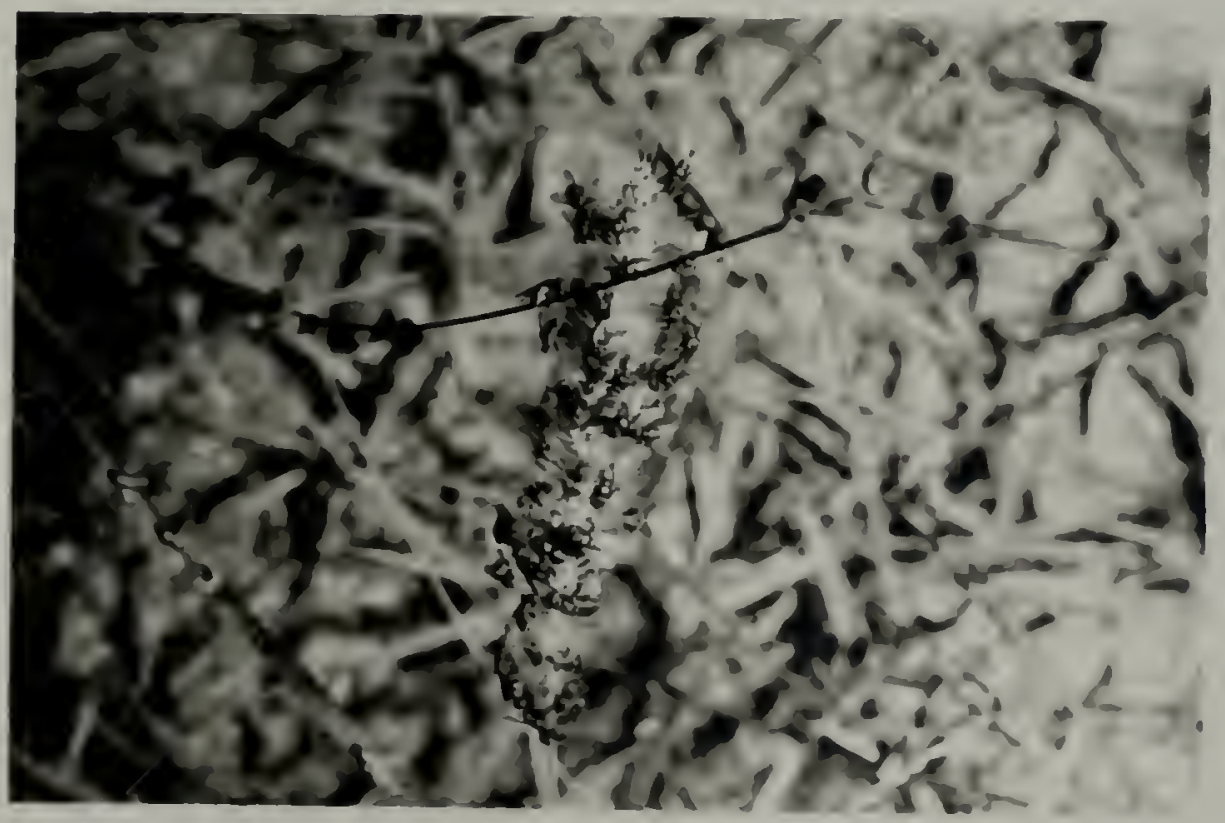

Fig. 19. P. cuprina roosting on grass tassel at night at city landfill. 


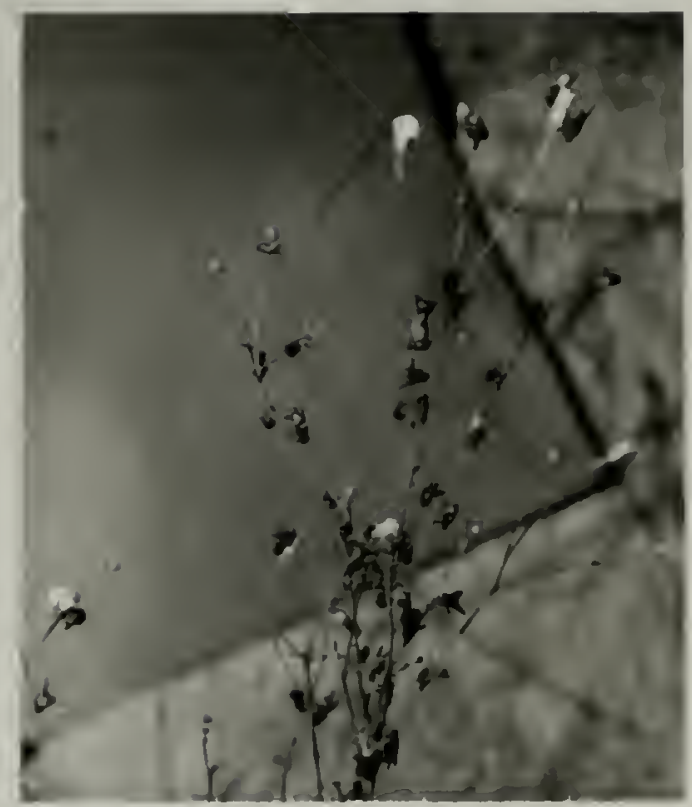

Fig. 20. Predominantly M. domestica roosting on weed at night at city landfill.

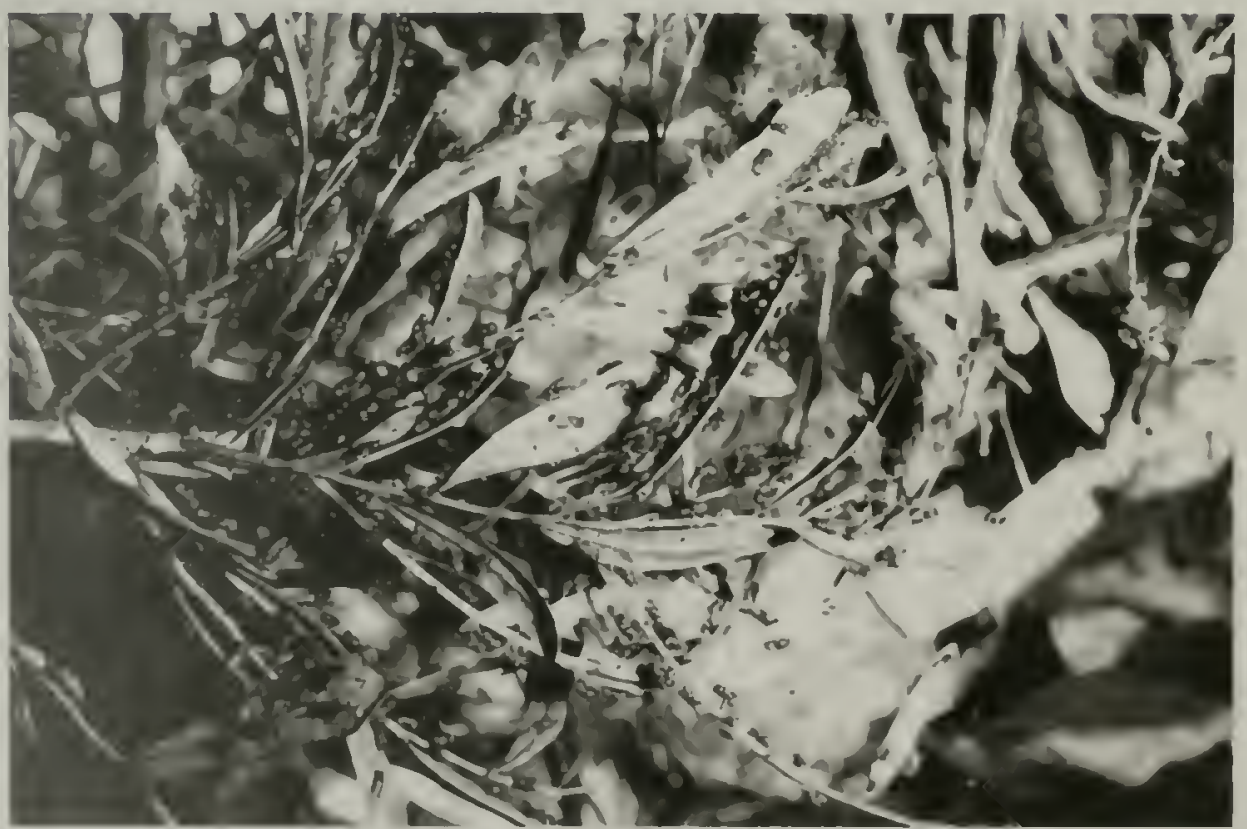

Fig. 21. Predominantly $\underline{C}$. macellaria with some $\underline{M}$. domestica roosting on dead brush in refuse at night at city landfill. 
remained in these areas 45-60 minutes and mating was widespread during this period. The activity diminished and $f l i e s$ began appearing on the refuse where they remained until dusk when they returned to the roosting sites. House flies and $\underline{P}$. cuprina were both observed to follow this pattern and both occurred in the same mating area simultaneously.

The roosting sites were centered around the most recently dumped refuse. M. domestica rested on the refuse, especially brush in the refuse, and on the surrounding vegetation immediately adjacent to the refuse. There appeared to be little selection of plant species chosen as resting sites but there was a preference of height. House flies appeared most often on plants $1 / 2-1 \mathrm{~m}$ in height. House flies have previously been reported to roost preferably on ceilings, trees, and shrubs in rural a reas $(2,33,41)$.

Cochliomyia macellaria were observed to roost on leafless or dead branches $1-3 \mathrm{~m}$ in height. Brush in the refuse and plants immediately next to the refuse were preferred (Fig. 21).

P. cuprina was seldom observed roosting on the refuse and rested almost exclusively in grasses and weeds up to $1 \mathrm{~m}$ in height. Green (22) and Maier et al. (4i) observed similar behavior at a slaughterhouse as well as in urban areas. These flies roosted at a greater distance fran the refuse than did the house flies. If one walked from the refuse through the surrounding vegetation, he would first pass through a belt 2-5 m wide of plants containing roosting house flies. This zone would give way to a mixture of house flies and blaw flies and finally to an area where the blow flies were in the majority. The number of $f l i e s$ decreased rapidly with increasing distance from the refuse. Flies became relatively scarce after about $20 \mathrm{~m}$. 
Mortality

The determination of the natural rate of fly mortality in field populations is almost impossible since flies are such mobile insects. The determination of mortality rates of marked flies released in the field is even more difficult. Some observations on the effects of environmental factors and predation of marked and wild flies which may provide some information for the estimation of fly mortality are given in this section.

Flies at the landfill were preyed upon extensively by toads, spiders, ants, beetles, earwigs, dragonflies, and birds. Flocks of cattle egrets were observed feeding on adult flies and blackbirds were often seen feeding on the larvae in the refuse. Numerous toads inhabited the area and appeared to have little difficulty in acquiring a meal of flies in the grass and weeds at night. Earwigs hunted the fly roosting sites at night. These insects would grasp a resting fly with its pinchers and then feed on its struggling prey. Numerous spiders and ants patrolled the weeds and attacked the roosting flies. Ants were especially numerous in the early morning hours. Dragonflies hunted the area catching flies in flight during the day. It appeared that different species hunted at different hours of the day with tremendous numbers of dragonflies appearing at dusk.

To determine the effects the marking procedure had on the flies samples of approximately 500 flies from several releases were taken to the laboratory. The $\mathrm{fl}$ ies were anesthetized in a cold room $\left(2-4^{\circ} \mathrm{C}\right)$ and 50 male and 50 female $\underline{P}$. cuprina and $\underline{M}$. domestica were placed into a gauze cage. Fresh fly food and water were supplied each day. The dead flies 
were removed daily and the number and species recorded. A control cage was also set up which contained wild flies that had not been marked. The marked flies suffered mortalities of 10-15 percent within the first 24 hr, 15-25 percent within 48 hr, and 33-40 percent within 7 days. The control mortalities were $2-4$ percent, $4-6$ percent, and 10-25 percent respectively. These results were similar to those of Murvosh and Thaggard (43) where 25-30 percent mortality was recorded for marking flies by shaking anesthetized flies with a dust.

The above data show that the largest percentage of flies were killed within the first $48 \mathrm{hr}$, indicating that the marking procedure killed or mortally injured 15-25 percent of the flies marked. It should be noted that these results were under laboratory conditions and a greater loss could be expected in the field. This becomes more apparent since it was observed that the marked flies released at the landfill often groomed themselves approximately $2 \mathrm{hr}$ longer than the unmarked flies in the area. These marked flies were physically weakened and more subject to predation. Ants were particularly injurious at this time as they were observed to attack roosting flies by grasping their legs and the weakened $\mathrm{fl}$ ies were less likely to shake free.

The physical operation of the landfill also contributed to fly deaths. Flies in their search for food and breeding sites in the refuse would crawl into every available opening in the refuse. The crushing of the refuse by the bulldozer and the covering of the refuse with soil trapped and killed numerous flies. 


\section{Flies Released Around the City Landfill}

Methods. -- Four releases were made at sites $1 \mathrm{mi}$ or more from the center of the landfill. The purpose of these releases was to determine if $f l$ ies would travel that distance to the landfill.

Flies were captured by sweep net at night on the vegetation surrounding the landfill. These flies were placed in $15 \times 24 \times 27 \mathrm{~cm}$ gauze cages with approximately 3,000 flies in each cage. After a sufficient number of flies were captured, they were transferred to a large plastic bag by placing the sleeve of the cage in the bag and rapping sharply on the aluminum bottom of the cage. Because of the large number of $f l i e s$ in the cage and dampness of their wings, the flies tumbled into the bag. Dayglo fluorescent dust was placed in the bag at a rate of approximately 1 teaspoon per 2,000 $\mathrm{flies,} \mathrm{and} \mathrm{the} \mathrm{bag}$ gently agitated. These marked flies then were counted by volumetric approximation in which a waxed paper cup $(0.946$ 1) filled with flies was equal to $12,000 \mathrm{fl}$ ies and a $50 \mathrm{ml}$ beaker was equal to $500 \mathrm{flies}$. Approximately 8,000 flies were then placed in one of several $45 \times 45 \times$ $50 \mathrm{~cm}$ release cages. These cages were designed for fly release studies as the rear panel of the cage was hinged to facilitate removal of the flies. These cages were transported to the release sites and the flies released. Capture usually began around $9: 30 \mathrm{pm}$ and the releases were made about $1: 00$ am the following morning.

A sample of approximately 500 marked specimens was removed from the release cages and taken to the laboratory for identification. The percentage of each species in that sample was taken as representative of all the files in that release and was used in conjunction with the total number of flies released to calculate the number of each species released. 
The marked flies were recaptured at the landfill by sweep net after they were located by systematically examining the refuse and the surrounding vegetation with a portable battery powered ultraviolet light. These areas were examined for 7 nights following the release.

Each release employed a different colored marking dust. The sites, dates of release, and numbers and species of $f l$ ies released are given in Table 20.

Results. -- Flies were recaptured at the landfill from 3 of the 4 release sites as shavn in Table 20. These data show that an average of 0.097 percent of the $\underline{P}$. cuprina and 0.07 percent of the $\underline{M}$. domestica released at the last 3 sites were recaptured. The flies released at the 39 th Avenue location were subjected to several attractive loci and this may explain why no flies were recaptured from this area. A cow pasture was located immediately across the road from the release point and 10-15 residences were in the area as well as a hog farm. A direct line of flight from this release point to the landfill would require a fly to pass 3 residences, the hog farm, and $1.1 \mathrm{mi}$ of woodland. The remaining release points were at least $0.1 \mathrm{mi}$ from any residences and a direct line of $f l i g h t$ passed only through woodlands.

The results of these tests agree with other published reports that these 2 fly species can travel and infest areas over $1 \mathrm{mi}$ from the release or breeding site. Releases at greater distances were not attempted.

Flies Released at Landfill

Methods. -- Wild flies were captured, marked, and released at the center of the landfill in the manner described previously. Baited traps 


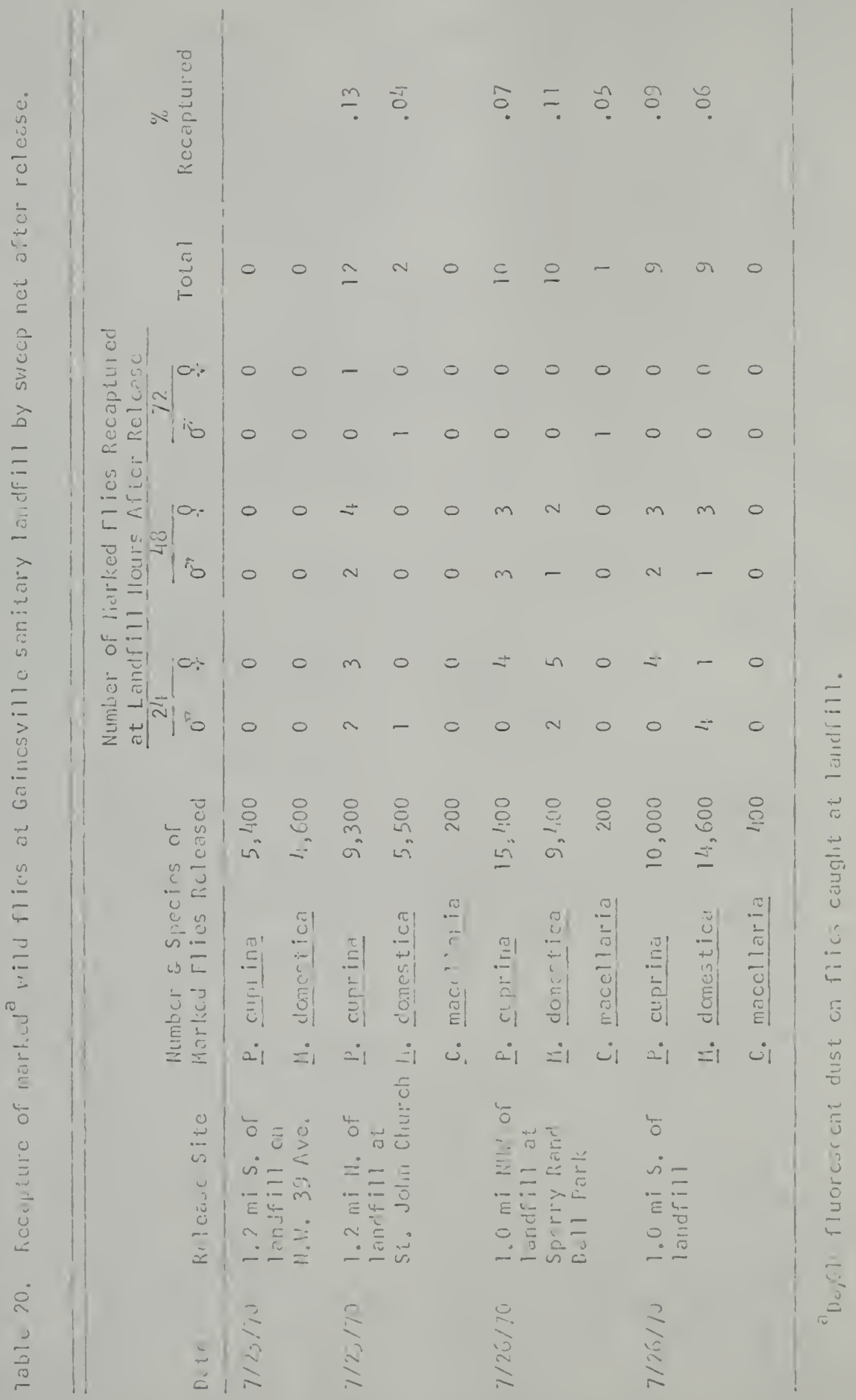


were used in addition to the sweep net capture method described above to recapture the marked flies. The traps were modified cone traps consisting of two 1 quart $(0.9461)$ plastic freezer jars taped together at the mouths. The bottoms were removed and replaced by an inverted screen cone. A putrified fish head was placed inside each trap as an attractant. The traps were placed at the 4 points of the compass in concentric circles $1.5,1.0$, and $0.5 \mathrm{mi}$ from the center of the landfill for the first 2 releases. The outer circle was moved to $0.25 \mathrm{mi}$ from the center for the remaining 5 releases. Captured flies were removed and fresh bait added daily.

Results. -- The results of the marked flies released at the landfill and later recaptured in the same area are given in Tables 21 and 22 . An average of 8.26 percent of the $\underline{P}$. cuprina and 1.89 percent of the $M$. domestica released were observed at the landfill 24 hr after liberation and these numbers decreased with each suceeding observation. In Table 23 these data are divided into the average percentages of flies observed for releases follawed within $24 \mathrm{hr}$ by rainfall and those where no rainfall was recorded (Table 24 ). These data show that releases follaved by dry days resulted in 10.17 percent recapture of $\underline{P}$. cuprina and this number decreased significantly with each suceeding observation. Those releases followed by rain resulted in an average of 6.84 percent recapture of $\underline{?}$. cuprina and this number had a significantly laver rate of decrease. Norris (43) reported that rainfall inhibits dispersal of P. cuprina and these data support that observation.

The majority of the flies released were not recovered. This was because of recovery error, mortality, and dispersal. The method of locating and counting the marked flies was exhaustive but it could not 


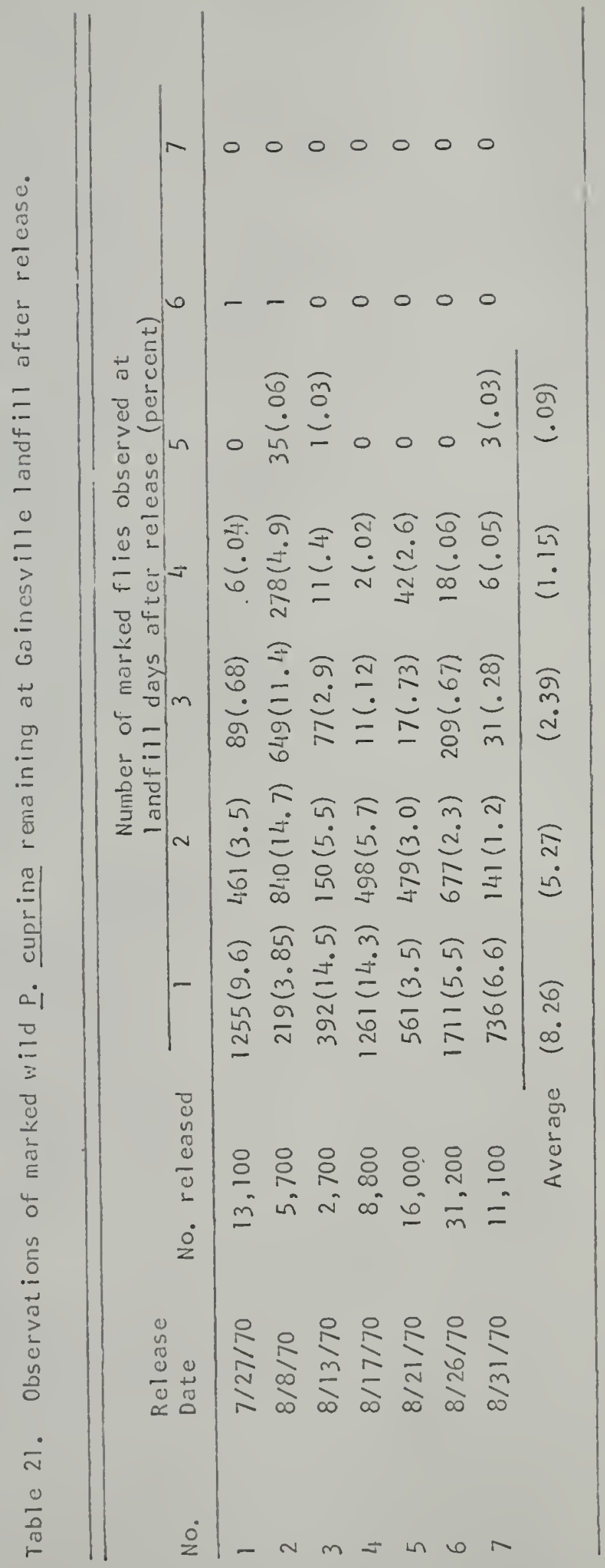




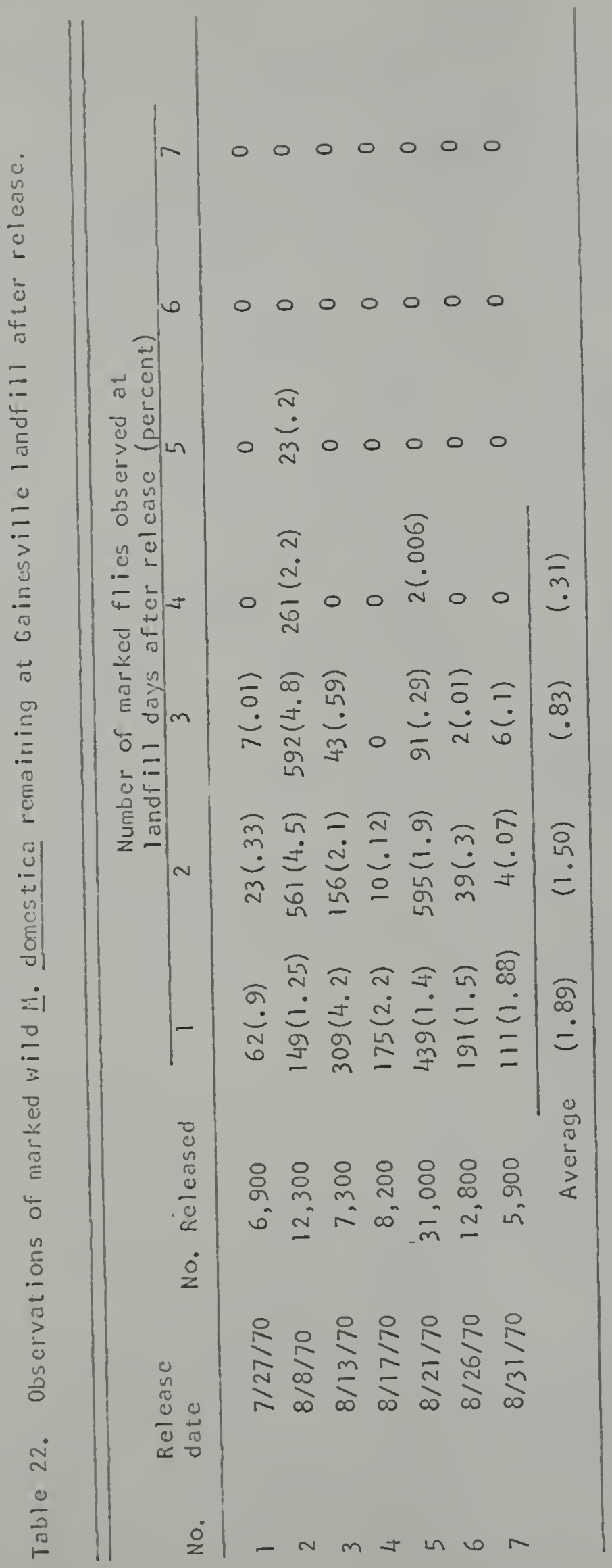




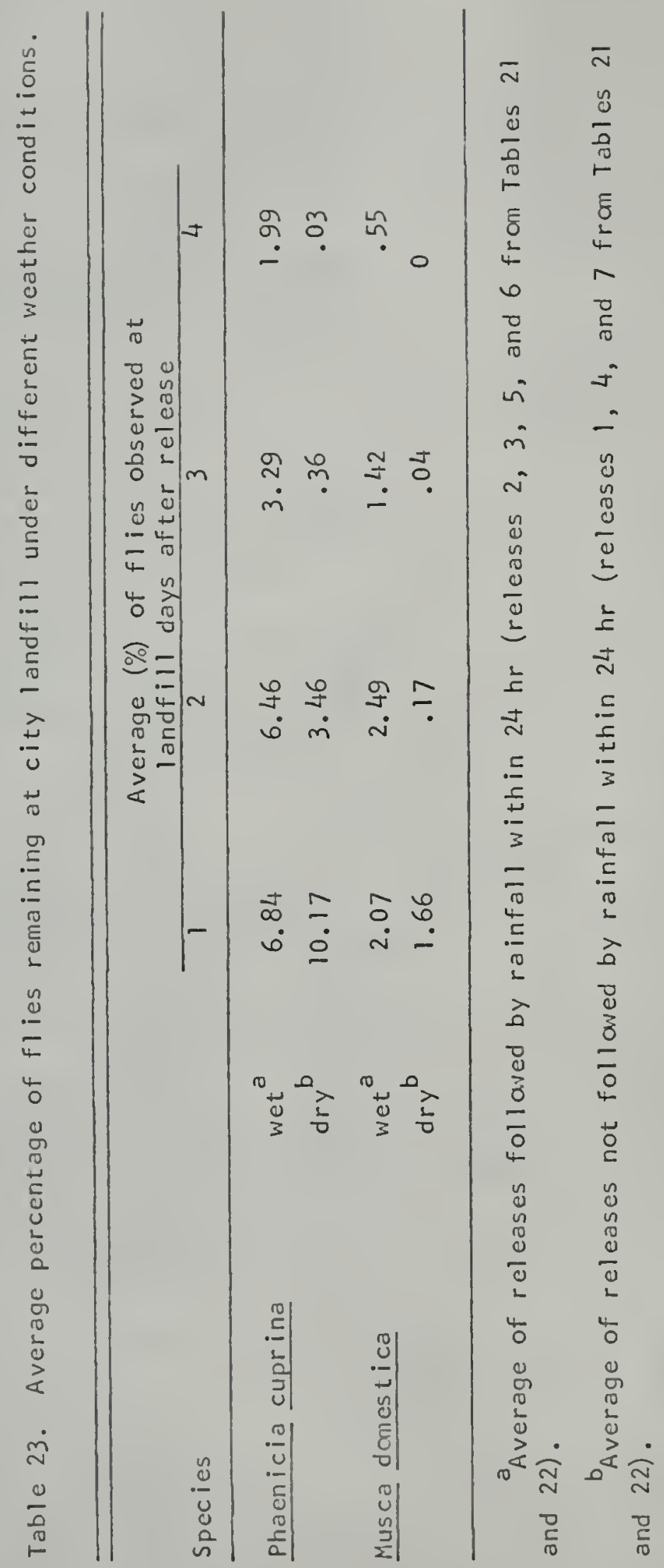




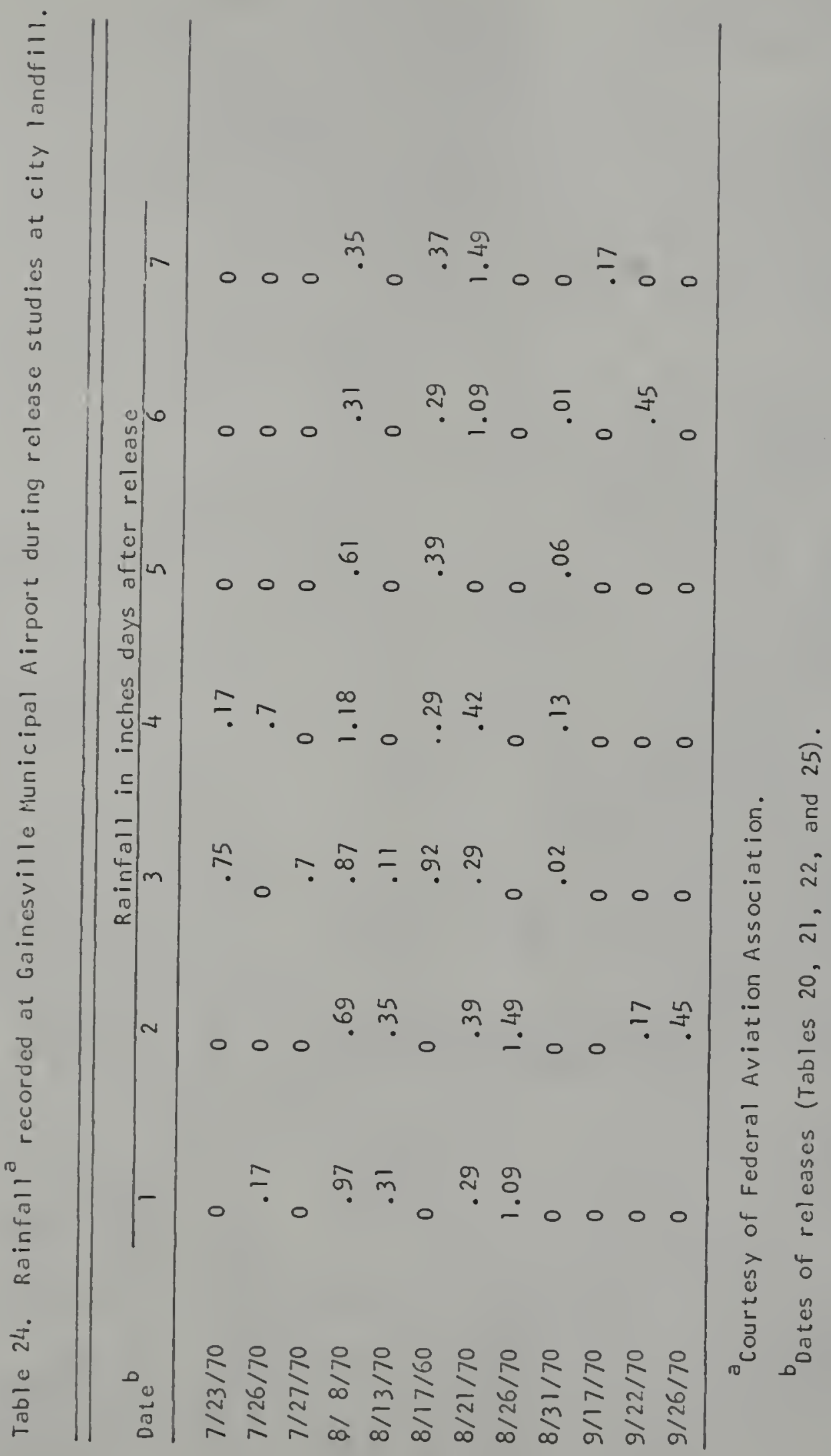


be expected to identify all of the flies present. Marked flies resting on the underside of leaves were difficult to locate and isolated patches of vegetation used as roosting sites may have been overlooked. Marked house flies roosting on the refuse were particularly difficult to find because of the tremendous quantities of refuse present. Mortality from marking was previously discussed and could be expected to amount to 15-25 percent of the released flies. Mortality from predatation and the natural death rate of the flies and dispersal accounted for the remaining flies. The assignment of any figure to each of these factors would be conjecture.

Information concerning dispersal patterns was minimal. Only 2 marked flies were captured in the traps surrounding the landfill. These were both $\underline{P}$. cuprina females captured in the same trap on the same day $1 / 2 \mathrm{mi}$ from the release site.

Release of Laboratory Reared $\underline{\underline{P}}$. Cuprina

Wild $\underline{P}$. cuprina caught at the landfill were reared to the $F_{2}$ generation in the laboratory on a diet consisting of Chunx and ground beef in a manner described previously. Two-day old adult flies were anesthetized in a cold room maintained at $2-4^{\circ} \mathrm{C}$ and marked with DayGlo fluorescent dust as described previously. The flies were counted volumetrically and placed into $45 \times 45 \times 50 \mathrm{~cm}$ release cages supplied with fly food and water and allowed to recover about $8 \mathrm{hr}$. The flies were transported to the 1 andfill and released about 10:00 pm. Flies were recaptured with sweep nets and baited traps as described previously. Laboratory reared releases were follawed by $24 \mathrm{hr}$ periods of no rainfall (Table 24). The results of these releases are shown in Table 25 


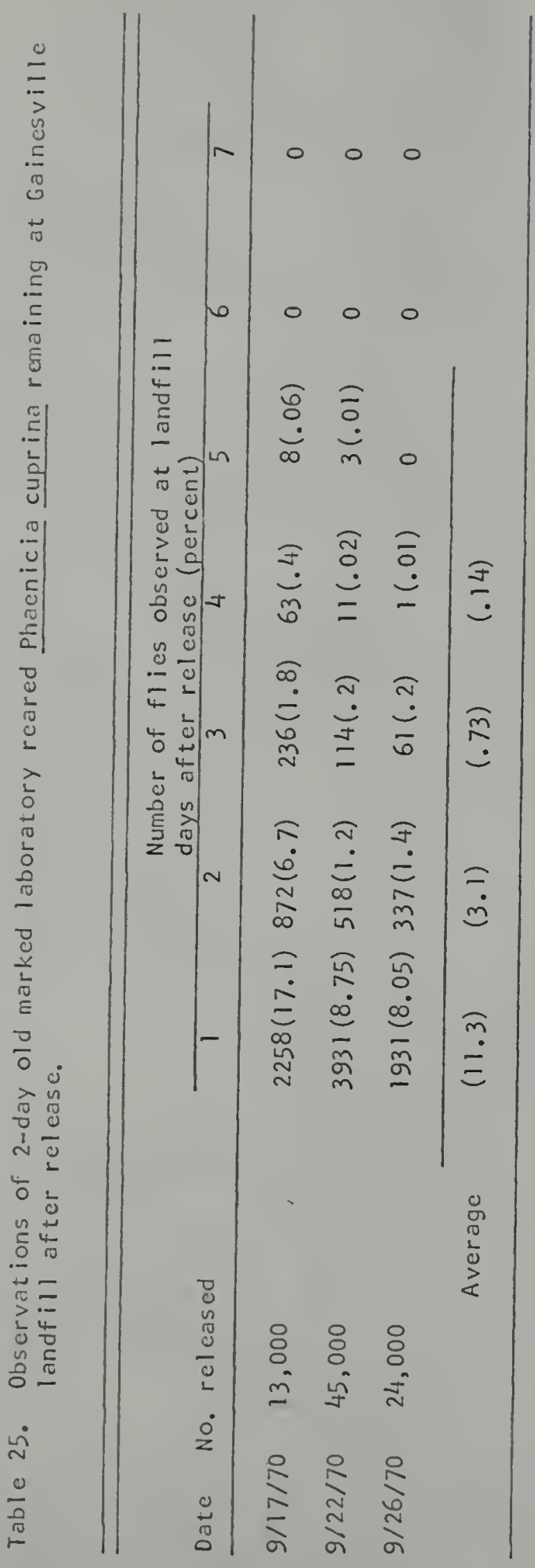


and are similar to those recorded for wild $\underline{P}$. cuprina liberated during a dry period (Table 23). No laboratory reared flies were captured in the baited traps. 
SUMMARY, CONCLUSIONS AND RECOMMENDATIONS

Investigations revealed that fly breeding at the compost plant was minimal under normal operating conditions. The major fly source was from larvae migrating from the refuse in the receiving building to protected areas where they developed into adults. This situation is not unique to composting facilities. Other disposal systems as central incineration or refuse transfer stations have similar problems. Any time refuse is centralized, transferred, or remains standing for any length of time, insects in the refuse may escape into the holding area. Thus, the results of the present investigation could be applied to other similar refuse handling operations.

The number of insects escaping from the larvae-infested refuse stored in the receiving building of ten exceeded 500,000 larvae per week during the summer months. As high as 88.8 percent of these larvae may become adults resulting in approximately 450,000 adult $\mathrm{fl}$ ies per week released into the environs. These flies were predominantly the greenbottle blaw fly, Phaenicia cuprina.

The reduction of these large numbers of flies can be accomplished by procedural changes in the handling of refuse and application of the axion that good sanitation is the most effective method of fly control.

Greater than 35 percent of the larvae escaping into the compost plant could be el iminated by not storing refuse overnight in the 
receiving building. Such a procedure may involve increasing the capacity of the equipment at the Gainesville plant. Although impractical in this case, this should be considered in the construction of new facilities. The problem of having insufficient refuse to begin operations in the morning could be el iminated by starting the working day at a later time.

The construction of the receiving building greatly influences larval survival. Refuse falls behind the wooden retaining walls and provides food and harborage to rodents, roaches, and fly larvae. The construction of a solid retaining wall that would prevent the accumulation of such wastes or one that provides access for easy cleaning would be more desirable.

The construction of a fly larvae trap behind the retaining wall would reduce the number of escaping larvae. Such a trap could be made by the construction of a sunken trough in the floor between the retaining wall and the building wall. This trough filled with water would drown migrating larvae. The trough could be cleaned by flushing.

The concrete floor of the receiving building has been chipped by the loading tractor at the edge of the receiving hopper producing an opening between the hopper and the floor. The construction of a lip over the edge of the hopper would reduce the debris and number of 1 arvae escaping into this area. This lip could be either metal or several inches of re-enforced concrete.

It was shown that a 40.6 percent reduction in the number of adult flies occurred when the area under the apron conveyor was cleaned and a possibie reduction of 67 percent was predicted. This demonstrates the value of good housekeeping. Not only are the number of flies reduced by 
cleaning but the dangers of herking with poisons and the potuntici pidturi of insect resistance and follution are clininated.

A cambination of s? eaning the erez uncer the spron convulor and

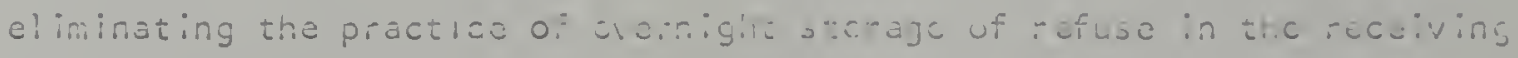

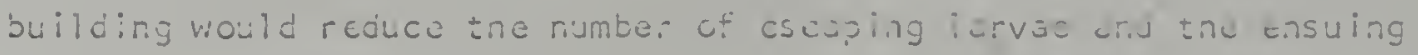
adult population of flies by 63.5 parcent. Tha appication of an insecticice would reduce the numiar of tha rensinirg flies.

Tho daily applicatian of a dichloryos ugar bait recucud the rumuer of flies caught in baited traps at the compost plant by Éj.7 percent. Pait bait anc iogging were less cifecuive and not recmmended. The application of a res idual insecticide to the night-time roostinz sites raducad the number of flies ut the plant oy more than $\$ 9$ percont. Dimethote Geve betiar than go percent zontrol for one week. Gardona was ineffective as a rosidual.

The latoratory soreening o: 12 commercial insecticides reveded tnat dimethoaze, paratnion, Dursban, naled, and diszinon were effective agoinst famile ?. cucrina aduits exposad in a wind tunnel. These results indicate that parsthion, Eursbar, naled, and diczinco may also be effective in iield tcstj for the con:ul of $\underline{P}$. cuprina.

A diat consisting of Chuni, a dry dog food, anc ground beaf was found superior to the $=11$ rieet ciet wnich rud previously buen usec to rear 2. custirn. The dog food dict producud a highur yicld in total rumber of filus, a cost less, and it produced less oifens ive ociors thwn the ail meot diet.

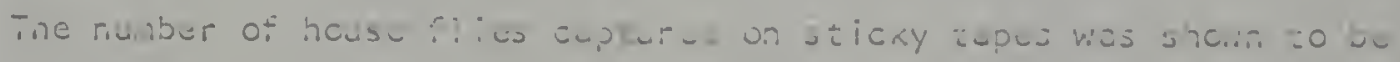

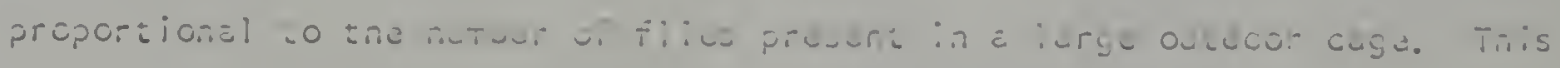


incicates that the fly population may be estimated by the number trapped. Wher a known number of marked house flies was released in the digester building an average of 1.6 percenti wer e recaptured on sticky tzpes. Thus, the tota! rumber of flies piesert in tha digester buidirg may be estimated by the mitiplication of 3.8 percent times the number of flies trapped.

A one-year stucy of house fil ies ir. the digesters revealeo that the number of house fl les fluctuated seasona!ly and that high temperatures in the cigester buiding during the sumer monuhs discouraged files ifco entering shat area.

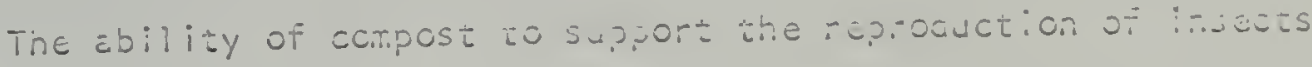

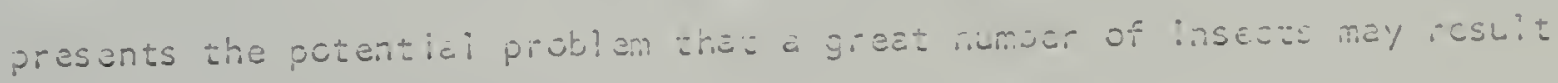
from this method of räuse disposal. Cbservations revealed that house files were the predominant irsect capable or breding in compost and they were limized by several faccors. Temperature was the primary factor limiring house fly breecing in compost. Temperatures in the digescers prevensed house ily deveiopment except in the top $2.5 \mathrm{~cm}$ of compost. The moisture cortent of the compost was a major factor affecting adult developmert from cggs in compost. Seventy-five percent moisture was the optimum roiscure content. It should be noted that compost at moistures adove 65 percent cculd not de processed because of equiprent limications. The moisture content of the compost in normal oparations ranged fram 4j-5,5 percurit which gave 1-i4 percert survival of eggs to pupae in laborato-y tasts.

The lergih of zime the refuje cheposted affutud hase ily deveicimant.

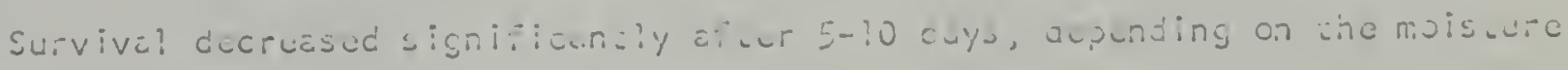
conturte 
The addition of law surage sludge zo tha ground refuse inciuses the ability of compost to support house fli ies. The effects of tha size of tha refuse partialas on survival wis not cleariy demonotratud b-t

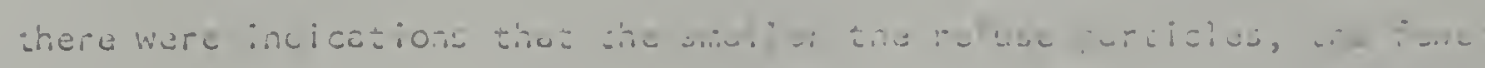
adults producus.

The noisture ard ige o: the compez had ro joverse efiects on the maturation of 48-hr olc house fly larváe in ca-post. Thus, woze lar las in the refuse that survived the grinding process and werc ab? = to migrate to areas where temperatures were not lotha: mi-hit devel op to adulas. hovever, i: was daronstratec that larvie could rou survive normol grinding.

Fly larvae were observed ir the compost in the digusters during April, May, Lune, Cctobar, Novmber, and Decemidr oí 1969, and more than 99 percent of those insects idencified were M. dchestice. Thoue flias may ba contiolled by removing and gindirg the campast before the house ily cen complete its life cycle. They can also be controlled by mixing the compost in the digester by the Agi-Loader so thai the larvae aro exposed to ithai temperatures.

Flignt and dispersal studies were conductad io determine fli ht ranges and patterris fran an attractive site. P. cunrira males il uil ail average $0: \div 9,405.4 \mathrm{~m}(12.1 \mathrm{mi})$ and a maxinim of $50,127 \mathrm{~m}(13.7 \mathrm{mi})$ whun

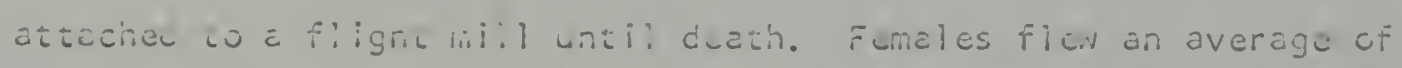
$25,235.2 \mathrm{~m}(! 5.7 \mathrm{mi})$ ard a raximum of $45,030 \mathrm{n}$ (2i.0 mi). ïhuse data represchi meximum : ight distuncez of the grunouttle blaw fly under

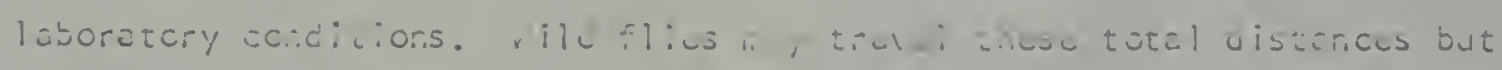

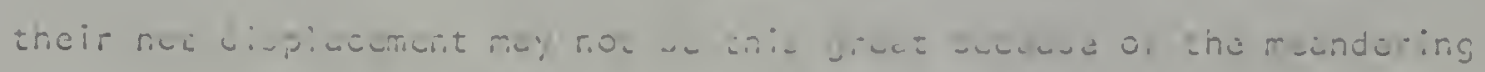

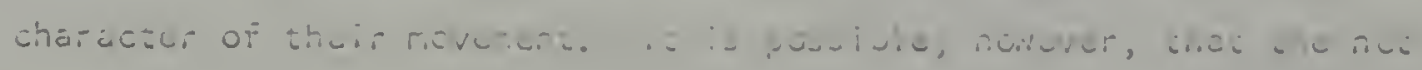


displacement may cxceed the laboratory distances when flies are blawn with the winds.

Vild?. cuprina and $M$. domestica raleasud 1 mi or more from the

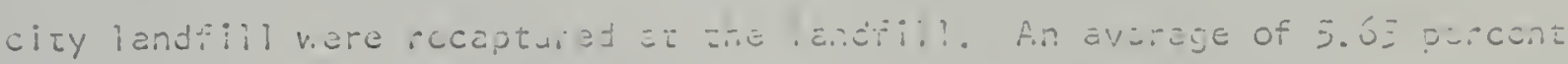

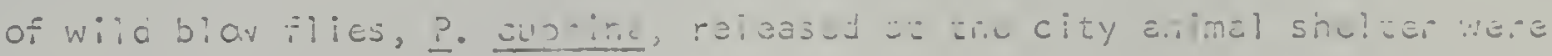
recaptured at the compost piant. Thase daza indicate that flies a ca attracted from the eirrounoing areas.

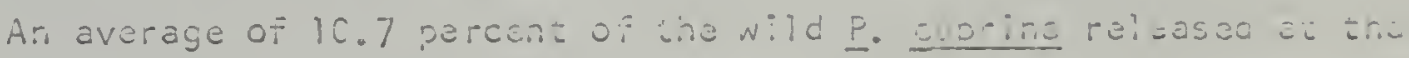
ecmpost plant were recaptured in thas a:es 24. hr later. Ar evurajo o:

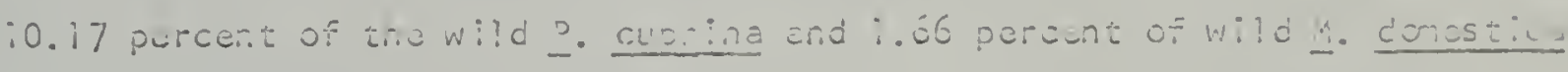

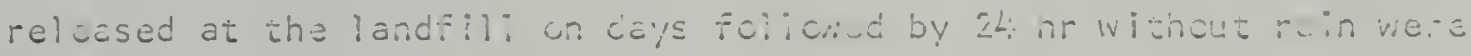

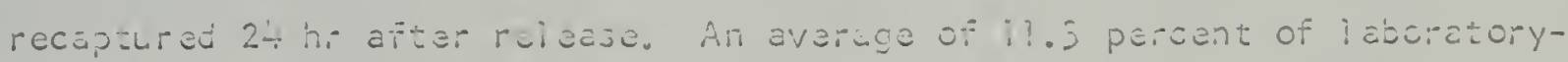
reared?. cuprina rel aased az tro land? l? Wure recapturco 2r hr after release.

Baited traps loceted at an apartment $200 \mathrm{~m}$ east of the caipost plant ard at the cisy arima! shalte. failed to capure any marked fi ius -eleasco at the composi, iani. Baited traps surrounding the city ?andTill captured oniy 2 tiiles aiter the release of 255,000 marked specinens.

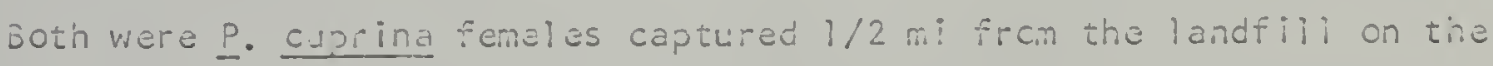
same day in tha sane trap. These data eppear to ircicate that the flics do noc disperse greatly Fom these very attractive loci.

The "sliubing are recomanciaticrs for composting:

1. Sefuse mist be procusued tne sario day it is ciel ivercd.

2. The refuse iccuiving area must be constructed to prolude the

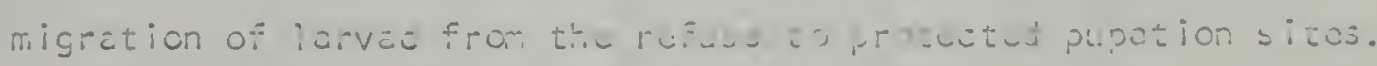

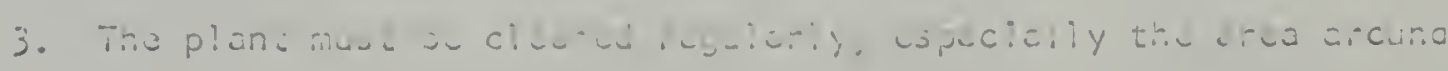


the refuse recuiving hopper which sncula be zicuned a minimu or cnec par licek.

4. Tre daily app!icalion of a dry dienl-pyos sugar bait and/a- the

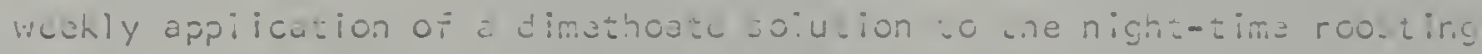
sites of the files should be concuetu wirch ucult files decarc a nuisance.

5. Tha moisture levul seiectce for a compositig procus should wa influenced by the breeding of ncuse files in canpost which inciecs as the moisture pproacies 75 perceni.

6. The grincing of the rciuse must be thoroigh to insure the death of larvad in the incoming refuse.

7. Larvai jreedirg in the digesters should bu dustroyed sy eithei ra-grinding or turaing the compost in the disesters.

8. Thu piant should be centraliy located to laver tiucking costs but preferably in an area az last che-hulf mile iram residences to reduce the ruisci-- ccused by files migrating into the surroundirg wrea.

9. Furtro: rescurch studius in cre aruas of fly dispersal from a camposting plant and Fiy b.eading in compost should be corducted. 
APPENDIX 
Appendix 1. -- Test for the precision of the counting technique used to determine total number of larvae collected under the apron conveyor.

\begin{tabular}{ccc}
\hline $\begin{array}{c}\text { Weight of sample } \\
(\mathrm{gm})\end{array}$ & $\begin{array}{c}\text { Number of } \\
\text { larvae }\end{array}$ & $\begin{array}{c}\text { Larvae.per } \\
\text { gram }\end{array}$ \\
\hline 514 & 3064 & 5.96 \\
566 & 3279 & 5.79 \\
708 & 4217 & 5.95 \\
430 & 2720 & 6.33 \\
642 & 3842 & 5.98 \\
\hline
\end{tabular}


Appendix 2. -- Fly larvae trapped under apron conveyor during 1969, at the Gainesville compost plant.

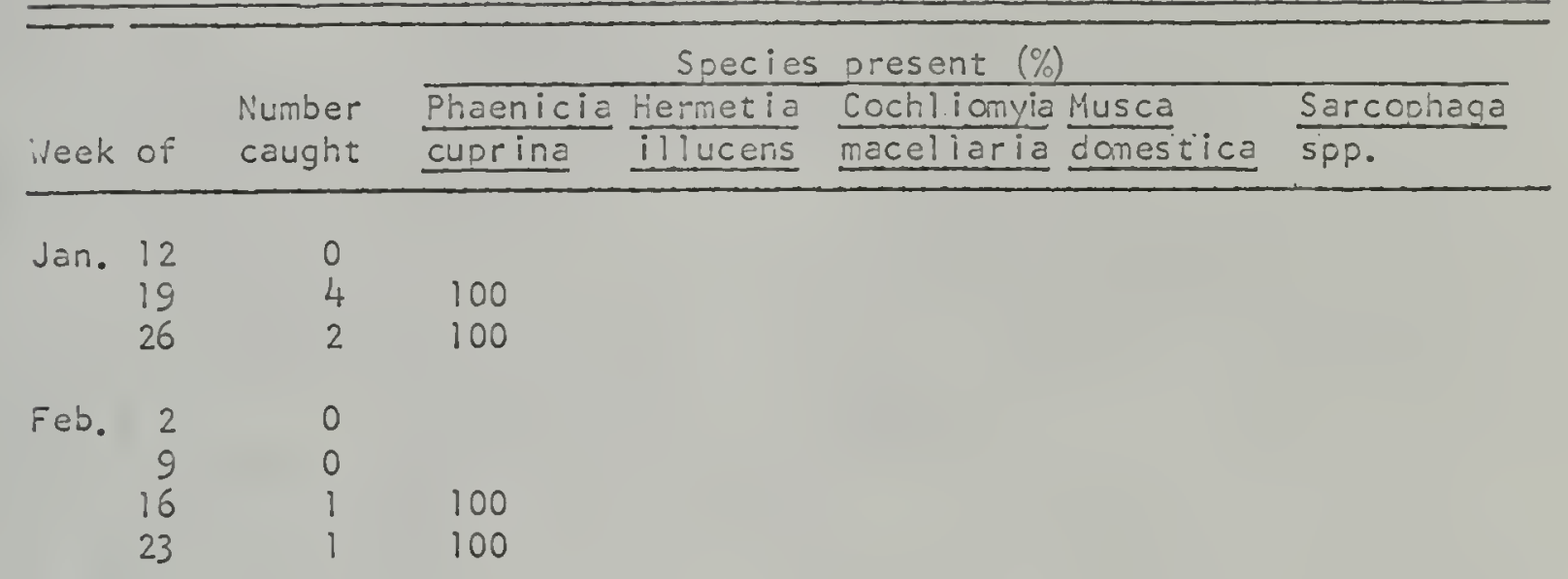

Mar. 20

$\begin{array}{rr}9 & 0 \\ 16 & 0\end{array}$

$23 \quad 12 \quad 100$

$30 \quad 130 \quad 91.5$

4.2

4.2

Apr. $6 \quad 10$

90.5

96.5

4.7

4.7

$13 \quad 78$

100

1.8

1.8

$27 \quad 285$

91.0

6.4

3.2

May 4614

$11 \quad 3297$

95.0

97.5

$18 \quad 592$

94.5

$25 \quad 1629$

96.0

2.0

3.0

1.0

.4

2.0

2.2

.1

1.2

1.8

1.5

96.5

.9

.6
1.0

1.5

.9

Jun. $\quad \begin{array}{rr}2004 \\ 8 & 4554\end{array}$ $15,22,29^{a}$

97.0

JuI. 63945

$13 \quad 4387$

96.4

93.5

$20 \quad 4500$

$27 \quad 4482$

96.5

96.6

.4

.7

6.0

1.6

.8

1.9

.6
.3

Aug. $\begin{array}{rr}3 & 3366 \\ 10 & 5669\end{array}$

96.4

98.4

$17 \quad 5749$

99.2

$24 \quad 3534$

98.7

$31 \quad 4350$

98.3

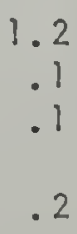

1.2
.7
.7
.7
.5

1. 2

.3

.2

1.8

1.5

.1

$\begin{array}{ll}.8 & .4 \\ .2 & .4 \\ .1 & .5 \\ & .7 \\ & .7 \\ & .8\end{array}$


Appendix 2 (Continued)

Species present $(\%)$

Number Phaenicia Hermetia $\frac{\text { Cochliomyia Musca }}{\text { macellaria }}$ domestica Sarcophaga

Week of caught cuprina illucens macellaria domestica spp.

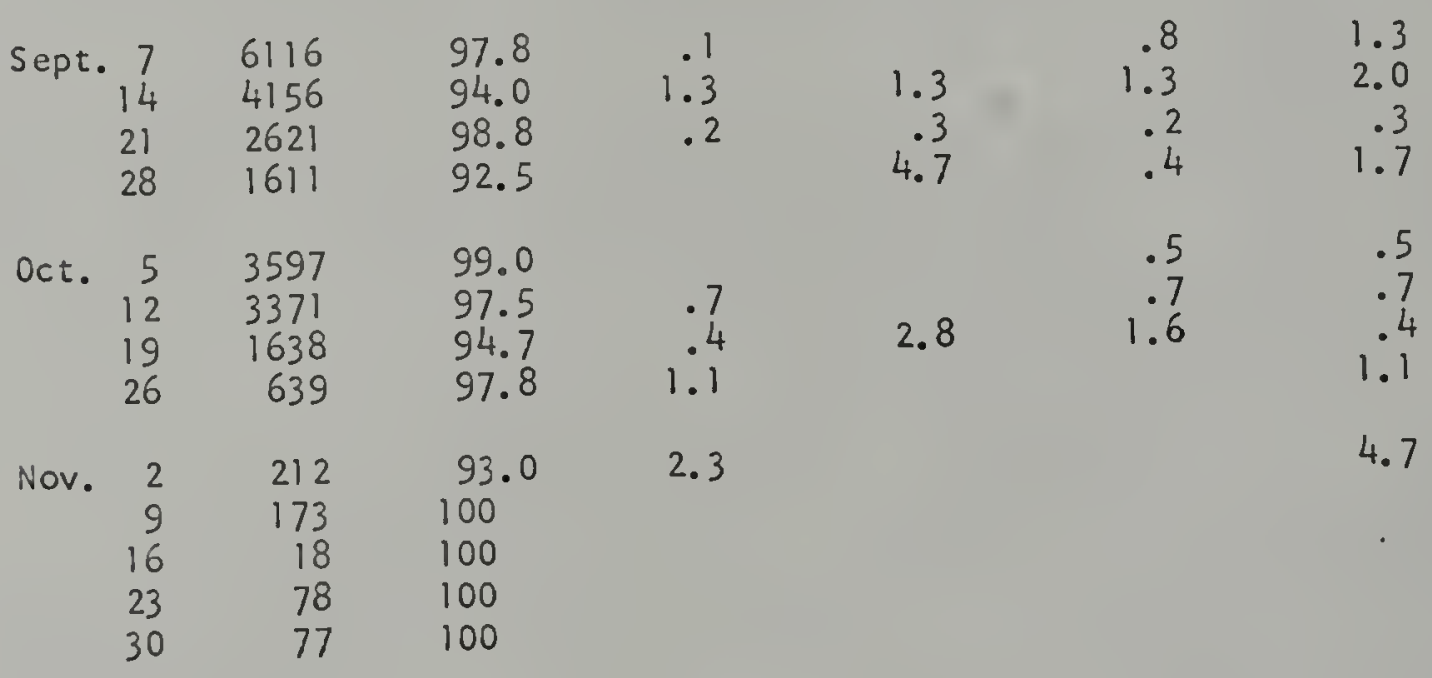

Dec. $\begin{array}{rrr}7 & 2 & 100 \\ 14 & 0 & \\ 21 & 2 & 100 \\ 28 & 0 & \end{array}$

aplant closed for repairs. 


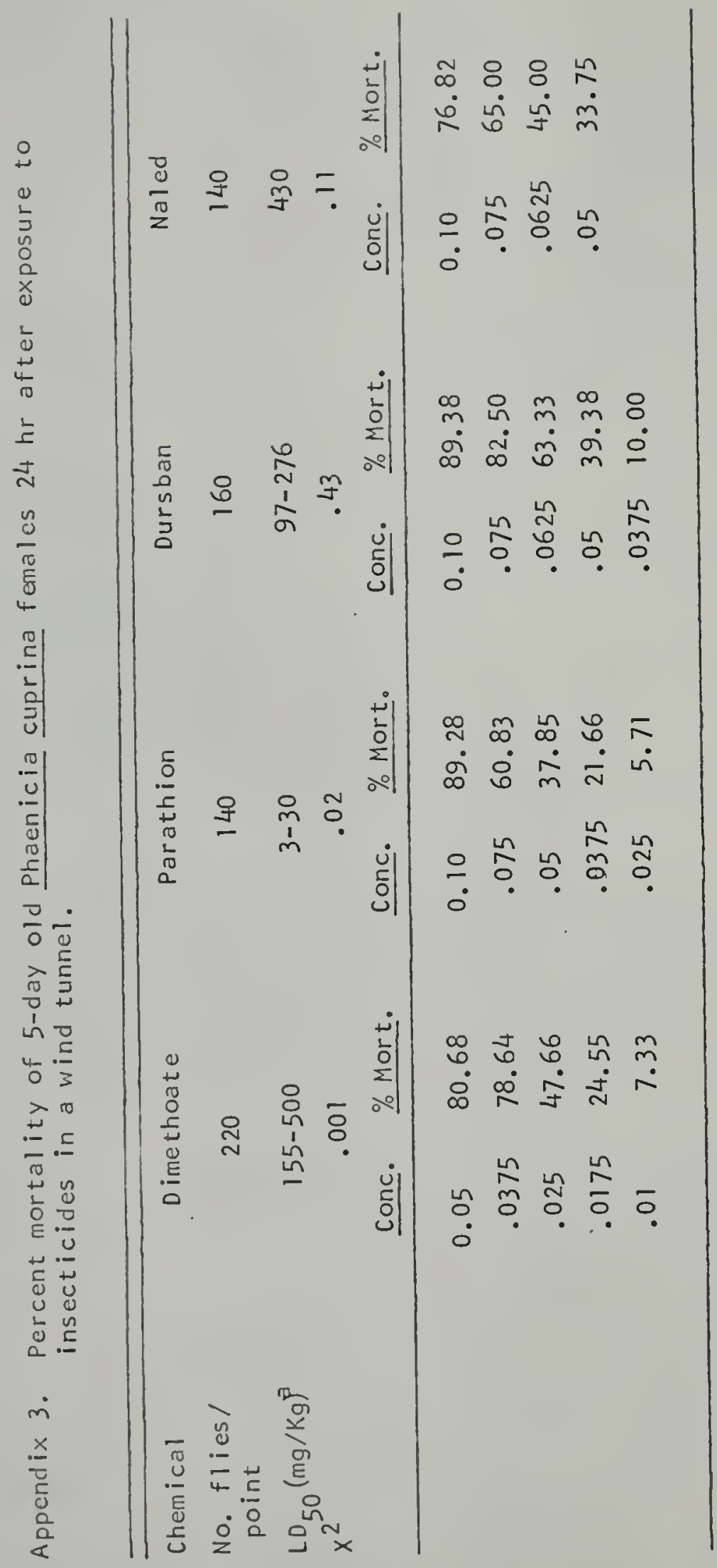




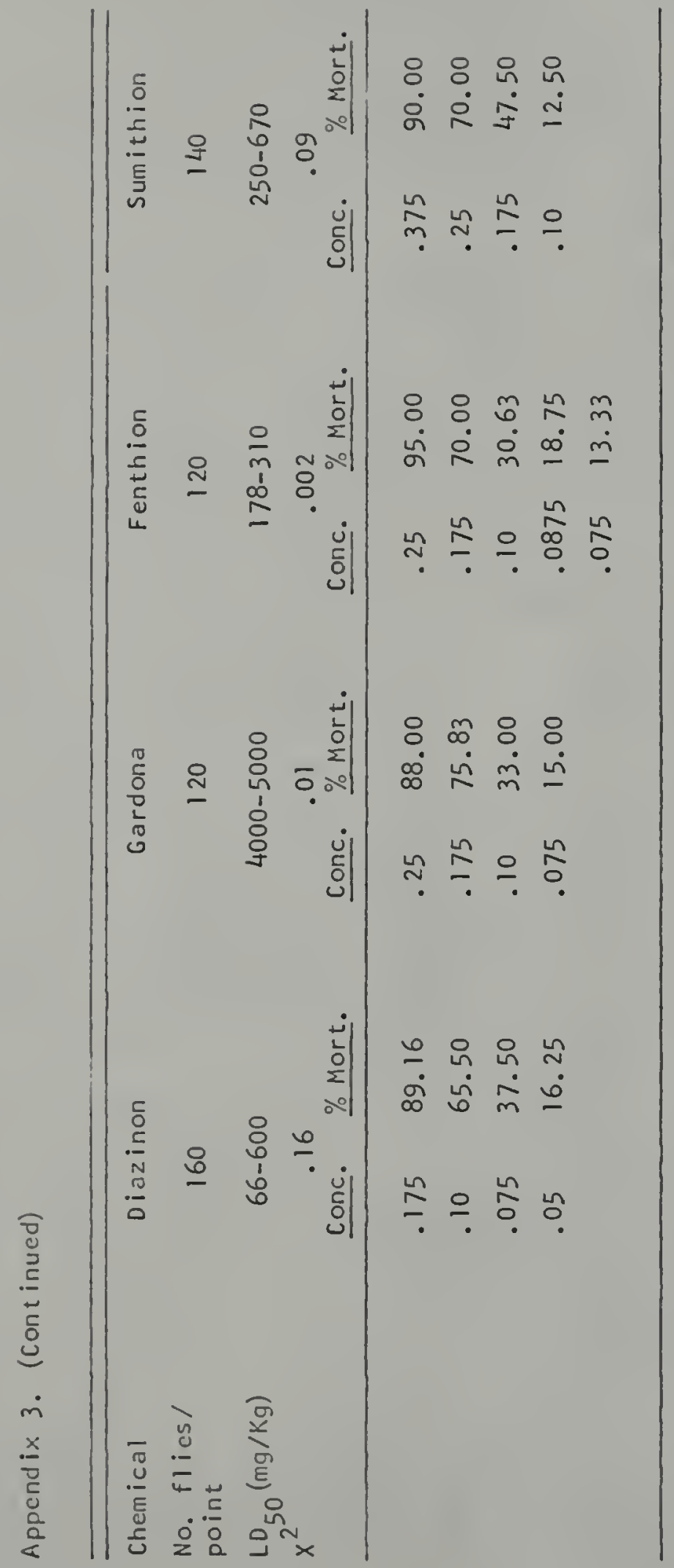




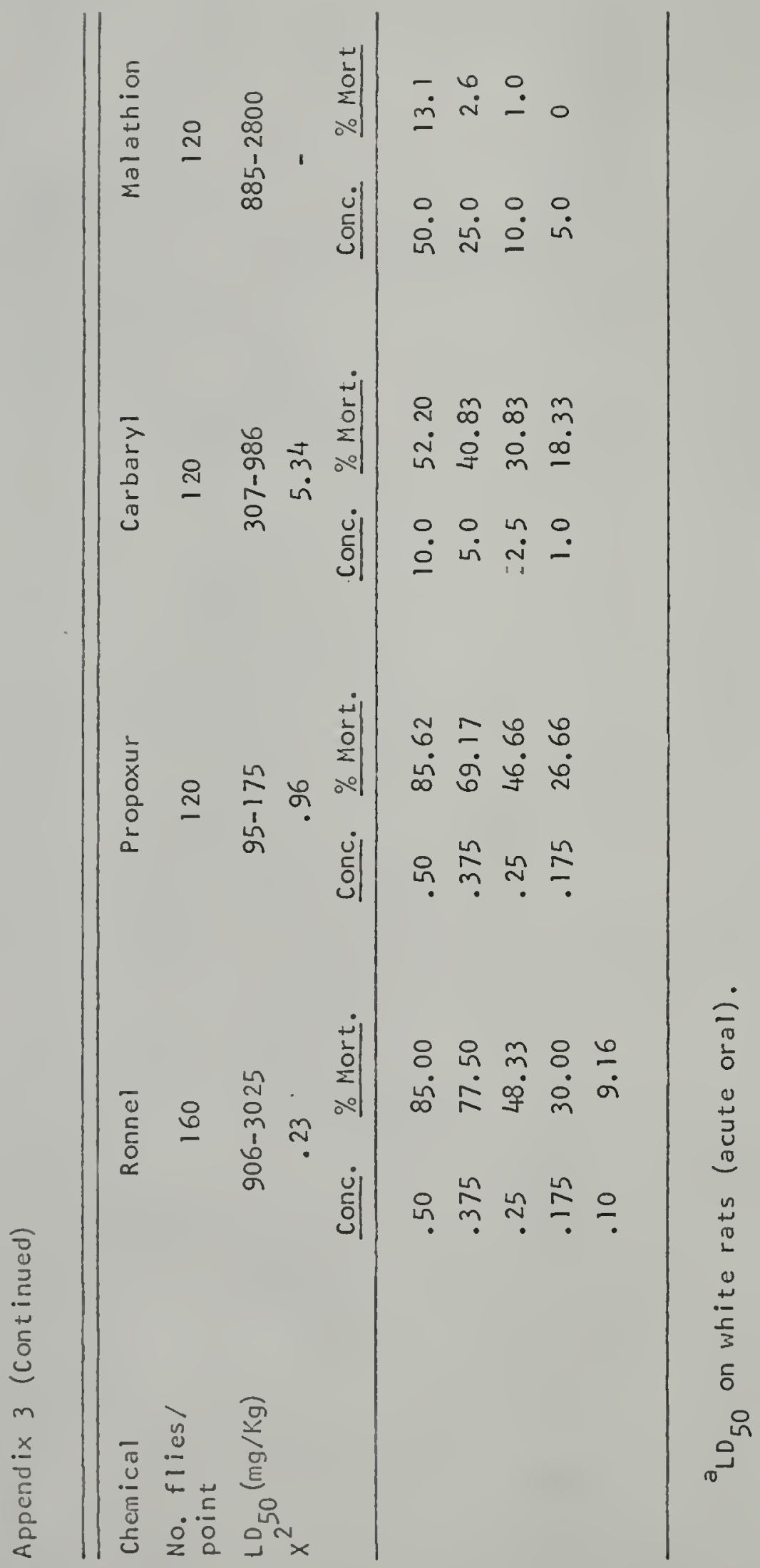


ม
0
0
1
0
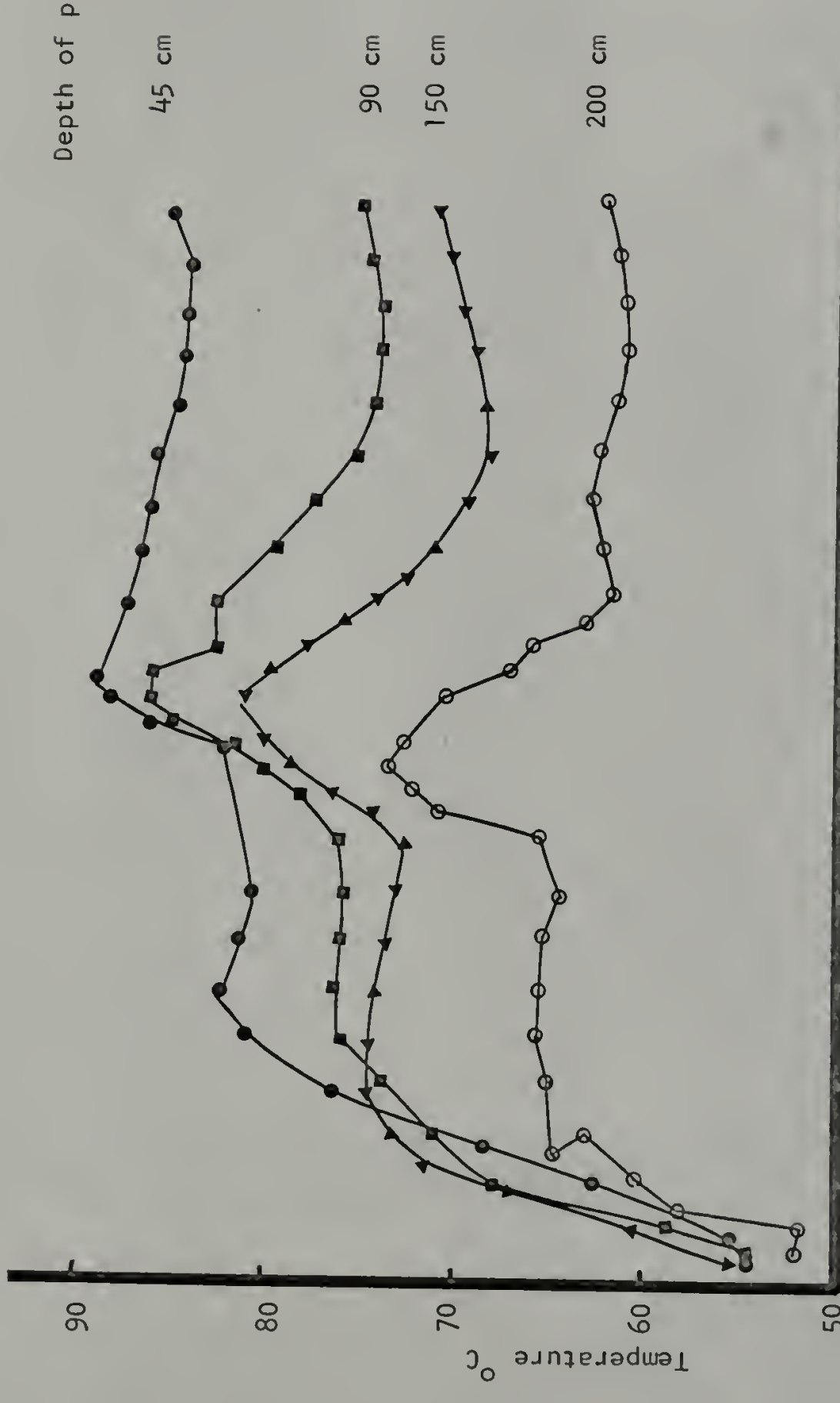

- N
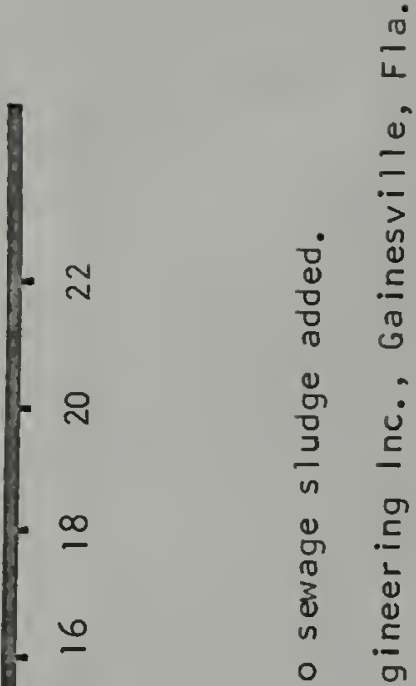

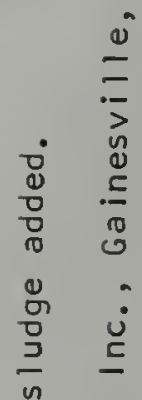

苗

I

है

$\frac{\pi}{n}$

$-2$

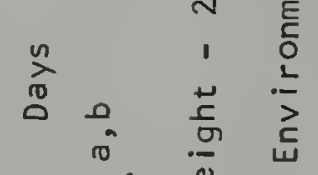

으

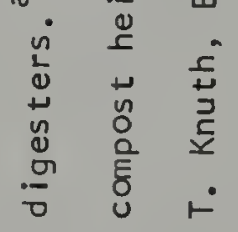

$\infty$

.

岇

$\pm$

茂

हूँ

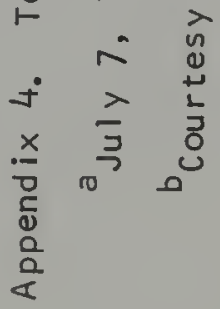


1. American Public Works Association. 1966. Municipal Refuse Disposal. Public Administration Service, Chicago. 528 p.

2. Anderson, J. R., and J. H. Poorbaugh. 1964. Observations on the ethology and ecology of various Diptera associated with northern California poultry ranches. J. Med. Entomol. 2:131-147.

3. Atkins, M. D. 1961. A study of the flight of the Douglas-fir beetle, Dendroctonus pseudotsugae Hopk. (Coleoptera: Scolytidae). 111 Flight capacity. Can. Entomol. 61:467-474.

4. Bailey, D. L. 1969. (Personal communication).

5. Bailey, D. L., G. C. LaBrecque, and P. M. Bishop. 1967. Residual sprays for the control of house flies, Musca domestica, in dairy barns. Fla. Entomol. 50:161-163.

6. Bailey, D. L., G. C. LaBrecque, D. W. Meifert, and P. M. Bishop. 1968. Insecticides in dry sugar baits against two strains of house flies. J. Econ. Entomol. 61:743-747.

7. Bailey, D. L., G. C. LaBrecque, and T. L. Whitfield. 1970. Laboratory evaluation of insecticides as contact sprays against adult house flies. J. Econ. Entomol. 63:275-276.

8. 1970. Resistance of house flies (Diptera:Muscidae) to dimethoate and ronnel in Florida. Fla. Entomol. 53:1-5.

9. Bailey, D. L., D. W. Meifert, and P. M. Bishop. 1968. Control of house flies in poultry houses with larvicides. Fla. Entomol. $51: 107-111$.

10. Brady, U. E., Jr., D. W. Meifert, and G. C. LaBrecque. 1966. Residual sprays for the control of house flies in field tests. J. Econ. Entomol. 59:1522-1523.

11. Busvine, J. R., J. D. Bell, and A. M. Guneidy. 1963. Toxicology and genetics of two types of insecticide resistance in Chrysomyia putoria Weid. Bull. Entomol. Res. 54:589-600.

12. Chambers, D. L., and T. B. O'Connel. 1969. A flight mill for studies with the Mexican fruit fiy. Ann. Entomol. Soc. Amer. 62:917-920. 


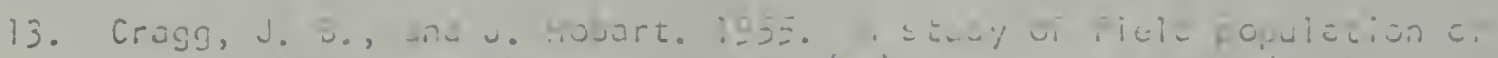
che siar flics Luciliac.szr (L.) and L. Scricil. (M.g.). A.n. Apoi. siol. 13:64;-0u.

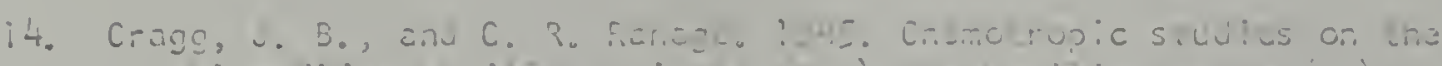

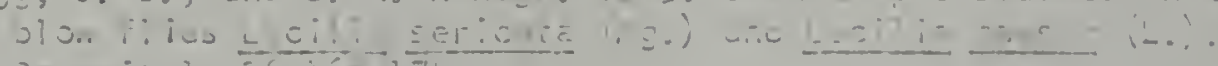
Pursitol. $35.150-175$.

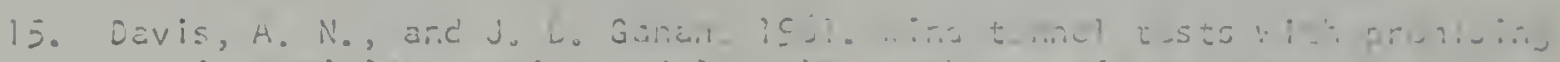

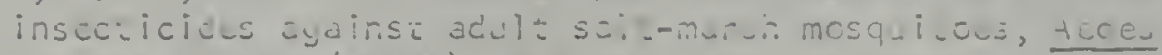

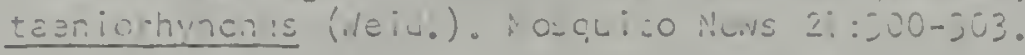

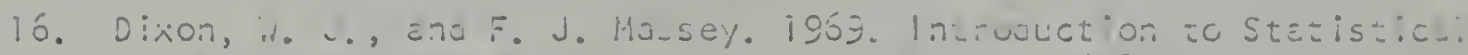

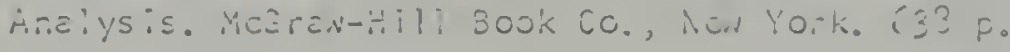

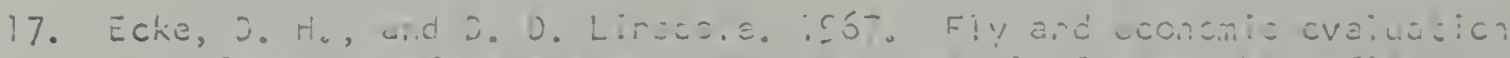

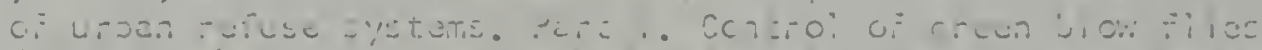

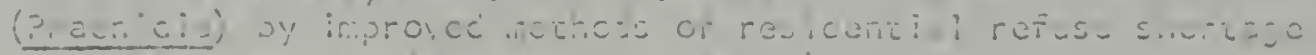

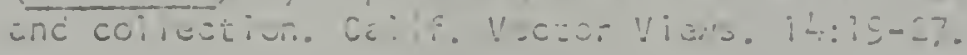

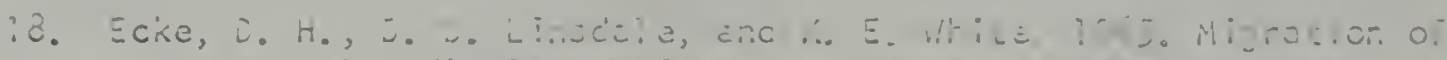

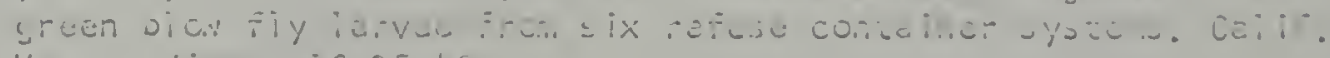
Vecto- V: viv=。: :2:35-4.

19. Finnw, D. J. ?S r\% Probit Anulysis: A Statistica? Trectmont or the

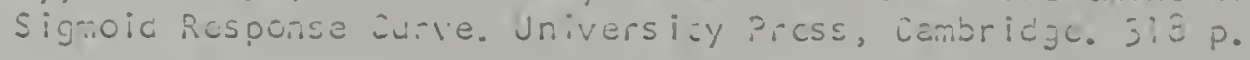

20. Gairesville riuniciral Uaste Conversion Authorily. 1969. Euiresville Compost Piant. An interiri Repert. U.j. Dep. Health, Elucation, and witate, inciniazi. 99 p.

21. Gilmole, 0., D. F. Iaterhouse, and C. r.. ric!ntyre. 19-6́. ma account of expc-ibiants undertakun to detarmine the naiural pasiation density of the sheap bicil tiy, Lucilla clisina viaid. Eull. Coun. Sci. Inc. Res. 110. 155. 55 P.

22. Cran, A. A. 195:. The control of bia: tiles infesting sluughterhousc. 1. Field cbservesions of the habies of blav thies. man. mppl. B:ol. $38: 475-4: 94$.

23. Creon, $A . A .$, and J. kane. 135-. The control of blal flics infasting slightur-houzes. 111. Laisu-scal e typer imunts dt a cancsticrǘs cupot. man. mepl. Eiol. 4.:1u5-17;.

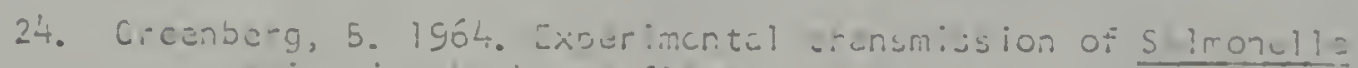
Everimu-iun by holise flics to mun. Amur. u. Hyg. 00:1-iy-156.

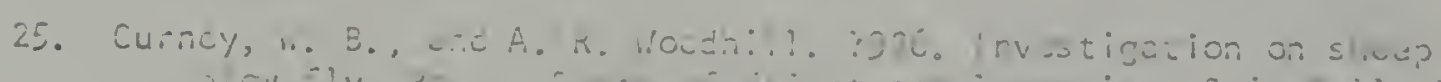

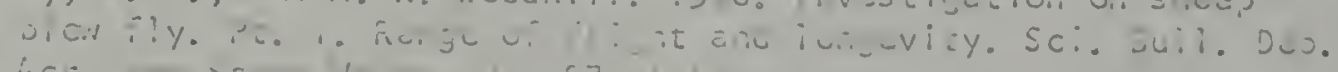

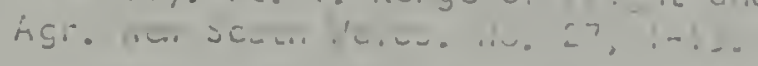

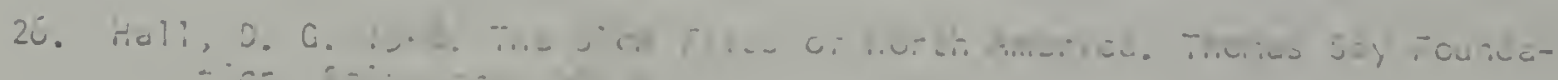

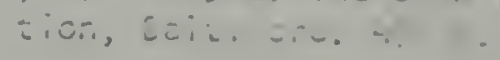


27. Howard, L. D. 19?2. The House Fiy Oiseuse Carricr, an Accunt ci Its Oangercus Activities and the Means of Jestroying 1t. John Murray, Londor. 3 ! 2 p.

23. James, M. T. $155 j$. Notes on the distributior, systemezic position, and variation oi sume cailiprori.aee, uit.n particular reference to the spceies of Westerin North Anc-ica (Liptera, Calliphoricae). Entonol. Soc. liash. Froc. 5z:143-1:8.

29. uchrson, C. G. 1969. Migration and Dispursal of lnsects by Flight. Muthuen and Co., Lordon, 7óz p.

30. Kawai, S., and O. Sutnaga. 1960. Studies of the method's of collectirg flics. 111 . On the effect of purpefaction of baits (fish). Endemic Diseases Eui?., Megasaki L'riv. 2:ól-66.

3i. Keller, J. C., H. C. .Ilscn, and C. N. Jmith. 1955. Polson baits for the conticl of blow ilites and house pllies. J. Econ. Encomo?. $40: 563-505$.

32. Kerr, R. W. 1964. Notes on a, thropoc resistarce to chanicals used in their cuntrol in Australia. ¿. Aust. Agr. Sci. 30:33-36.

3̇. Kiipetrick, J. W., and K. J. Quartarman. 1952, Field studies on the resting habits of il tes in relation to chemical control. Par: 11. in rurá? areas. Amer. J. Trop. Med, Hyg. 1:ic26-1031.

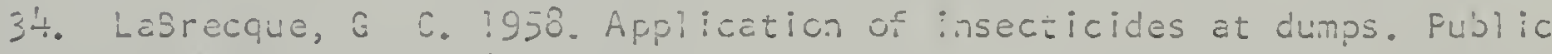
works. 12:92-93.

35. _. ISES. (Persond comunication).

36. Macheod, J., and j. Donitlly. 1957. Jome ecological relationships of natural populations of calliphorina blow ilies. J. Aniri. Ecci. 2ú::135-170.

37. - is58. Lozz distribution ano dispersal paths of olow tilies in hill councry. J. Anim. Ecol. 27:349-37!.

33. __._. :960. Natural features of blow fly movement. J. Anim. ECOI. 29:55-9j.

39. - 1962. Microgcographic aggregation i.n blar fily pcoulations. J. Mnim. Ecol. $3: 5255-543$.

40. - 1953. Discursai and interspersul of bion fly populationj. J. Finim. Eco?.32:?-32.

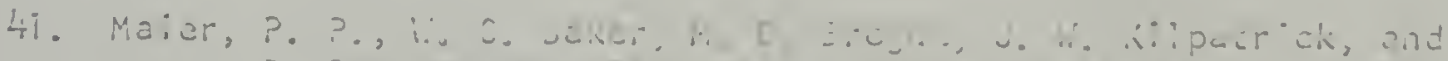

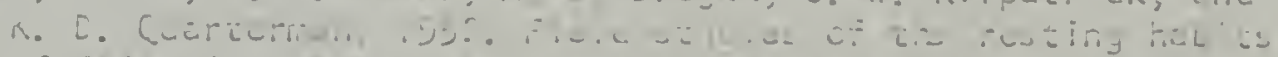

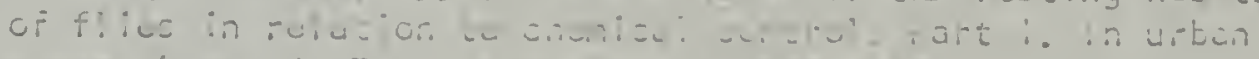

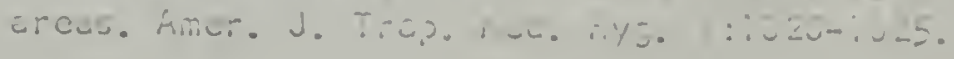


42. Muirhead-Thomson, R. C. 1968. Ecology of Insect Vector Populations. Academic Press, New York. 174 p.

43. Murvosh, C. M., and C. W. Thaggard. 1966. Ecological studies of the house fly. Ann. Entomol. Soc. Amer. 59:533-547.

44. Norris, K. R. 1959. The ecology of sheep blaw flies in Australia. Monogr. Biol. 8:514-544.

45. 1965. The bionomics of blaw flies. Annu. Rev. Entomol. $10: 47-68$.

46. 1966. Daily pattern of flight activity of blow flies (Calliphoridae:Diptera) in the Canberra district as indicated by trap catches. Aust. J. Zool. 14:835-853.

47. Nuorteva, P. 1966. Local distribution of blow flies in relation to human settlement in an area around the town of Forssa in south Finland. Ann. Entamol. Finland. 32:128-137.

48. Ogata, K., N. Nagai, N. Koshimizu, M. Kato, and A. Wada. 1960. Release studies on the dispersion of the house $f l i$ es and the blow flies in the suburban area of Kawasake City, Japan. Jap. J. Sanit. Zool. 11:181-188.

49. 0lson, T. A., and R. G. Dahms. 1945. Control of house fly breeding in partly digested sludge. J. Econ. Entomol. 38:602-604.

50. Parker, R. R. 1916. Dispersion of Musca domestica (L.) under city conditions in Montana. J. Econ. Entomol. 9:325-354.

51. Pickens, L. G., N. O. Morgan, J. G. Hartsock, and J. W. Smith. 1967. Dispersal patterns and populations of the house fly affected by sanitation and weather in rural Maryland. J. Econ. Entomol. $60: 1250-1255$.

52. Quarterman, K. D., J. W. Kilpatrick, and W. Mathis. 1954. Fly dispersal in a rural area near Savannah, Georgia. J. Econ. Entomol. 47:413-419.

53. Quarterman, K. D., W. Mathis, and J. W. Kilpatrick. 1954. Urban fly dispersal in the area of Savannah, Georgia. J. Econ. Entomol. 47: 405-412.

54. Raybould, J. N. 1964. An improved technique for sampling the indoor density of African house fly populations. J. Econ. Entomol. 57: $445-447$.

55. 1966. Techniques for sampling the density of African house fly populations: I. A field camparison of the use of the Schudder Grill and the Sticky fly-trap method for sampling the indoor density of African house flies. J. Econ. Entamol. 59:639-644. 
56. 1965. Techniques ior sempl ing the density of Africen house fiy populations: 11. A field cciuarison of the Schudder

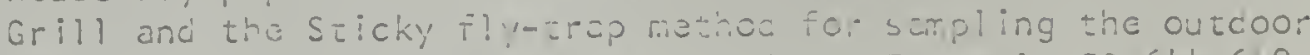
densizy of African house tilis. J. Econ. Entcnol. 59:5!1-648.

57. Riches, $\mathcal{H} . H_{.}$, and P. J. D.Suilivar. 1957. The value of the

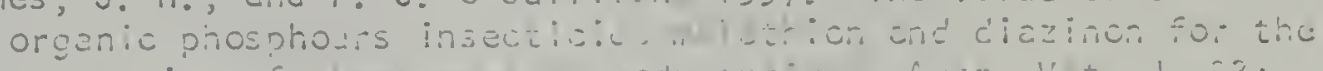

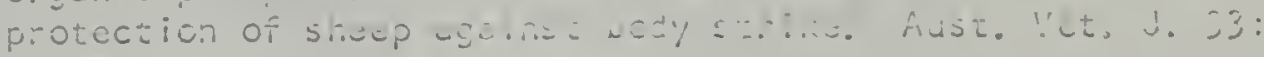
$34-30$.

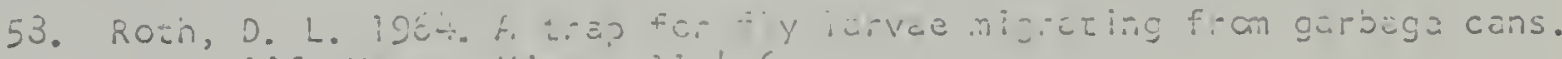

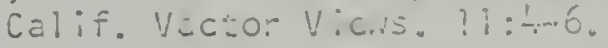

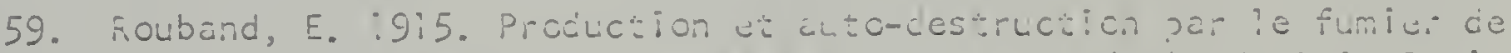
chevai ces incliches domescioues. Compt. Rend. Aced. Sci. Paris. $161: 325-327$.

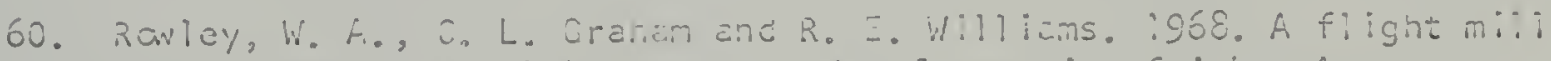
systcm for the iaboratcry study of injaquito filighto Arn. Entcmol. Scc. Amer. $6.1507-15 ? \div$.

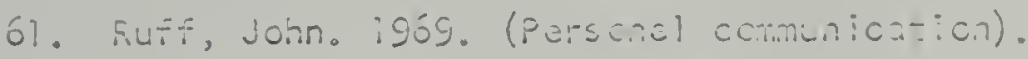

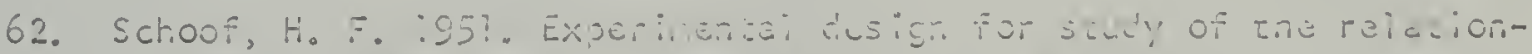
si ip betweun g-ili codnts, 2z t-treps, ina population icvels

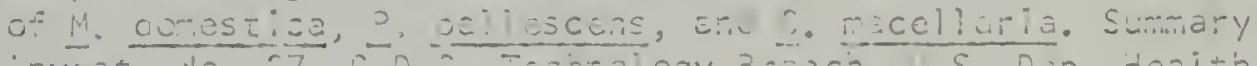

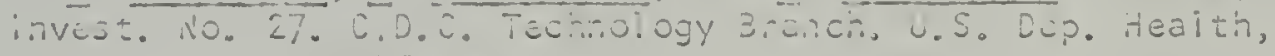
Ecueation, and dcisici.

63. _... i539. How far do flies f.y? pest control. 27:ió-18, $20,22,26$.

6\%. Schoo:, t. F., and R. E. S.iverl\% 1954. 14l\%ip! e release studies on the dispe:sion of Musca carss:ica at Phoonix, Arizoria. j. Econ. Entcinol. 47:330-030.

65. Schuntner, C. A., and $! . J$. Roulston. ,268. m resistunce mechanism in organophoschorus-res istent strairs of shecp plow fly (Llcilia cusrina). Alst. J. B:01. Sci. $21: 173-170$.

66. Scudder, H. 1. 19:- A nev technioue for semping the density of house i:y popuiaticns. Putlic Health Rep. 6́2:681-686.

67. Snanahon, C. J. 1958. Resisiarce to dis?dir and alcrin in Lucilia cupitina Wiej. J. Alist. Inst. Agi. Sei. 24:157-i58.

$60^{\circ}$

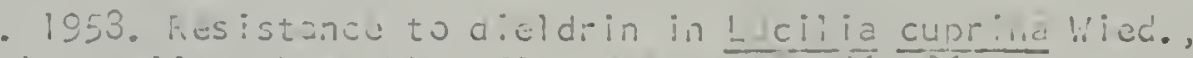
the Australian sheep blon fiy. Nazhre it?:050-35:.

69.

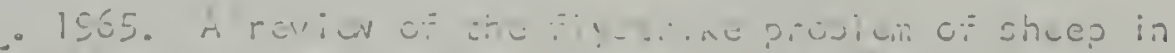

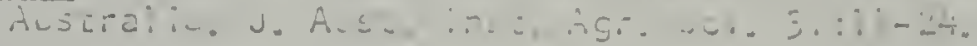

70.

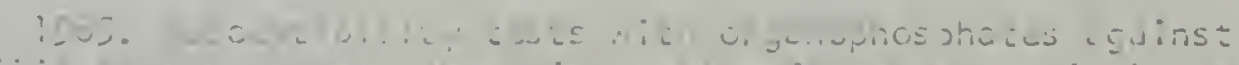
tua:

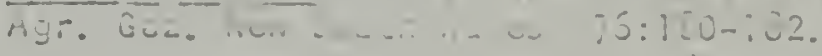


71. - 1y56. Developm nt of a changud isporse in Lucilia cuprina (ifivd.) to organophosohorus insecticices ir. Na: south dilus. Eull. Entcinol. Res. 57:93-100.

72. 1966. Organophos: holus co? erance in sheup blow flies. Agr.

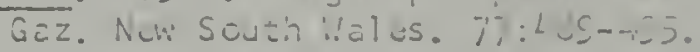

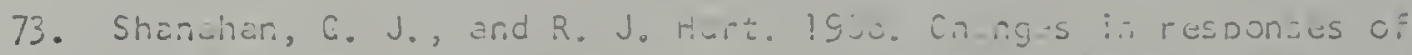

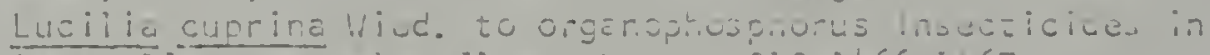

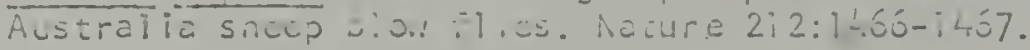

74. Shinoda, 0., and 7 . Ando. is35. Ciurnal rnyenm o: filies. Eot. Zooi. $3: 1 i 7-121$.

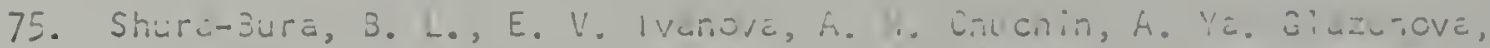

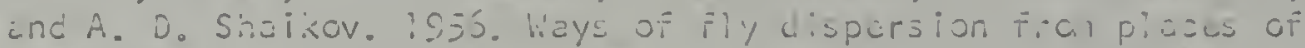
mús breeding in Leringrac. Rev. Enianol. UaSR. 35:33-345ó.

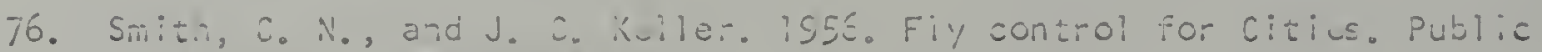

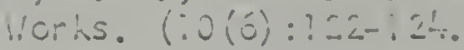

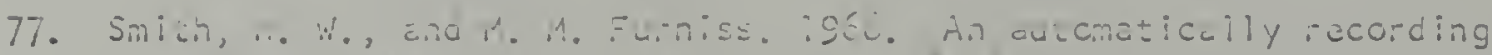
insect filint mili. Cor. Entcrioi. Su:245-252.

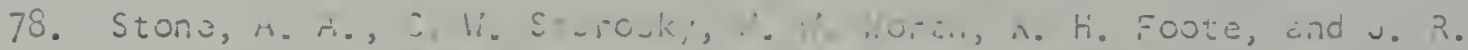

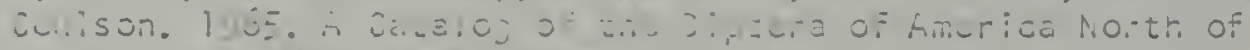

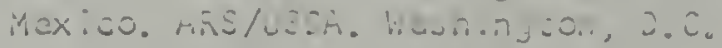

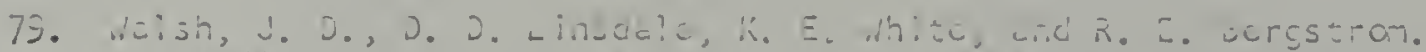
iS53. Fly la -val migiaticn iren residencial refuse contuinurs ir. the city of Fiesno. Cai: i. !ector V c:3. 15:55-6:.

30. Waternouse, J.F., uní S. J. Paramonov. 1950. The status of thu two spezics of Lisilia (Jiptcra, Cailiphoridae) attacking sncep in Ausiralic, anst. J. jci. Rus., Ser. z: Riol. Sci. 3:j10-336.

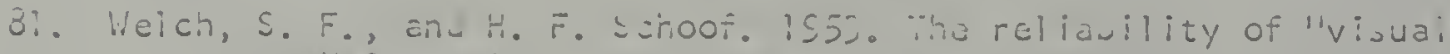
survey" ir evaluating fly d́unsitics foi ccomunity control programs. Hiner. J. Tiros. Hcd. Hyg. 2:1131-1136.

32. West, L. S. 1j51. The Hcuse Fiy. Comstock Pualishing Co., I haca, A. Y. 584 P.

83. Yates, 1. H., A. 1. Lindquist, and J. S. Butts. 1952. Further Sildies of dispersion of ?? ies tagged With radiodctive phosphoric acid. $\therefore$ Econ. Enzomol. $4: 5: 547-549$. 


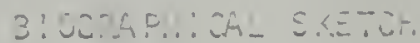

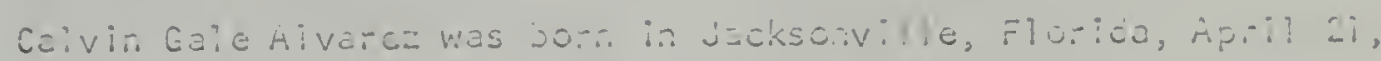
1943. Le attunded primary anc sacondary soncols in that crea ard grachated fron Rinculatigti School ir June, ?SS:

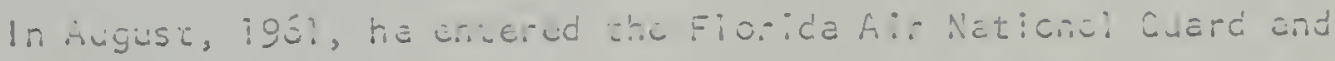
was an active rescrvist unoti hiz clestiarge in unne, $: 567$.

He enterct the Lniverity o: Ficalia in Furlery, 156a, and received a Bacheio: of Scicnce dosree wi ha a major in chtomology in April, igós, and a Master fí Science degree witu a major in artomology In Maren, is58. From Aprit, ije8, to tre present he has been a united States Pubilic haaitn Service Trainee working tavard the degree oi Dector of Philesopity.

he is a nomber of the Entomological Society o: America and the Ficrida Encomological Seciaty.

He merictithe former udith Gaynell Narable of Newport News, Virginia on May 7, 1960. 
1 certify that 1 have read this study and that in my opinion it conforms to acceptable standards of scholarly presentation and is fully adequate, in scope and quality, as a dissertation for the degree of Doctor of Philosophy.

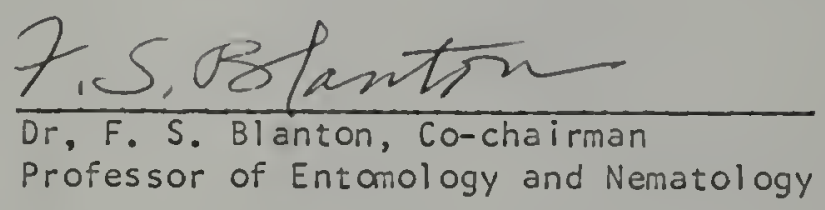

1 certify that 1 have read this study and that in my opinion it conforms to acceptable standards of scholarly presentation and is fully adequate, in scope and quality, as a dissertation for the degree of Doctor of Philosophy.

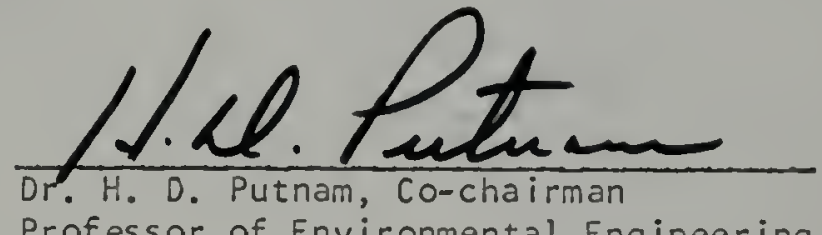

I certify that 1 have read this study and that in my opinion it conforms to acceptable standards of scholarly presentation and is fully adequate, in scope and quality, as a dissertation for the degree of Doctor of Philosophy.

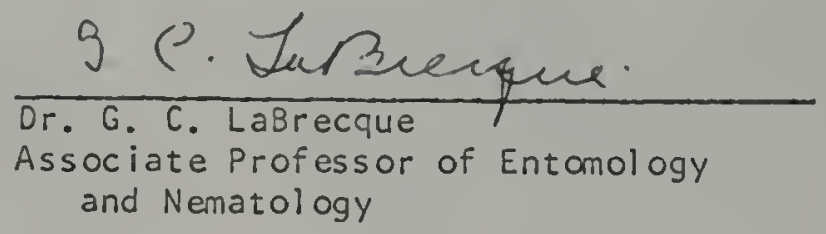

This dissertation was submitted to the Dean of the College of Agriculture and to the Graduate Council, and was accepted as partial fulfillment of the requirements for the degree of Doctor of Philosophy. March, 1971

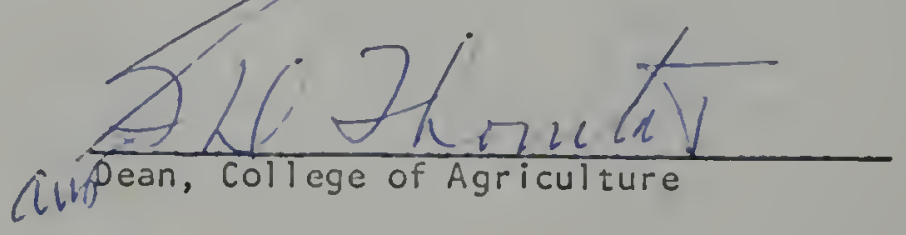




$$
8298-7
$$

